\title{
Peace and Violence after Conflict
}

\author{
Shoko KOHAMA \\ Nara, Japan
}

B.A. University of Tokyo, 2006

M.A. University of Tokyo, 2008

A Dissertation presented to the Graduate Faculty of the University of Virginia in Candidacy

for the Degree of Doctor of Philosophy

Department of Politics

University of Virginia

December 2014 


\section{Contents}

Abstract

$\begin{array}{lll}\text { Acknowledgments } & \text { viii }\end{array}$

1 Introduction 1

1.1 Motivation ............................. . . . . . . . . . . .

1.2 The Argument ............................. 8

1.3 The Scope of This Research _. . . . . . . . . . . . . . . . . . . . 12

1.4 Literature on Post-Conflict Peace . . . . . . . . . . . . . . . . . . . . . . . 13

1.4.1 Theories of Post-Conflict Peace . . . . . . . . . . . . . . . . . 13

1.4.2 The Role of Formal Agreements . . . . . . . . . . . . . . . . . . . . 14

1.4.3 Material Conditions of Post-Conflict Peace . . . . . . . . . . . . . 15

1.5 Outline of the Dissertation . . . . . . . . . . . . . . . . . . . 16

2 A Theory of Post-Conflict Peace 18

2.1 A Basic Model . . . . . . . . . . . . . . . . . . . . . . . . . . . 21

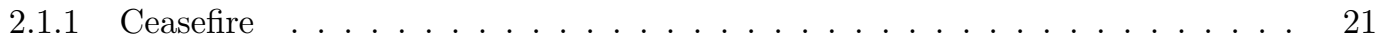

2.1.2 Post-Conflict Phase . . . . . . . . . . . . . . . . . . . . 24

2.1.3 Results of A Basic Model . . . . . . . . . . . . . . . . . 27

2.2 A Full Model . . . . . . . . . . . . . . . . . . . . . . . . . . . . . 29

2.2.1 Outcomes and General Mechanisms . . . . . . . . . . . . . . . 32

2.2.2 Analysis: Resumption of Fighting . . . . . . . . . . . . . . . . 35

2.2.3 Analysis: Achievement of Ceasefire . . . . . . . . . . . . . . . . 38 
2.3 Summaries and Implications . . . . . . . . . . . . . . . . . . . . . . . 42

3 Explain the Duration of Ceasefires 45

3.1 Dataset on Ceasefires . . . . . . . . . . . . . . . . . . . . . . 47

3.2 Measurement of Violent Resource Transfer . . . . . . . . . . . . . . . . . . . . . . 49

3.2.1 Territorial Change . . . . . . . . . . . . . . . . . . . . . . . . . . 49

3.2 .2 Characteristics of Territorial Change . . . . . . . . . . . . . . . . . . 51

3.2 .3 Terms of Settlement $\ldots \ldots \ldots \ldots \ldots \ldots$

3.3 Alternative Hypotheses $\ldots \ldots \ldots \ldots \ldots \ldots$

3.4 A Statistical Model . . . . . . . . . . . . . . . . . . . . . . . 58

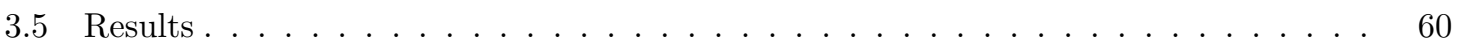

3.5.1 Resource Transfer Causes Unstable Peace . . . . . . . . . . . . . . . . . . . . 60

3.5.2 "Who Gets What" Matters . . . . . . . . . . . . . . . . . 65

3.6 Summary of Findings $\ldots \ldots \ldots \ldots \ldots \ldots$

4 Illustration: Sino-Vietnamese Conflict $\quad 70$

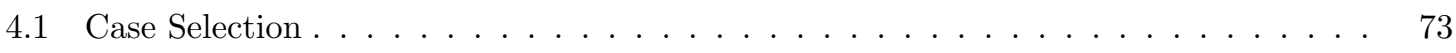

4.2 Puzzles: Ceasefires between China and Vietnam _ . . . . . . . . . . . . . 74

4.3 Theoretical Predictions and Competing Arguments . . . . . . . . . . . . . . . 76

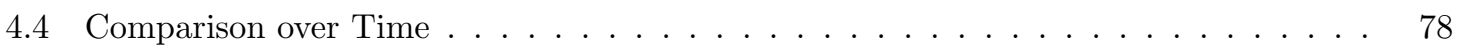

4.4.1 Road to the First Sino-Vietnamese War . . . . . . . . . . . . . . . . 79

4.4 .2 The First Sino-Vietnamese War . . . . . . . . . . . . . . . . . . 81

$4.4 .3 \quad$ Fragile Ceasefire $\ldots \ldots \ldots \ldots \ldots$

4.4.4 The Second War and Post-War Peace . . . . . . . . . . . . . . . 85

4.5 Comparison across Locations $\ldots \ldots \ldots \ldots \ldots \ldots \ldots$

4.5.1 Between 1974 and $1988 \ldots \ldots \ldots \ldots$. . . . . . . . . . . . 89

4.5.2 Resumption of Conflict in March 1988 and after . . . . . . . . . . . . 92

4.5 .3 Rise in Hostility in $2014 \quad \ldots \ldots \ldots \ldots$

4.6 Past and Future of the Sino-Vietnamese Relationship . . . . . . . . . . . . . . . 95

$\begin{array}{llr}5 & \text { Conclusion } & 97\end{array}$

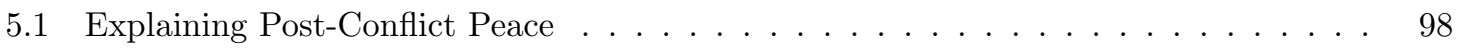

5.1.1 Why and Under What Conditions Does Fighting Resume? . . . . . . . . . 98 
5.1 .2 Findings of Empirical Analysis . . . . . . . . . . . . . . . . 100

5.1.3 Future Avenue of Research ..................... 103

5.2 Implications for International Relations . . . . . . . . . . . . . . . . . . . . . . 104

5.3 Constructing Post-Conflict Peace . . . . . . . . . . . . . . . . . . . . . . . . . . . 108

Appendix A Proof of the Model $\quad 111$

Appendix B Descriptive Statistics of Variables 114

$\begin{array}{llr}\text { Appendix C } & \text { List of Cases } & 116\end{array}$

$\begin{array}{ll}\text { Appendix D Post-Estimation Analysis } & 121\end{array}$

D.1 The Effect of Territorial Change (Table 3.1) . . . . . . . . . . . . . . . . . . . . . . 121

D.2 The Nature of Territorial Change (Table 3.2) . . . . . . . . . . . . . . . . . . . . 125 


\section{List of Figures}

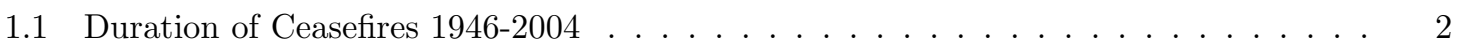

2.1 A Strategic Game of Ceasefire . . . . . . . . . . . . . . . . . . . . . . . . 22

2.2 A Basic Model: The Sequence of Moves . . . . . . . . . . . . . . . . . . . . . . 26

2.3 The Loser's Strategies . . . . . . . . . . . . . . . . . . . . . . . . . . . 28

2.4 A Full Model: The Sequence of Moves . . . . . . . . . . . . . . . . . . . . . . . 31

2.5 The Loser's Strategies in A Full Model . . . . . . . . . . . . . . . . . . . . . . . . 34

3.1 Density and Area of Exchanged Territories _ . . . . . . . . . . . . . 55

3.2 Effects on the Likelihood of War Resumption (Model 5 in Table 3.1) . . . . . . . . 63

3.3 Characteristics of the Gainer and Survival of Post-War Peace (Model 3 in Table 3.2) 66

4.1 Map: Southeast Asia in 2012 (Central Intelligence Agency, 2012) . . . . . . . . . . 75

4.2 Map: South China Sea (Central Intelligence Agency, 1988) _ . . . . . . . . . . . 88

D.1 Deviance Residuals of the original analysis (Model 5, Table 3.1) . . . . . . . . . . 122

D.2 Dfbeta of the quasi-original analysis (Model 1, Table D.1) . . . . . . . . . . 123

D.3 Dfbeta of the post-estimation analysis (Model 4, Table D.1) . . . . . . . . . . . 123

D.4 Deviance Residuals of the original analysis (Model 3, Table 3.2) . . . . . . . . . 126

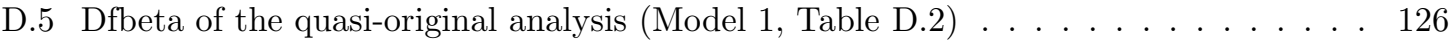




\section{List of Tables}

3.1 Replications and the Effect of Territorial Change . . . . . . . . . . . . . 61

3.2 Characteristics of Territorial Change and Post-War Peace . . . . . . . . . . . . 67

4.1 Predictions of Existing Theories . . . . . . . . . . . . . . . . . . . 77

4.2 Theoretical Predictions: the Duration of Ceasefires . . . . . . . . . . . . . 87

B.1 Summary Statistics . . . . . . . . . . . . . . . . . . . . . . 114

B.2 Cross-Correlation Table . . . . . . . . . . . . . . . . . . . . 115

D.1 Robustness Check, Table 3.1 in Chapter $3 \ldots \ldots$. . . . . . . . . . . . . . . . . 124

D.2 Robustness Check, Table 3.2 in Chapter $3 \ldots \ldots \ldots \ldots \ldots \ldots$. . . . . . . 127 


\section{Abstract}

This dissertation investigates why certain post-conflict peace between states last longer than others. Many ceasefires break down within a few years, which suggests that despite tremendous costs, violence has been a surprisingly ineffective means of solving international disputes, although existing literature assumes that armed conflict mitigates the causes of conflict. Specifically, two theoretical puzzles are drawn from this observation. The first puzzle is why conflicting parties often dishonor ceasefires to which they once mutually agreed. Because rational adversaries must believe that they are better off terminating conflict than continuing fighting at the moment of the conflict's termination, they should not have an incentive to renege on the settlement in the same environment. The second puzzle is why countries fail to peacefully renegotiate an initial settlement and resort to force when they become dissatisfied with it. Revisionist wishes do not necessarily imply that further fighting is inevitable because adversaries can peacefully renegotiate the terms of the original settlement if necessary. This situation is all the more puzzling considering that, in the framework of the existing literature, combat resolves the cause of conflict, whether it is informational asymmetry or a commitment problem.

To solve these questions, this dissertation provides a game-theoretic model that analyzes conflict termination, renegotiation, and conflict resumption as a single process. My theory demonstrates that uncertainty regarding the degree to which resources acquired during conflict empower the gainer determines the stability of post-conflict peace because the divergence between the ex-ante expectation and ex-post realization of the gainer's post-conflict power growth provokes a revisionist and opportunistic incentive for the loser. Specifically, conflict resumes when the country who obtained resources, such as territory, during a conflict fails to fully exploit the resources because such temporal stagnation in resource usage incentivizes the loser to seek an opportunity to recapture some resources before the gainer can fully utilize the resources. Conversely, the loser appeases his growing 
opponent and fighting does not resume when the gainer's power increases more than anticipated because the loser does not want to confront a strong opponent.

The disturbing effects of uncertainty are amplified, ceteris paribus, if a greater amount of resources is transferred; if the gainer is expected to be more capable of extracting obtained resources; and if capable gainers, such as democracies, obtain resources that reward investments, such as colonies. The logic behind these findings is that, in such circumstance, the losing party has a greater incentive to react to the temporal stagnation of the gainer's resource usage more opportunistically, anticipating that it would have to give up more resources to appease the growing gainer if it did not resume conflict now.

Empirical analyses confirm these arguments. The statistical analysis of ceasefires between 1946 and 1997 demonstrates that ceasefires that include resource transfer such as territorial change are thirteen times more likely to break down than those without territorial change. Moreover, the analysis shows that ceasefires are most likely to break down when wealthy democracies obtain large and populated territory. The case study on the Sino-Vietnamese conflict also shows that the nature of transferred resources conditional on the gainer's capability of exploiting them is the key to explaining fragile ceasefires at their land border and relatively stable ceasefires in the South China Sea.

This study provides sensible grounds for determining successful third party intervention, identifying a fundamental barrier to achieving post-conflict peace and suggesting the role of a third party in removing the barriers. A third party, whether it is purely peace motivated, biased, greedy, diplomacy reliant, or military reliant, will not undermine peace as long as it intervenes before a ceasefire agreement is reached and behaves in a way that is consistent with the initial agreement because adversaries make optimal choices about terminating or continuing a conflict, taking into account the intervention by the third party. Moreover, given that settlement is achieved, counter-intuitively, a purely peace-motivated third-party must not attempt to tie the gainer's hands for post-conflict extraction of resources, but rather, it should help the gainer utilize resources when it turns out that her power growth is less than expected. This is because peace requires that the losing party does not develop any incentive to challenge the gainer. In other words, post-conflict intervention is feasible only if the gainer has trouble exploiting resources obtained during the preceding conflict. 


\section{Acknowledgments}

I owe my gratitude to many people for their advice, support and encouragement with this dissertation. My deepest gratitude goes to my adviser, Jeffrey W. Lego, who has always encouraged me to ask intriguing questions, setting an excellent personal example and embodying the power of reason that eventually leads a scholar to the truth. The best fortune I had in graduate school was having a person of intelligence, grace, and wit like him as my adviser. This dissertation could not have been completed without the support from David Leblang whose luminous comments helped me move forward in difficult times and find a way out of a never-ending loop of thinking. I also extend my sincere gratitude to Todd S. Sechser. Not only did I learn the field of International Relations from him while I worked as his teaching assistant, but the idea of this project came into existence in his excellent graduate class. I am grateful to Allan C. Stam for his attendance at my oral defense and for his comments, which are full of wisdom. I also wish to express my gratitude to Fumiaki Kubo at the University of Tokyo for his guidance in academia and for his longstanding support. I also thank John M. Owen IV and Michael Gilligan, who enabled me to study at New York University as a visiting student.

I am blessed with a wonderful cohort at University of Virginia, New York University, the University of Tokyo and Hokkaido University. They have been the best friends and rivals, sharing in my hopes and struggles during my graduate studies. I cannot name all, but I would like to acknowledge Kaori Norikane with whom I studied at the University of Tokyo. Her passing was my greatest sorrow, but I am thankful to have spent my days in graduate school with her, a woman who loved the beauty of life. I am grateful to my parents for their love and assistance. I could not have pursued my passion without them. Finally, I wish to thank Kazuto Ohtsuki for his tremendous moral support. I am excited to tackle riddles of this world, hand in hand with him, for the rest of my life.

I must acknowledge that this project was supported by the financial support of JSPS KAKENHI Grant Number 90595670. 
chaperer 1

\section{Introduction}

Why do certain periods of post-conflict peace last longer than others? This study examines why adversaries revert to fighting after a short ceasefire in certain cases, whereas they successfully uphold post-conflict peace in others. Looking back the history of international relations, we can easily see that the length of post-conflict peace varies significantly across cases. Israel and Egypt failed to achieve peace after the Six Day War in 1967 and engaged in a series of armed confrontations that are called the War of Attrition. After the October War in 1973, in contrast, they reached stable settlement that has been maintained to date. Similarly, following the First Sino-Vietnamese War in 1979, China and Vietnam engaged in continuing armed incidents, which escalated into another full-scale war in 1987. After the Second Sino-Vietnamese War, however, they have maintained peace along the land border and completed demarcation of the border. Why did they achieve post-conflict peace in one occasion, and not in the other?

Many armed conflicts have resulted in fragile ceasefires that broke down within several years and that led adversaries to another round of fighting, which implies that violence has been a surprisingly ineffective means of resolving disputes among nations. Of 56 pairs of countries engaged in full-scale war between 1946 and 2004, more than $40 \%$ of them reverted to another full-scale war. ${ }^{1}$ Moreover, when ceasefires broke down, they did so within a short period. More than $15 \%$ of ceasefires between 1946 and 2004 led to another militarized confrontation within five years and nearly $30 \%$ of them reverted to fighting within ten years. ${ }^{2}$ Surprisingly, among failed ceasefires, more than $30 \%$ broke down within one year. Figure 1.1 shows the number of ceasefires that failed after a given period of

\footnotetext{
${ }^{1}$ The list of cases provided by Fortna (2004) is supplemented by the author, referring to Expanded War Data (v.2.1) (Gleditsch, 2004). See the appendix for the list of cases.

${ }^{2}$ Censored cases are not included in the number of failure but included in the population.
} 


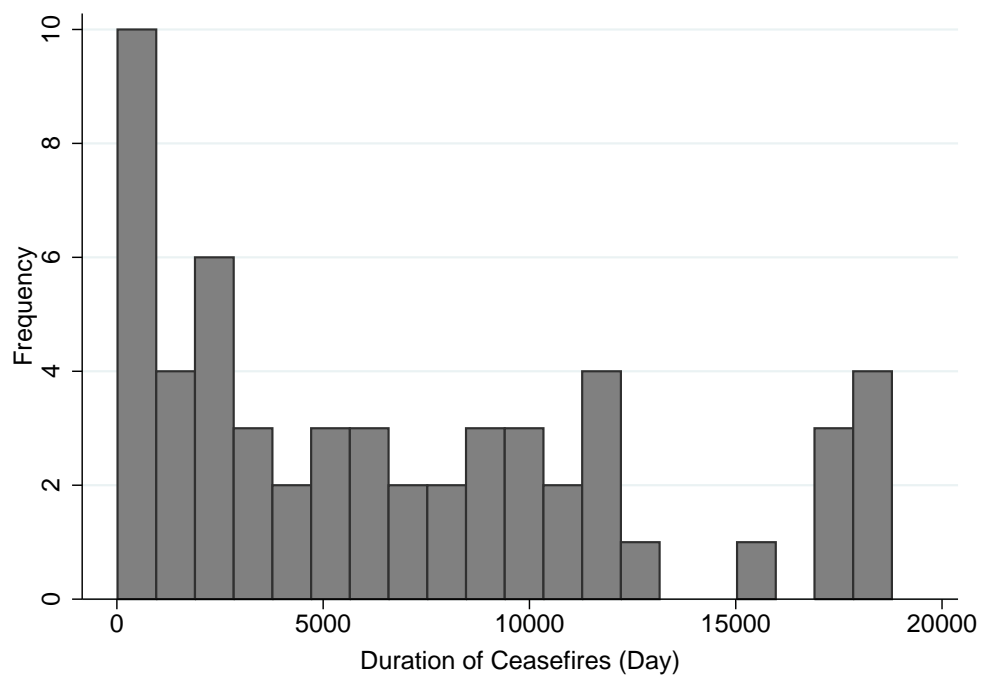

Figure 1.1: Duration of Ceasefires 1946-2004

time, implying that the risk that fighting resumes is significantly high immediately after settlement and then gradually decreases. ${ }^{3}$ If conflict really helps adversaries solve disagreements, the risk of fighting would be the lowest right after conflict is terminated, gradually increasing as the external environment transforms. On the contrary, the likelihood of conflict resumption is in fact the highest right after settlement is achieved. This implies that armed conflict may provoke another round of violence. If conflict often fails to solve disputes and to create peace, for what are lives and wealth sacrificed? A natural question that arises is under what conditions conflict leads to peace or further violence.

The primary goal of this study is to identify a fundamental barrier to achieving post-conflict peace and suggest the role of a third party in removing the barrier. I elucidate a mechanism through which adversaries honor or dishonor ceasefires; therefore, it is not my principal purpose to examine the effect of specific peacekeeping devices, such as mediation and formal agreements. Rather, this study takes a step back and investigates why adversaries resume fighting after a short period of time - before asking how to stop them from doing so.

I demonstrate that uncertainty regarding the degree to which resources acquired through conflict empower the new owner determines the stability of post-conflict peace. Adversaries often seize or lose resources such as territories and natural resources through fighting. In the Spanish-American War in 1898, for instance, the United States acquired former colonies of the Spanish Empire, including

\footnotetext{
${ }^{3}$ Censored cases are included in the figure. Excluding them does not significantly change the observed patterns.
} 
the Philippines, Guam and Puerto Rico, as well as secured de facto control over Cuba. Spain, on the other hand, lost almost all of its foreign colonies as a result of the war. Such resource transfer significantly affects the post-conflict balance of power between adversaries. Yet, post-conflict power growth per se is not very detrimental to post-conflict peace because belligerents can choose not to terminate conflict if power-growth is too threatening.

A crucial issue is that adversaries are unsure how much power they can extract from resources obtained during conflict at the moment of settlement. It is often difficult to predict what can be done with newly acquired resources such as territories. Making matters worse, even parties that seize resources are uncertain about future power growth. Therefore, they are unable to moderate the problem through communication.

A tragic example is the Chaco War where Bolivia and Paraguay competed over Gran Chaco, which was believed to be rich in oil. Through three years of deadly fighting, Bolivia seized a quarter of Gran Chaco, whereas Paraguay retained the rest. After settlement, however, no significant oil reserve has been discovered in Gran Chaco. ${ }^{4}$ Bolivia and Paraguay must not have expected that they would be left with the scarcely populated, hot, and dry lowland. Thus, uncertainty, which is inherent in resource transfer, brings instability into settlement because the opponents possibly seek to renege from the initial agreement when the growth of the gaining party turns out to be more or less than expected at the moment of settlement.

Post-conflict peace breaks down precisely when the growth of the gaining side is less than expected and the relatively declining party finds an opportunity to take some resource back. In other words, resumption of conflict is caused by opportunistic behavior of the declining party, rather than its fear of the growing opponent. Observing the actual growth of the gainer after settlement, the parties can revise the original agreement through either peaceful renegotiation or violent fighting. This study shows that the losing party chooses to fight when it realizes that its opponent's resource extraction is less than expected because it seeks to gain some resources back before the resources are fully utilized. In contrast, when it observes that the other's power growth is more than expected, it appeases the adversary through peaceful renegotiation rather than resumes conflict because it wishes to avoid fighting with the strong opponent.

The disturbing effects of uncertainty is modified or reinforced by factors such as the nature of resources and the capabilities of the gaining party of extracting resources. I focus particularly on "who gets what" in the initial conflict. Suppose that there are two types of resources: potential

\footnotetext{
${ }^{4}$ In 2012, the President of Paraguay announced that a large oil field was discovered in this region.
} 
colonies and "lootable" resources such as diamonds and timber (Ross, 2004b). They differ in the extent to which an owner must invest to extract the benefit. Countries must invest in political and economic infrastructure to fully cultivate colonies, whereas almost anyone can easily exploit and consume "lootable" resources.

Therefore, uncertainty has the most detrimental impact on post-conflict peace when wealthy democracies acquire colonies. This is because economic wealth enables the new owner of colonies to invest to economic and political infrastructure that is necessary for development. Similarly, democratic institutions are known to incentivize political leaders to provide more public goods such as national security than autocratic leaders who tend to distribute spoils of war among political elites to effectively buy their support (ex. Bueno de Mesquita et al., 2003; Lake, 1992; Reiter and Stam, 2002). Thus, wealthy democracies are more capable of converting the obtained resources into military power, and hence, the opponent has a more opportunistic incentive to rush to take resources back whenever it can. When poor autocracies are on the gaining side, in contrast, "lootable" resources are more dangerous to post-conflict peace because such resources can be exploited by such insufficiently capable gainers.

The findings of this study contributes to research and practice of peace and violence in three ways. First, I provide a basic framework for analyzing post-conflict peace, which addresses adversaries' self-selection to ceasefire by treating pre- and post-conflict phases as a continuous process. To fully understand why adversaries dishonor ceasefire, we should take into account the fact that they agreed to a ceasefire in the first place. Otherwise, we may end up with logically incoherent reasoning. If we want to know why a person returns a jacket on the next day of purchase, we must first understand why he or she purchased it after spending two hours in a fitting room, and then analyze what caused the change of mind or what prevented him or her from making the right decision on the previous day.

It must be emphasized that conflict resumption is distinct from conflict onset analyzed in literature such as Fearon (1995) because, in cases of conflict resumption, the initial conflict solves the general causes of bargaining failure such as uncertainty and adversaries deviate from settlement that they once mutually agreed under such conditions. Apparently, this puzzle of "why he or she returned the jacket" is different from a question of "why he or she did not purchase the jacket." As just saying "the person didn't like it" does not fully explain the behavior considering that he or she once purchased it, we cannot fully understand why ceasefire breaks down by simply analyzing 
the post-conflict phase. We must investigate termination and resumption of conflict as a continuous process.

Second, this analytic framework provides sensible grounds for determining successful third party intervention, identifying a fundamental barrier to achieving post-conflict peace and suggesting the role of a third party in removing the barriers. Specifically, a third party, whether it is purely peace motivated, biased, greedy, diplomacy reliant, or military reliant, will not undermine peace as long as it intervenes before a ceasefire agreement is reached and behaves in a way that is consistent with the initial agreement. Adversaries make optimal choices about terminating or continuing a conflict, taking into account the intervention by the third party.

Moreover, given that settlement is achieved, counter-intuitively, a purely peace-motivated thirdparty must not attempt to tie the gainer's hands for post-conflict extraction of resources, but rather, it should help the gainer utilize resources when it turns out that her power growth is less than expected. This is because peace requires that the losing party does not develop any incentive to challenge the gainer. In other words, post-conflict intervention is feasible only if the gainer has trouble exploiting resources obtained during the preceding conflict.

Lastly, this study suggests that it is worth reconsidering the role of war in international relations and exploring under what conditions violence helps nations create peace without assuming that combat mitigates causes of war in general. I claim that conflict is not a general solution to disputes and that the utility, if any, of conflict largely depends on the nature of the resources at stake and the characteristics of adversaries, although scholars have more or less assumed that violence helps opponents solve disputes since Carl von Clausewitz asserted that "war is an instrument of policy" (Von Clausewitz, 1976, p.605). This assumption leads scholars to argue that conflict is terminated when its causes are mitigated through fighting (ex. Blainey, 1988). In reality, however, conflict is an ineffective, and often a counterproductive, solution to international disputes. Considering that "we make war in order that we may live at peace" as Aristotle asserts, we must investigate post-conflict peace to fully understand the role of violence in international politics (Aristotle, 2004, p.271). ${ }^{5}$

In the remainder of this chapter, I first present two theoretical puzzles that motivate this project. Specifically, this project addresses why adversaries dishonor ceasefires that they once mutually agreed to, and why they fail to peacefully renegotiate terms of settlement when revisionist wishes arise. I then summarize the core arguments of this study. Adversaries fail to maintain post-conflict peace

\footnotetext{
${ }^{5}$ Aristotle says that "it is commonly believed that happiness depends on leisure; because we occupy ourselves so that we may have leisure, just as we make war in order that we may live at peace."
} 
because resource transfer during conflict causes them to take opportunistic behavior rather than to uphold ceasefires. Such opportunistic motivations are reinforced or modified by factors such as the nature of resources exchanged and the characteristics of opponents. Then, I elaborate on the scope of this research. In the fourth section, I review existing studies on post-conflict peace and suggest what is missing. I conclude this chapter by discussing research methods and the structure of the dissertation.

\subsection{Motivation}

In addition to the empirical and normative problem raised above, two theoretical puzzles motivate this project. The first one resides in the very fact that conflicting parties often dishonor ceasefires. Fighting resumes because one or both of the adversaries breaks the ceasefire. Although this statement may sound obvious, it is puzzling because "[a]n agreement (either explicit or implicit) to end a war cannot be reached unless the agreement makes both sides better off" (Wittman, 1979, p.744). ${ }^{6}$ When opponents consider whether to terminate conflict, they carefully examine if they are better off agreeing to ceasefire or continuing to fight. Then, they choose to terminate conflict only if they believe that ceasefire is the better option. If that is the case, it is unlikely that they have reasons to renege later.

In other words, ceasefires that are doomed to be dishonored would not make both sides better off and hence would no be agreed because, in such cases, belligerents should keep fighting until either side completely defeats or disarms the other (Reiter, 2009; Wagner, 2000). It might be conceived that ceasefires often fail because one or both parties intends to betray the other from the onset and prepares for the next combat behind the scenes during armistice. Keeping Wittman's statement in mind, however, this explanation is logically flawed because a rational actor would never agree to terminate fighting if it knows that the other side will be unfaithful. Thus, a theory of post-conflict peace must be able to present a mechanism that forces adversaries to dishonor a ceasefire to which they once mutually agreed.

An analogous example to this puzzle is a divorce. A divorce is common these days but it involves a puzzle. A couple may decide to divorce because they feel their personalities are incompatible or because one spouse cannot endure the loud snoring of the other. In any case, to fully understand why they divorce, we must take into account the fact that they got married in the first place. It

\footnotetext{
${ }^{6}$ Werner and Yuen (2005) elaborate on the issue of endogenous agreements in the context of post-conflict peace.
} 
may be true that their personalities do not get along. From a theoretical point of view, however, the account is not fully convincing because they would not have married if their characters were truly incompatible. This could happen if a couple meets each other through omiai, or a traditional Japanese-style blind-date where a go-between, who often has higher social standing than parents of the would-be couple, formally introduces a man and a woman (same-sex couples are unlikely to go through omiai) with their parents. In this case, the couple may not know each other well before marriage, and notice incompatibility of their personalities or intolerable volume of snoring later. On the other hand, such realization is less likely if the couple dates and lives together for years. If so, something must happen to change the couple's feelings toward each other. Post-conflict peace is similar to the latter case because adversaries undergo a series of fighting and exchange information on each other before they agree to a ceasefire (I am not saying that dating is similar to war). All in all, to fully understand the reason for a divorce (or ceasefire), we must investigate the factors that cause the couple to dishonor their pledge of everlasting love that they once mutually committed to.

Dismissing the process preceding a ceasefire or marriage causes not only theoretical inconsistency but also biased inference in empirical analysis. If we ignore the process of marriage, we may conclude that a couple divorces because their personalities are incompatible. As explained above, this cannot be a complete explanation of their divorce, taking into account the fact that they self-selected into marriage in the first place. This is a so-called problem of selection effects, which "occur when factors that influence the choices that produce cases also influence the outcome or dependent variable for each case" (Fearon, 2002, p.7).

Observed in this light, empirical analysis solely focuses on post-conflict phase may lead to biased inference. For instance, it may be conceived that the outcome of battles influences the duration of ceasefire. A straightforward argument is that a ceasefire is more durable when one side clearly prevails than when conflict ends in tie. Yet, when we take into account self-selection into ceasefire, adversaries who terminate conflict even after an ambiguous outcome of fighting may inherently differ from others. Such opponents may be less concerned with the issue at stake, and hence less likely to engage in anther conflict. If so, the ambiguous result of fighting is associated with a longer duration of ceasefire. This does not mean, however, that indecisive fighting causes peace. Once we control for the selection effects such as belligerents' resolve, the indecisive outcome of battles may have a negative impact on post-conflict peace.

Another theoretical puzzle is why former adversaries fail to peacefully renegotiate the terms of the initial settlement and resort to force again when disagreements arise, even though the initial 
conflict must have minimized the causes of fighting. In regard to partnership, we can easily imagine that a couple periodically faces difficult problems in maintaining their marriage. One may cheat on the partner or one may find it unbearable that the partner puts socks starting with the right foot. Although these could be potential reasons for a divorce, they do not necessarily lead to parting. They are able to go to attend counseling or reach an agreement to put on socks starting with the left foot on weekends.

Similarly, former adversaries do not have to fight another conflict even if they want to revise the initial settlement because they can coerce each other to accept the new terms of agreement. For instance, China and India have successfully updated their agreements over the Himalayan border since the Sino-Indian War in 1962. In 1993 and 1996, they signed the Sino-Indian Bilateral Peace and Tranquility Accords in which they officially accept the "Line of Actual Control" established after the war. Later in 2011, responding to India's concern over China's military build-up, they announced that they would engage in a dialogue to avoid confrontation. Thus, revisionist incentives are unable to fully explain why actors fail to renegotiate terms of settlement peacefully.

It must be emphasized that this puzzle is different from the common question of "why do states fight rather than settle peacefully" because, in cases of post-conflict peace, the initial conflict solves the general causes of bargaining failure such as uncertainty. Recalling that conflict is believed to moderate the causes of fighting, it is all the more puzzling why belligerents resort to force to revise the terms of settlement.

\subsection{The Argument}

A fundamental barrier to maintaining a ceasefire is uncertainty regarding the extent to which resources transferred during conflict increases the military power of the new owner. Adversaries often seize resources such as territory from the opponent, regardless of whether the resources are the primary stake of the conflict. Once fighting is over, the new owner of the resources starts utilizing it. Since the gains from the territory may be invested to arms, results in a post-conflict shift in power.

Such a shift in power, however, does not directly cause adversaries to resume fighting if they are able to anticipate what will happen in the future because they never terminate the initial conflict if they anticipate that they will revert to fighting later. Thus, post-conflict growth of power may not be a plausible account for conflict resumption, when we take into account adversaries' self-selection to the ceasefire and treat pre- and post-conflict stages as a continuous process. 
Thus, uncertainty plays a crucial role in conflict resumption. Uncertainty brings instability into settlement of the initial conflict because the opponents possibly seek to renege on the initial agreement when the growth of the gaining party turns out to be more or less than expected at the moment of settlement.

They revert to fighting precisely when the growth of the gaining side is less than expected and the relatively declining party finds an opportunity to take some resource back. In other words, a vital obstacle to post-conflict peace is opportunistic behavior of the declining party, rather than its fear of the growing opponent. Observing the actual growth of the gainer after settlement, the parties can revise the original agreement through either peaceful renegotiation or violent fighting. This study shows that the losing party chooses to fight when it realizes that its opponent's resource extraction is less than expected because it seeks to gain some resources back before the resources are fully utilized. In contrast, when it observes that the other's power growth is more than expected, it appeases the adversary through peaceful renegotiation rather than resumes conflict because it wishes to avoid fighting with the strong opponent.

Empirical observations confirm that resource transfer as a result of conflict has a negative effect on the prospect of post-conflict peace. To examine the effect of resource transfer, this study analyzes the effect of territorial change during war on the duration of ceasefires that achieved between 1946 to $1997 .{ }^{7}$ As the theory suggests, ceasefires following territorial change are significantly less durable than those without territorial change. Specifically, ceasefires following territorial change are thirteen times more likely to break down at a given time than those without territorial change. This finding holds regardless of whether the exchanged territory is the primary issue at stake.

While uncertainty enables adversaries to resume fighting, it also encourages them to settle conflict under a situation where they would otherwise not under certain conditions. In other words, uncertainty modifies the detrimental effect of a commitment problem stemming from shifting balance of power. If we analyze conflict termination and resumption as a single process, adversaries' decisions of conflict termination largely depend on what they expect to happen in the future. In general, they never agree to a ceasefire when conflict is expected to resume or when it is too costly to maintain ceasefire through appeasement. The losing party agrees to settlement only when it does not have to give up a great amount of resources to maintain post-conflict peace. Thus, the window of opportunity for settlement is quite limited. However, uncertainty enlarges the window under some conditions. Under uncertainty, belligerents settle conflict even under situations where

\footnotetext{
${ }^{7}$ Note that uncertainty is unobservable and assumed to be omnipresent.
} 
they would otherwise not. It should be remembered that the losing acts opportunistically in the post-conflict phase. The same motivation encourages it to take the risk of settlement, awaiting a desirable external shock.

Although uncertainty is omnipresent in conflict, its effects are systematically modified or reinforced by factors such as resource allocation realized through the initial conflict, the gainer's capability, and the nature of resources. In general, adversaries are more likely to prolong conflict and, if a ceasefire is reached, to resume fighting when the power-growth through resource extraction is expected to be large. This is because in such a case the declining party has a greater incentive to take opportunistic behavior whenever it can.

First, a decisive, but not absolute, victory by one side causes adversaries to prolong conflict and to return to fighting if a ceasefire is reached. Empirical analysis of ceasefires between 1946 and 1997 demonstrates that a ceasefire becomes short-lived if larger territory is exchanged as a result of conflict. This explains why adversaries often prolong conflict even after the outcome of conflict becomes apparent. For example, Japan never agreed to terminate World War II until two atomic bombs were dropped on Hiroshima and Nagasaki, although it was apparent that Japan was losing the war and the Allies had offered war termination. Germany made the same decision. Both countries did not surrender until they were completely defeated and disarmed. Although their decisions seem irrational at a first glance, this study suggests that they were consequences of rational decisionmaking because peace with Allies would have been unacceptably expensive for the leaders of Japan and Germany. Thus, they kept fighting not because they hoped to roll back, but because the shadow of undesirable post-war peace made them desperate.

This argument also explains why weak states often resume fighting against strong states (See Sechser, 2010). For instance, in the Winter War between the USSR and Finland in 1939 and 1940, the Soviet Union occupied Karelia, Salla, the Kalastajansaarento Peninsula, islands in the Gulf of Finland and Hanko Island, which exceeded $10 \%$ of Finland' pre-war territory, including its industrial center and important ports. The disastrous defeat did not discourage Finland from fighting another war, however. Following the German invasion of the USSR in 1941, Finland fought back and started so-called the Continuation War. That is, observing the trouble in Moscow, Finland did not miss the opportunity to take some resources back from it. Thus, a decisive victory of one side often results in prolonged conflict and unstable post-conflict situation even if a ceasefire is achieved because such vast resource transfer gives the losing party greater opportunistic motivation. 
Second, if the gainer becomes more capable in exploiting newly obtained resources, ceasefire becomes less likely and it is more likely that fighting will resume. In other words, wealthy democracies are more capable of extracting resources, and hence less capable of committing to post-conflict peace. Wealthy countries possess capital and technology to extract resources. Likewise, democratic countries are more likely to produce public goods such as national security, whereas autocratic leaders tend to spend spoils of conflict to private transfer among elites to satisfy them. It is well known that medieval feudal kings distributed conquered territories among patrons in exchange for their war efforts. Thus, wealthy democracies are capable of exploiting resources, and hence motivate opponents to take opportunistic behavior.

This may help us understand why democracies, particularly the United States, are likely to fight absolute war. The United States has engaged in a number of absolute wars, including World War II, the Afghanistan War, and the Iraq War in 2003. People often say that the United States is "exceptional" in its ways of conducting war because it tends to demand unconditional surrender and impose regime change upon total victory. Some argue that the tendency stems from the "American creeds" and its idealistic tradition since Woodrow Wilson (ex. Hunt, 1987). Others attribute this tendency to its inclusive political institutions (Bueno de Mesquita et al., 2004). This study complements these arguments, suggesting that wealthy democracies fight prolonged wars because their capabilities prevent them from constructing durable post-conflict peace, which discourages them from agreeing to a presumably fragile ceasefire in the first place.

Thirdly, the durability of ceasefire is greatly affected by "who gets what" in conflict, that is, the nature of resources conditional on the characteristics of the gainer. Suppose that there are two types of resources: potential colonies and "lootable" resources such as diamonds and timber. They differ in the extent to which an owner must invest to extract benefit. Countries must invest in political and economic infrastructure to fully cultivate colonies, whereas almost anyone can easily exploit and consume "lootable" resources. Uncertainty has the most detrimental impact on post-conflict peace when wealthy democracies acquire colonies. Provided that the gainer is insufficiently capable, the relationship reverses, that is, "lootable" resources such as diamonds are more detrimental to peace than potential colonies. Statistical analysis of ceasefires between 1946 and 1997 shows that ceasefire is the least durable when wealthy democracies obtain more populated territory, whereas ceasefire is much more durable when poor autocracies acquire the same territory.

This argument has relevance for the recent quarrel between China and Vietnam in the South China Sea. Hostility between Beijing and Hanoi over territorial sovereignty in the area escalated to a 
number of armed incidents in 2014, triggered by China's oil exploration in the area. Although their dispute over maritime resources in the region has existed since the mid-1970s, it had not become militarized for long time because, as this study argues, both countries were incapable of exploiting maritime resources in the area's deep water during the 1970s and 1980s. The economic development of China enhanced its capacity for extracting such resources, and caused intensified confrontations in the South China Sea. This episode indicates that it is vitally important to consider the combination of the nature of resources with the characteristics of adversaries to fully understand the effect of resource transfer between countries.

These implications suggest that the utility, if any, of violence varies across cases, conditional on the type of resources exchanged and the characteristics of the gaining party. Conflict results in stable post-conflict peace under some conditions and further violence under others. Fighting might help belligerents create stable peace when insufficiently capable countries obtain potential colonies, whereas fighting cannot be an effective solution to disputes when wealthy and strong countries compete over colonies, as the colonial wars among the great powers in the 18th and 19th centuries indicate.

\subsection{The Scope of This Research}

I address the scope of this study in three respects before I further proceed. First, this dissertation studies post-conflict peace among nations and does not explicitly address conflict involving subnational groups. Although the theory in this project may have implications to civil war, I limit the scope of the study to international conflict in this dissertation.

Second, I must clarify the definitions of conflict, absolute war, conflict resumption and peace. I study conflict among nations, namely any conflict as long as it involves armed confrontation. In other words, the subject of this study is not limited to full-scale war but includes small-scale confrontation. Studying any form of conflict among nations, I make a distinction between absolute war and nonabsolute (conventional) conflict. Absolute war is conflict in which one side completely disarms the other and imposes regime change, as the United States did in the Afghanistan War and the Iraq War in 2003. Absolute war is extensively studied in Reiter (2009) and Lo, Hashimoto and Reiter (2008), who argue that foreign imposed regime change fosters post-conflict peace. Yet, this study focuses on peace following conventional conflict and not absolute war because imposed regime change fundamentally transforms the relationship between former belligerents (See Ohtsuki, 2013). This 
implies that conflict is considered to resume as long as the same pair of countries engages in conflict after a period of no military confrontation. Therefore, when I talk about peace, I focus solely on non-existence of violence. Hence, I use terms such as armistice, ceasefire, peace and settlement interchangeably as long as there are no violent incidents between previous opponents.

Finally, this study's focus on violent resource transfer excludes some types of conflict such as humanitarian intervention from the scope of the analysis. Although I often refer to territory or natural resources as an example of resources, the scope of this study is not limited to them. Resources can be anything that potentially increases the military power of countries. In this sense, some policy concessions are also considered resources. A possible example is the U.S. invasion of Grenada in 1983 where the Reagan Administration disposed of the socialist regime. ${ }^{8}$ The United States obtained few material gains in the incident. Yet, it "seized" Grenada from the USSR and Cuba, which had strategic and symbolic meaning to American power in the context of the Cold War. By highlighting resource transfer, however, some cases are excluded from the analysis. For instance, purely humanitarian intervention, if any, may be out of the scope of this study because parties are unlikely to gain valuable resources through such conflict.

\subsection{Literature on Post-Conflict Peace}

This section reviews influential literature on post-conflict peace to illuminate contributions of this study. I first argue that enough theories regarding post-conflict peace have not been developed. I then offer existing explanations of post-conflict peace. They are grouped in two approaches: one focuses on the role of formal agreements and the other highlights underlying material conditions. The latter approach features three factors, including post-conflict power shift, inconsistent battle outcomes and third-party involvement. I review each argument and indicate what can be added by this study.

\subsubsection{Theories of Post-Conflict Peace}

Post-conflict peace is surprisingly lacking in theory despite the rich literature on conflict initiation and termination. This is because most existing literature inadequately assumes that the onset or termination of conflict marks the end of a dispute between states. Most studies assume that war mitigates causes of conflict and that disputes, or more broadly interactions, among states end with

\footnotetext{
${ }^{8}$ This is also an example of absolute war.
} 
onset or termination of conflict. This presumption turns scholarly attention away from an important question of how violence relates to the settlement of international disputes in a broader sense.

Moreover, we recognize the potential flaw of this assumption by simply recalling that a number of conflicts occurred because of the failure to achieve sustainable peace after the preceding wars, such as World War II and the October War. Furthermore, the existence of so-called "enduring rivalries," which are characterized by such recurrent confrontations of the type that India and Pakistan face, also implies that violence seldom guarantees to be a successful solution of international disputes (ex. Diehl, 1998; Diehl and Goertz, 2001; Goertz and Diehl, 1993). If conflict often fails to induce a settlement, we must examine how and to what extent fighting enables adversaries to achieve postconflict peace. In other words, to what extent does conflict truly work as "an instrument of policy" as Clausewitz's classical notion asserts (Von Clausewitz, 1976, p.605)?

This theoretical gap is all the more problematic, considering the growing demand for more effective third-party involvement in conflict. Most of existing literature investigate the role of a third-party in conflict management, assuming that the external force must mitigate general causes of conflict such as informational asymmetry and a commitment problem (ex. Kydd, 2003, 2006). As I mentioned above, however, conflict termination and resumption involve distinct dynamics from those

of general conflict onset, considering that causes of conflict are often expected to be modified through combats even without third-party involvement. This study provides sensible analytic framework of determining successful third party intervention, identifying a fundamental barrier to achieving postconflict peace and suggesting the role of a third party in removing the barriers.

\subsubsection{The Role of Formal Agreements}

An influential argument states that formal agreements help adversaries to sustain post-conflict peace. For instance, Fortna (2004) argues that settlement is more durable if formal agreements involve arms control provisions, demilitarized zones and others because such agreements raise the cost of attack, reduce uncertainty, and control accidental incidents. Although it may be conceived that formal agreements are mere epiphenomena to underlying conditions for peace, there is some evidence that agreements are actually exogenous and have an independent effect on post-conflict peace. In fact, Fortna confirms that strong formal agreements are installed when adversaries are otherwise unlikely to maintain peace.

This, however, raises a question of why adversaries in easy cases avoid strong treaties and then fail to maintain peace. If rational belligerents in such cases can foresee the unstable post-conflict 
situation and if formal treaties are effective, they must have signed strong agreements. When we take into account the fact that opponents strategically choose terms of formal agreements, a theory must be able to explain why adversaries dishonor formal agreements that they selected by themselves.

\subsubsection{Material Conditions of Post-Conflict Peace}

Another explanation of post-conflict peace highlights the significance of underlying material conditions. There are two lines of argument in this camp. One claims that ceasefire breaks down when material conditions underlying the original settlement significantly change during ceasefire. Werner (1999) finds strong empirical support for this argument. She demonstrates that ceasefire is more likely to break down when unexpected external shocks greatly shift the post-conflict balance of power between previous belligerents. Similarly, from a theoretical point of view, Powell (2012) implies that large external shocks relative to the rate of power transition may cause negotiated settlement to fail, although he does not explicitly theorize it.

As Werner (1999) admits, however, opponents do not necessarily resort to force when they become dissatisfied with the original settlement because they can peacefully renegotiate the terms of settlement. As I mentioned previously, this study elucidates a mechanism through which adversaries fail to renegotiate the terms of settlement which revisionists wish had arisen.

Another explanation claims that adversaries are more likely to return to fighting when the initial agreement becomes "obsolete," i.e., inconsistent with material conditions. Werner and Yuen (2005) identify two factors which make agreements more vulnerable to obsolescence. Namely, inconsistent battle outcomes do not render quality information, and hence, prevent actors from precisely conceiving the balance of power. Such an agreement is more likely to become inconsistent with an actual post-conflict situation. Moreover, settlement is more likely to become incompatible with material conditions and opponents' expectation if it is imposed by the third-party. They confirm with statistical tests that these two factors significantly decrease the duration of ceasefire. Yet, it remains unclear why adversaries stop fighting (i.e., stop exchanging information), leaving considerable uncertainty unmodified. Likewise, third-party involvement per se is not enough to theoretically explain an unstable settlement because rational adversaries would not agree to inherently precarious settlement even under pressure of a third-party. 


\subsection{Outline of the Dissertation}

In the remainder of the project, I investigate a mechanism through which adversaries terminate, renegotiate and resume fighting in the shadow of post-conflict resource extraction and explore factors that affect their decisions. To this end, I combine three research methods and allow them to complement each other. Specifically, I employ a game-theoretic approach to develop a theory of post-conflict peace, a large- $\mathrm{N}$ statistical analysis to test the general explanatory power of the theory and case studies to trace causal chains of the theory through detailed historical accounts.

Chapter 2 provides a game-theoretic model to show why and under what conditions uncertainty regarding post-conflict resource exploitation causes adversaries to resume fighting. The theory elucidates a mechanism through which adversaries achieve, renegotiate and renege from settlement. A game-theoretic model helps to disentangle complex interaction between countries in conflict in a logically coherent way. A theory is essentially abstract, simplifying an environment under which adversaries interact. I do not claim that the real world is as simple as the game describes; rather, I argue that it is so hard to establish post-conflict peace even in a very simple setting, to say nothing of the real world. I aim to highlight the core mechanism through which post-conflict peace is maintained or challenged with a game-theoretic approach.

Specifically, the theory in Chapter 2 demonstrates that uncertainty regarding post-conflict resource extraction plays two key roles: It causes adversaries to restart fighting under some conditions, whereas, under certainty conditions, it also encourages them to agree to ceasefire under situations where they would not do so without uncertainty. The effect of uncertainty is reinforced and modified by factors such as the nature of the resources at stake and the characteristics of adversaries. Because uncertainty always exists among nations, the theory argues that the occurrence of ceasefire and its failure are essentially explained by "who gets what" during conflict. Thus, the theory not only presents the general mechanism of post-conflict peace but also generates hypotheses that can be empirically tested.

Chapter 3 and 4 present empirical tests of the theory, combining statistical analyses and historical case studies. Chapter 3 offers statistical evidence that the theory helps to explain the duration of ceasefire. I use data on ceasefires between 1946 and 1997 and on territorial change as a result of conflict. Combining these data, I demonstrate that territorial transfer as a result of conflict significantly causes adversaries to resume fighting. Moreover, as the theory suggests, the detrimental effect of territorial transfer is greatest when a wealthy democracy acquires large populated territory, 
whereas the impact is moderated when a poor autocracy acquires such territory. The statistical analyses confirm that the theory is consistent with general patterns in the observed data.

In addition to statistical tests, I also provide a detailed examination of historical cases in Chapter 4. Although Chapter 3 confirms that the theory helps explain general patterns in the data, it does not fully examine the causal logic of the theory. In particular, it does not fully account for countries' motivation to terminate and resume conflict. Chapter 4 closely traces the causal chains of decision making though a detailed historical analysis. Because the general explanatory power of the theory is examined in Chapter 3, the analysis focuses on how violent resource transfer fosters peace and violence.

To this end, I delineate the process of recurrent confrontations and ceasefires between China and Vietnam, focusing on "who gets what" through conflicts. China and Vietnam are known for their long-time rivalry since the unification of Vietnam in the mid-1970s. Since then, they have engaged in a number of armed confrontations, including two full-scale wars. The Sino-Vietnamese conflict was motivated by territorial disputes at the land border and in the South China Sea and were militarized in each of these locations. Although all territorial disputes have persisted since the mid-1970s, actual armed confrontations in each area show distinct patterns in their timing and intensity. Chapter 4 argues that the key to understanding such patterns is "who gets what" during conflict in each location, as the theory predicts.

The concluding chapter summarizes the theory and findings of this project. I present approaches and arguments that people who are interested in post-conflict peace may find helpful. I also lay out a future avenue of research and contributions of this project to the study of international relations. Finally, I conclude this dissertation with some policy implications for third-party intervention. 
Chapter 2

\section{A Theory of Post-Conflict Peace}

This chapter provides a theory of post-conflict peace, addressing two theoretical puzzles regarding resumption of conflict. Precisely, the theory explores conditions under which adversaries deviate from a once mutually agreed ceasefire and fail to peacefully renegotiate terms of settlement.

The keys to solving the puzzles are resource acquisition during conflict and its usage by adversaries during ceasefire because the post-conflict power of adversaries largely depends on what they obtain and lose during the conflict. The Spanish-American War in 1898 marked a crucial turning point for both the United States and Spain. The United States acquired former colonies of the Spanish Empire, including the Philippines, Guam and Puerto Rico, as well as securing de facto control over Cuba. As a result, the United States became one of great powers and departed more or less from its long-standing isolationist position. Those territories were not only the first US foreign colonies but also became important bases of American military deployment in the Pacific to date. The war, in contrast, had a devastating impact on Spain. Spanish fleets, the core of its military might, were incapacitated during the war. Spain also lost almost all of its foreign colonies in the succeeding Treaty of Paris. Thus, the war brought an end to the history of the Spanish Empire, which had since the 15 th century.

Countries and other political entities vary in how they use such acquired resources. When the United States obtained colonies, it treated them in a very different manner from what Spain had done. As is extensively theorized in Acemoglu and Robinson (2006), the Spanish Empire usually established extractive institutions in colonies, whereas the United States developed relatively inclusive institutions in the sense that political power and economic wealth widely spread among members of the community. 
A good example is the contrast between Nogales in Santa Cruz County of Arizona in the United States and Nogales in the Mexican state of Sonora. The United States purchased a part of Nogales from Mexico during the Gadsden Purchase in 1853 to moderate rising tension at the border in the aftermath of the Mexican-American War. By then, the border areas had been essentially the same city divided by a boulevard. Since that part of Nogales was incorporated into the U.S., however, the fate of the two areas has diverged. Simply stated, the United States was more capable of cultivating the territory than Mexico. In the U.S. side, American capitalists and settlers developed silver mines, extended railroads and opened up ranches. The Mexican side of the city suffered from lack of capital, turmoil with Native Americans and political instability, which undermined spontaneous economic development. Even today, the average income of a household in Nogales, Arizona is approximately $\$ 30,000$ a year, whereas the average household annual income in Nogales, Sonora is approximately one-third that (Acemoglu, Robinson and Woren, 2012, p.7).

The examples indicate that resource transfer in conflict significantly affects the post-conflict power of adversaries and that the degree of growth varies across new owners. If so, belligerents will carefully examine the impact of a new resource allocation when they terminate or restart conflict.

The effect of resource transfer is, however, often unpredictable during conflict, as learned from the tragic story of the Chaco War. Gran Chaco is a region of South America bordering Bolivia, Paraguay and Argentina. The region was believed to be rich in oil in the early 20th century, when petroleum became one of the most important energy sources. Bolivia nurtured its ambition to seize Gran Chaco and started invading the region, inhabited by an indigenous population, while Paraguay claimed ownership of the region. Their dispute eventually escalated to war. After three years of deadly fighting, Bolivia seized a quarter of Gran Chaco, whereas Paraguay retained the rest. The division was later confirmed by a formal agreement. After the settlement, however, no significant oil reserve has been discovered in Gran Chaco. ${ }^{1}$ Bolivia and Paraguay were left with the scarcely populated, hot, and dried lowland. The war only served to trap Bolivia and Paraguay, two of the poorest countries in South America, in economic disaster and successive political instability. Neither of them must have expected this tragic outcome at the time of the ceasefire.

Uncertainty regarding post-conflict resource extraction, as is exemplified in the Chaco War, poses a difficult dilemma for adversaries in conflict. During conflict, they face a choice of continuing to fight or of terminating the conflict. If they choose to keep fighting, they must undergo bloody battles, and conflict will not end until one party completely defeats the other. Prolonged combat will cause

\footnotetext{
${ }^{1}$ In 2012, the President of Paraguay announced that a large oil field was discovered in this region.
} 
further destruction of human lives and material valuables. However, ceasefire is not an infallible alternative. At the moment of decision, adversaries are uncertain about what would happen in the post-conflict world. They may be able to build a wealthy colony or may be left with an almost useless field. Moreover, they may be able to maintain peace forever or may end up with resumed warfare. Thus, they face a serious trade-off between absolute war and potentially unstable settlement.

To investigate adversaries' struggles and successes in such a trade-off, this chapter provides a formal model in which adversaries in conflict interact in the shadow of uncertain post-conflict resource extraction. Under such uncertainty, they decide whether to agree to ceasefire, to renegotiate terms of settlement or to resume fighting. The key feature of the model is that three important phenomena, i.e., ceasefire, renegotiation and resumption of fighting, are endogenized. This setting allows me to explore why parties choose to restart fighting when they had the alternative options of not terminating conflict at the beginning or of renegotiating the issue. This is crucial in understanding a mechanism of post-conflict peace, rejecting seemingly plausible but actually incoherent explanations. If we want to explain why a couple divorces, for instance, it is not satisfying to just say that their personalities are incompatible because they married before divorce. If their personalities are truly incompatible, they would not have married in the first place. Thus, there must be something that made them change their minds or that made incompatible persons marry by mistake. Thus, to understand a comprehensive mechanism of post-conflict peace (or divorce), we must analyze the process of ceasefire (marriage) and renegotiation (divorce mediation) together.

The theory demonstrates that the durability of post-conflict peace is affected by the nature of acquired resources conditional on adversaries' capabilities of converting such resources into military power. Post-conflict peace is most difficult to maintain if one of adversaries is a wealthy democracy and it obtains potential colonies. In contrast, when the gainer of new resources is a poor autocracy, post-conflict peace is less durable if it seizes strategically important locations or natural resources such as diamonds because even a poor country can convert such resources into military power.

Moreover, the theory indicates that the primary cause of resumed fighting is opportunistic behavior of adversaries and not their preventive motivations. This is because they can moderate fear of a growing opponent through appeasement, whereas the same mechanism is unable to deter opportunistic behavior.

Another important implication of the theory is that uncertainty involved in post-conflict resource exploitation has both negative and positive impacts on peace: it causes fighting to resume, but it also allows adversaries to settle conflict in a situation where they would not without uncertainty. 
In the following section, I first introduce the basic model, which analyzes interactions between adversaries, assuming that only one type of resources exists and no uncertainty exists. Then, I provide a full model involving heterogeneous types of resources and uncertainty regarding postconflict resource extraction. Based on the full model, the effect of various factors on ceasefire and post-conflict peace is analyzed. I conclude the chapter by summarizing the findings of the theory, offering empirically testable hypotheses, and discussing the scope of the theory.

\subsection{A Basic Model}

This section provides a basic model analyzing ceasefire, renegotiation and resumption of fighting without introducing a variation in the natural characteristics of resources and uncertainty in the post-conflict phase. The model aims to highlight the impact of post-conflict resource exploitation on post-conflict peace and on ceasefire. It illustrates the basic mechanism through which actors stop fighting and maintain peace in the shadow of post-conflict power growth.

\subsubsection{Ceasefire}

In the game introduced here, two players are in conflict. ${ }^{2}$ One side of the belligerents initially possesses a good such as territories and natural resources that is valuable to both sides. Let us assume that their evaluations of the good are identical for the sake of simplicity. The challenger is aiming to seize a portion of the good through conflict. The initial value of the good is represented by $\rho>1$. Note that the value of factors denoted by Greek letters is exogenously given to the model, whereas the value of factors in alphabets is determined by the actors' choice, i.e., is endogenous to the model. Throughout combats, the good at stake is more or less destroyed and the value of the good decreases from its initial value $\rho$, which is a standard setting in the current literature. The post-destruction value of the good is normalized to unity for simplicity.

Another important role of conflict, in addition to destruction, is redistribution of the good: the initial owner loses his exclusive control over the good and his opponent obtains a share of the good. This sort of reallocation of goods is very common in international war as well as in civil war. In the Chaco War mentioned above, Bolivia seized a quarter of Gran Chaco, while Paraguay retained the rest. A share of the good that the challenger newly obtains is denoted by $\alpha \in(0,1]$, whereas the initial owner maintains control over the rest, $1-\alpha$. I assume that the challenger is able to acquire

\footnotetext{
${ }^{2}$ In this model, a process of conflict initiation is suppressed because conflict onset is extensively examined elsewhere.
} 


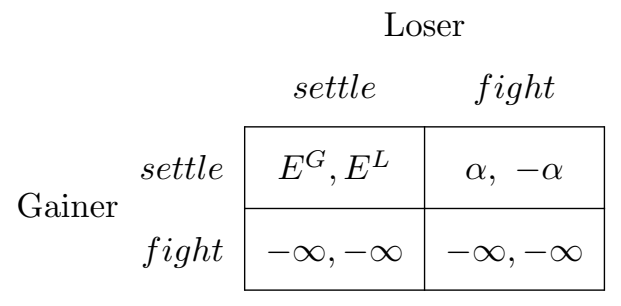

Figure 2.1: A Strategic Game of Ceasefire

a positive amount of the good because it makes a challenge only if it can do so in expectation. Moreover, the result of conflict is exogenously determined to focus on the consequence of resource transfer rather than its cause. It can be interpreted that belligerents have already made optimal choices during conflict and the process is suppressed in the model. The value of $\alpha$ will be defined later.

Hereafter, I define the challenger as the gainer (or she) and the initial owner as the loser (or he). Using the example of the Chaco War, Bolivia is the gainer who seizes $\alpha=\frac{1}{4}$ while Paraguay, the loser, maintains $\frac{3}{4}$ of Gran Chaco. Remember that this definition is not necessarily consistent with the common notion of battle outcomes. In fact, it is considered that Paraguay won the Chaco War according to battle outcomes. Meanwhile, he lost a part of the control he had claimed. Therefore, this study denotes Paraguay as the loser. Although there would be many ways to define "victory," I solely focus on reallocation of the resource to highlight the impact of such resource transfer on ceasefire and its failure.

Given the new resource allocation $\alpha$ and $1-\alpha$, players simultaneously decide whether they keep fighting or terminate conflict, as described in Figure 2.1. Each player has a choice of seeking settlement or fighting. Ceasefire is achieved only if both players choose to settle. When ceasefire is achieved, the gainer and the loser receive $E^{G}$ and $E^{L}$, respectively. These values are determined by the players' expectation regarding what will happen during ceasefire and will be defined later. If both players keep fighting, they will end up with an undesirable outcome such as absolute war, which is represented by $-\infty$ in the bottom-right corner. This setting does not really mean that adversaries suffer from an infinite amount of destruction. It merely expresses that the situation is quite undesirable for both players.

When the gainer keeps fighting and the loser chooses to settle, they are in as bad a situation as absolute war, which is expressed in the bottom-left corner. This could be interpreted as follows. The players are to fight a deadly war if the gainer, who is potentially the stronger or greedier party, continues fighting. Thus, when the gainer seeks peace and the loser keeps fighting, the situation is 
not so disastrous: the gainer obtains $\alpha$, and the loser ends up with $-\alpha$. That is, the gainer retains all of the acquired resources ${ }^{3}$, whereas the loser suffers from damages, depending on the resource allocation resulting from the conflict.

What does this setting capture? Under this situation, the gainer has a very strong desire for settlement due to the significantly undesirable consequence of fighting, or $-\infty$, regardless of the loser's choice. Here, I do not assume that she is peaceful in nature. Far from it, she is the party who seeks to alter the status quo in the first place. The purpose here is to illustrate a situation where players still fail to achieve settlement or maintain post-conflict peace, even if the greedier party is satisfied with the outcome of the initial conflict and is eager for peace. This model aims to explore the core mechanism that drives states to absolute war or conflict resumption, analyzing the worst outcome under the best conditions.

To further comprehend the reasoning, suppose that a male hyena successfully catches a prey in savanna. When he licks his chops in anticipation of a good meal, a giant female lion shows up and pounces on the hyena. They engage in a bloody combat (this study does not analyze why they start fighting), trying to tear the prey off to each side. What will happen to the two beasts? They wonder whether to stop the fight, looking at a portion of the prey each has gained out of the corner of their eyes. The worst scenario for both of them is that the queen of beasts never stops fighting. Regardless of the hyena's action, both will be fatally wounded and the prey will be torn into uneatable pieces. If the lion ceases to attack and the hyena does not, she successfully protects the portion of prey she has seized up to that point. The hyena gets his portion of the prey mangled and himself severely injured. Under this setting, the lion always chooses to cease the battle to avoid deadly wounds and retain her meal. She does not want to kill the hyena for an additional meal and is willing to end the battle.

Although the hyena knows it, there is a mysterious case where he continues to attack the lion because his choice largely depends on his expectation of what will happen after the battle ends. Thus, the game clarifies conditions under which the hyena dares to continue the battle even though the queen of beasts is willing to release him. It should be noted that I do not limit the analysis to a case where considerable disparity of power exists between adversaries. Rather, I explore conditions under which adversaries fail to research ceasefire even if the stronger and greedier side is willing to do so. It is needless to say what will happen if this assumption does not hold.

\footnotetext{
${ }^{3}$ Note that the value of the gainer's payoff here is inconsequential as long as she is slightly better off than the case of absolute war.
} 
If both players agree to settle, they proceed to a post-conflict phase. It should be noted that "settlement" does not require a formal agreement or a peace treaty as far as adversaries stopping fighting. Any mutual agreement must be self-enforcing, that is, it is in both parties' interests to stop further fighting, regardless of the existence of a formal treaty. A formal treaty, if compiled, should be regarded as a "representation" of a self-enforcing agreement.

It should be noted that the game in Figure 2.1 can be interpreted as an illustration of a conflict, or of each battle in conflict. The model places no arbitrary distinction between conflict and combat, as long as they realize a new resource allocation. For instance, China and Vietnam engaged in a series of intensive fighting at the land border from 1983 to 1987. The hostility peaked in 1987, which is often called the Second Sino-Vietnamese War. A question arises of whether the confrontations in 1983 were a part of the war. One understanding is that a conflict happened and terminated in 1983, resumed and ended in 1986, and resumed again in 1987. Another interpretation is that China and Vietnam fought a five-year war with periodical truces. The game introduced here can be applied to both interpretations: it is compatible with the former interpretation if we interpret the game as an illustration of each battle and with the latter if we consider the game as a representation of an entire conflict. Thus, the distinction between ceasefire and a truce of combat is not meaningful in this game.

\subsubsection{Post-Conflict Phase}

If players successfully agree to settle, the gainer and the loser retain a share of the good $\alpha$ and $1-\alpha$, respectively. Then, the gainer starts exploiting the spoils and converts the benefits into military power. As in the case of both Nogales, the gainer varies in her capability of converting newly obtained resources into military power. I denote this capability with a multiplier $\theta>1$. Thus, her post-conflict military capability after a certain period of time consists of $\alpha$ and $\theta$. Because both $\alpha$ and $\theta$ are positive, the gainer's power growth increases as the war spoils increase and as her capability increases.

Note that $\theta$, like other parameters in Greek letters, is exogenously given. That is, some countries are inherently more capable of extracting benefits from resources than others. It is assumed that her choices during conflict as well as during ceasefire do not influence her capabilities of extracting resources. Likewise, the game does not address the process in which her capabilities of extracting resources are determined. For instance, she may face a trade-off between utilizing obtained resources for domestic production or for military build-up (Powell, 1999). The model does not explore such a 
"guns and butter" problem so as to highlight the loser's reaction to the gainer's growth rather than the dilemma the gainer faces. The model assumes that the gainer already chose $\theta$ optimally under her environment and that the process is suppressed, as Fearon (1996) does.

In reality, the value of $\theta$ is influenced by various factors, including economic wealth, technologies and political institutions, as the history of the twin cities of Nogales shows us. Before Americans reached the region, Nogales had been scarcely cultivated. Although Jesuit missionaries settled there, their economic activities were limited. When Americans reached the area, they actively invested capital and labor into the land and extracted great fortunes out of it. Capitalists and settlers passionately developed silver mines, extended railroads and opened up ranches. They believed that, with their labor, "the waste lands will be redeemed from barrenness, towns grow into cities; and her mineral wealth, instead of being a curse, as now, will constitute her greatest element of prosperity" (Thompson and Cram, 1968, p.366).

Despite the thriving of the Arizona side, "Sonora [of the Mexican side] remained seriously underpopulated, preventing the creation of a stable labor force and limiting the formation of internal market." Indeed, "[b]esides numerous flour mills, some cottage enterprises, and one textile mill, Sonora possessed no significant manufacturing." There were a couple of reasons for this. The state of Sonora was exhausted from persistent confrontations with the Yaquis and Mayos, which "continually depleted state resources and deterred Mexican immigration to the state;" moreover, "few elites had amassed sufficient capital to initiate sustained economic development" (Salas, 1992, pp.431-432); In addition to the lack of stability and capital, fierce rivalries among politicians and military officers undermined the state's governance because a political leader facing such severe competition uses resources to buy off support from elites rather than invest to produce public goods such as market and security (Bueno de Mesquita et al., 2004). Although the economic situation of the Mexican side started improving at the turn of the century, the development largely relied on American capital in mining, railroads and agriculture.

Attention to post-conflict resource extraction is the key feature of the model. It highlights an important aspect of conflict and its aftermath. Many existing theories such as Powell (1999) build on the assumption that states can immediately exploit gains in conflict and let them choose to fight or negotiate without any notion of interval. In reality, however, adversaries must spend time and effort to utilize acquired resources, and they vary in their capabilities of doing so.

Once the loser observes the gainer's power growth, he chooses whether to restart conflict or initiate renegotiation. If the loser decides to launch an attack, fighting resumes and the game ends. 


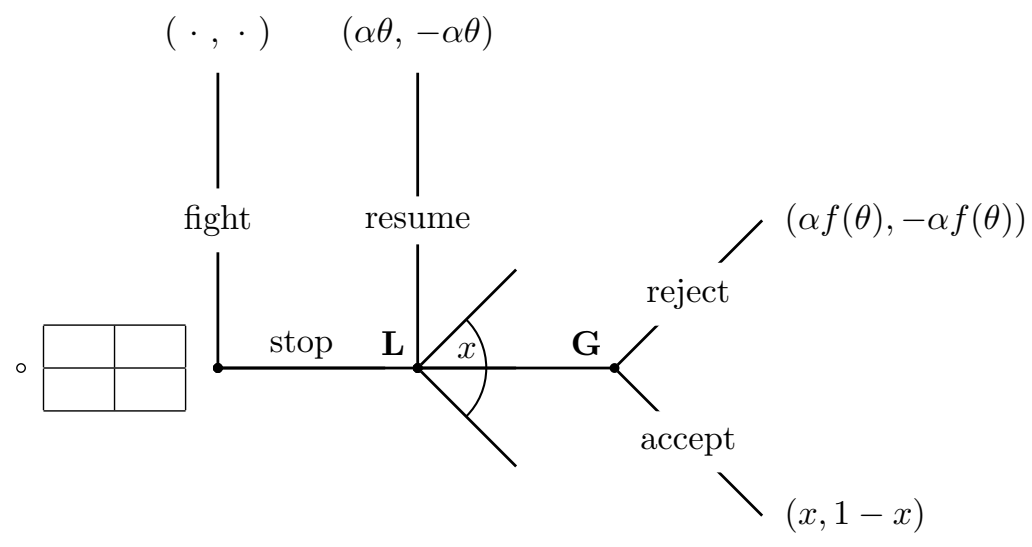

Figure 2.2: A Basic Model: The Sequence of Moves

In the renewed conflict, the gainer and the loser gain $\alpha \theta$ and $-\alpha \theta$, respectively. This implies that a more capable gainer who obtained more resources in the initial conflict wins even more in the renewed fighting and also causes greater damage to the loser. ${ }^{4}$ Note that the total value of the good at stake shrinks to 0 due to destruction in conflict.

If the loser chooses to renegotiate, he offers new terms of settlement such that the gainer possesses $x \in \mathbf{R}$, and the loser holds the rest, $1-x$. Here, $x$ can be any value on the real line, which implies that both players possess sufficient reserves of resources to appease the other. $x$ can be larger, smaller or equal to the initial endowment of the gainer. If larger, the loser tries to appease her with more resource transfer. If smaller, the loser demands that the gainer give some resources back. If it is equal, he is satisfied with the present settlement.

While the loser chooses new terms of settlement, the gainer is not allowed to make a counteroffer. That is, the loser engages in renegotiation with a high hand. This may sound odd considering that his power is relatively decreasing as the gainer's power grows. I adopt this setting to create the most desirable setting for the loser to maintain post-conflict peace. It allows me to highlight a mechanism through which the loser dares to resume fighting in a situation where ceasefire is likely to be maintained.

In the last node of the game, the gainer chooses whether to accept the deal or wage another conflict. If peaceful renegotiation is achieved, a new resource allocation $(x, 1-x)$ is realized. The game ends, and peace is maintained. If the victor rejects the offer, however, fighting resumes, and

\footnotetext{
${ }^{4}$ It is assumed for simplicity that the outcome of renewed warfare solely depends on the amount of the good seized in the initial conflict and the gainer's capability. This setting gives the loser a strong incentive to maintain the initial agreement, which is useful to clarify conditions in which the loser dares to resume fighting.
} 
the gainer and the loser end up with $\alpha f(\theta)$ and $-\alpha f(\theta)$, respectively. Before explaining the details of this outcome, it should be noted that the gainer is guaranteed to have positive payoffs regardless of the realized path in the post-conflict stage. Regardless or whether ceasefire is violated or maintained, she is better off terminating fighting in the initial conflict (Figure 2.1). As explained in the previous section, this framework allows me to explore conditions under which players fail to achieve ceasefire even with such a "benevolent" gainer.

The outcome of conflict is dictated by the gainer's further extraction of the acquired good. It can be interpreted that a certain period of time passes during renegotiation, which enables the gainer to further exploit resources. At this time, the gainer's power growth is denoted by a function $f(\theta)$,

where $f(\theta)>\theta, \lim _{\theta \rightarrow 1} f(\theta)=1$ and $\frac{\partial f(\theta)}{\partial \theta}>0$. In non-technical terms, her power growth derived from one unit of resources increases from $\theta$ to $f(\theta)$, while the loser offers a new allocation of the good. The value of $f(\theta)$ increases in $\theta$, which implies that a more capable gainer can extract more and more benefits from the resources at hand. This is intuitive, considering that American capital, technology, and labor have rendered an even greater disparity between the twin cities of Nogales after a century.

\subsubsection{Results of A Basic Model}

The equilibrium is characterized by players' strategies in the ceasefire phase and the post-conflict phase. In the initial stage, they simultaneously choose whether to settle or fight. They proceed to the post-conflict stage if both players decide to settle. Then, the loser chooses whether to resume fighting or offer $x$ for renegotiation. Receiving the offer, the gainer decides whether to accept or reject. Let $\sigma^{G}=\left\{s_{1}^{G}, s_{2}^{G}\right\}$ denote a pair of pure-strategies of the gainer where she chooses $s_{1}^{G} \in\{$ settle, fight $\}$ in the ceasefire game and $s_{2}^{G} \in\{$ accept, reject $\}$ in the post-conflict phase. Likewise, $\sigma^{L}=\left\{s_{1}^{L}, s_{2}^{L}\right\}$ denotes a set of pure-strategies of the loser where he chooses $s_{1}^{L} \in\{$ settle, fight $\}$ in the ceasefire phase and $s_{2}^{L} \in\{$ resume, $x \mid x \in \mathbf{R}\}$ in the post-conflict phase.

Lemma 1 The following pair of strategies constitutes the pure-strategy SPE. $\sigma^{G}=\{$ settle, accept $\}$ and

$$
\sigma^{L}= \begin{cases}\{\text { settle, } \alpha f(\theta)\} & \text { if and only if } f(\theta)<1+\frac{1}{\alpha} ; \\ \{\text { fight, } \alpha f(\theta)\} & \text { if and only if } 1+\frac{1}{\alpha} \leq f(\theta)<\theta+\frac{1}{\alpha} \\ \{\text { fight, resume }\} & \text { otherwise }\end{cases}
$$




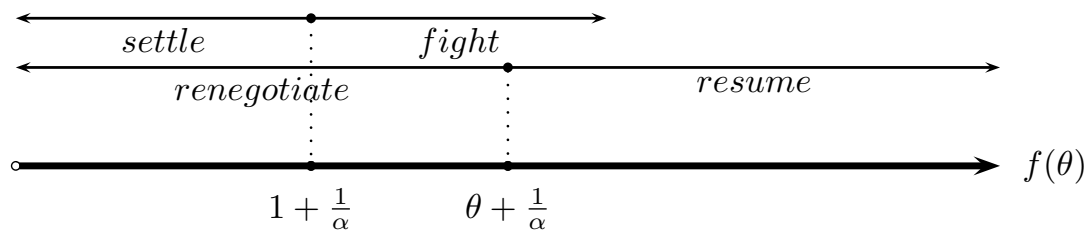

Figure 2.3: The Loser's Strategies

Proof See the appendix.

The result is graphically presented in Figure 2.3 which plots the loser's set of strategies against the value of $f(\theta)$. The bar in the middle shows the loser's strategy in the post-conflict phase. It indicates that he offers renegotiation if the gainer's post-conflict resource exploitation is sufficiently small, whereas he restarts fighting if it is large. The bar on the top demonstrates the loser's choice in the phase of conflict termination. The graph implies that he agrees to a ceasefire if the gainer's post-conflict resource exploitation $(f(\theta))$ is small, whereas he never terminates the initial conflict otherwise. The threshold between settle and fight in the initial stage is lower than that between renegotiate and resume in the post-conflict phase. Thus, obtaining settlement of the initial conflict is more demanding than achieving renegotiation. Remember that only the loser's decision is binding in achieving initial settlement. Three implications are derived from this result:

Remark 1 Under complete information, conflict never resumes if it is terminated.

In the equilibrium, fighting never resumes, and terms of settlement are peacefully revised, given that ceasefire is reached. First, when the loser prefers renegotiation to conflict resumption, he can always strike a bargain because, under complete information, he knows the exact amount he must offer the gainer. Second, he will never terminate the initial conflict if he anticipates that he will resume fighting in the post-conflict phase because he is better off in prolonged conflict than in resumed fighting. Under complete information, he can perfectly predict what will happen in the post-conflict phase. Thus, the loser terminates the initial fighting only if post-conflict peace is maintained.

Remark 2 When the gainer's post-conflict power growth is moderately small, players fail to settle the initial conflict not because the loser fears unstable post-conflict situation but because he is afraid of successfully achieving expensive post-conflict peace. 
Failure to renegotiate is not the main cause of unsuccessful settlement in this scenario. In the model, renegotiation is always attainable if he seeks it because the loser is assumed to have sufficient resources and information to successfully strike a renegotiation. However, as mentioned above, the threshold of choosing settlement in the initial stage is more demanding than that of choosing renegotiation in the post-conflict phase. Therefore, there is a case where the loser does not settle the initial conflict even though post-conflict peace is maintained through renegotiation. More precisely, adversaries do not cease the initial fighting if it is too costly for the loser to appease the gainer whose power growth is considerably high. In this case, the loser may be better off continuing fighting rather than undergoing expensive renegotiation. Hence, termination of conflict is difficult to achieve not because players fear an unstable future but because the loser is often afraid of achieving undesirable peace.

Remark 3 The terms of settlement do not directly cause conflict to resume.

Some scholars such as Fortna (2004) and Werner and Yuen (2005) argue that terms of settlement are consequential in maintaining settlement. In contrast, this model implies that terms of settlement as well as the temporary outcome of conflict are largely inconsequential in understanding post-conflict peace because players can renegotiate them later. In the model, for instance, the initial conflict renders a resource allocation $(\alpha, 1-\alpha)$. Once conflict is terminated and renegotiation is achieved, peace is maintained under a new resource allocation $(\alpha f(\theta), 1-\alpha f(\theta))$. The temporary outcome of conflict is decisively important when we assume that conflict perpetually fixes the post-conflict balance of power between countries. Yet, when we take into account the post-conflict renegotiation, the terms of settlement are not completely tenacious.

Although conflict never resumes in this basic model with complete information, conflict often resumes in reality. To explain this intriguing phenomenon, the next section introduces a stochastic component in the gainer's post-conflict power growth and analyzes under what conditions such uncertainty makes conflict more likely to resume.

\section{$2.2 \quad$ A Full Model}

Post-conflict power growth often entails uncertainty. In the Chaco War discussed earlier, both Bolivia and Paraguay were unable to predict how much power, i.e., oil, they could extract from the newly obtained areas of Gran Chaco. The key problem associated with such an uncertain situation 
is that even the gainer herself is unsure about how much growth the new resources will bring, ex ante of conflict termination. The information is revealed only after she actually possesses the resources and starts utilizing them.

Thus, this type of uncertainty contrasts with well-known private information, which one party monopolizes and often cannot credibly share with others. Although private information and signaling have been the main focus of war theory, they may not play central roles in explaining post-conflict peace because informational problems are considered to more or less disappear through "unmanipulable" fighting, i.e., the nature of conflict necessitates the transmission of true information. Rather, I focus on a novel type of uncertainty emerging from conflict. Because neither party possesses precise information regarding post-conflict growth, the uncertainty is not moderated through signaling.

Although such uncertainty always exists and cannot be resolved through the parties' actions, its effect varies across cases, depending on the external environment. Therefore, the following model analyzes factors that mitigate or reinforce the detrimental effects of such uncertainty on ceasefire and post-conflict peace.

The model incorporates uncertainty by introducing a stochastic component $\epsilon$ to the gainer's capability $\theta$. I assume that $\epsilon$ is uniformly distributed over $\left[-\frac{1}{2 e}, \frac{1}{2 e}\right]$, where $e>0$, which is common knowledge. That is, players' ex ante calculations about post-conflict power involve an error term and they only know what the value is likely to be, which could be wrong ex post. In sum, the gainer's post-conflict power after a certain period of time increases in the resource endowment from the initial conflict $\alpha$, her capability $\theta$, and the stochastic component $\epsilon$.

Both players observe the actual value of $\epsilon$ only after a ceasefire is achieved and they proceed to the post-conflict phase. Once the loser observes the gainer's power growth with the revelation of the value $\epsilon$, he chooses whether to restart fighting or initiate renegotiation, as he did in the basic model in the previous section. This time, the players' payoffs differ from those in the basic model. Namely, in the renewed conflict, the gainer and the loser gain $\alpha(\theta+\epsilon)$ and $-\alpha(\theta+\epsilon)$, respectively. If $\epsilon$ is positive, both players underestimated the gainer's power growth at the moment of settlement. If it is negative, they overestimated the gainer's growth and her actual growth turns out to be less than expected.

It should be noted that the full model involves both a short-term and a long-term growth of the gainer's power. In the first move of the post-conflict stage, the gainer experiences initial growth $(\theta)$, which involves uncertainty $(\epsilon)$. The gainer's growth during renegotiation is denoted by $f(\theta)$ and does not involve uncertainty. This can be interpreted such that the initial growth of the gainer is 


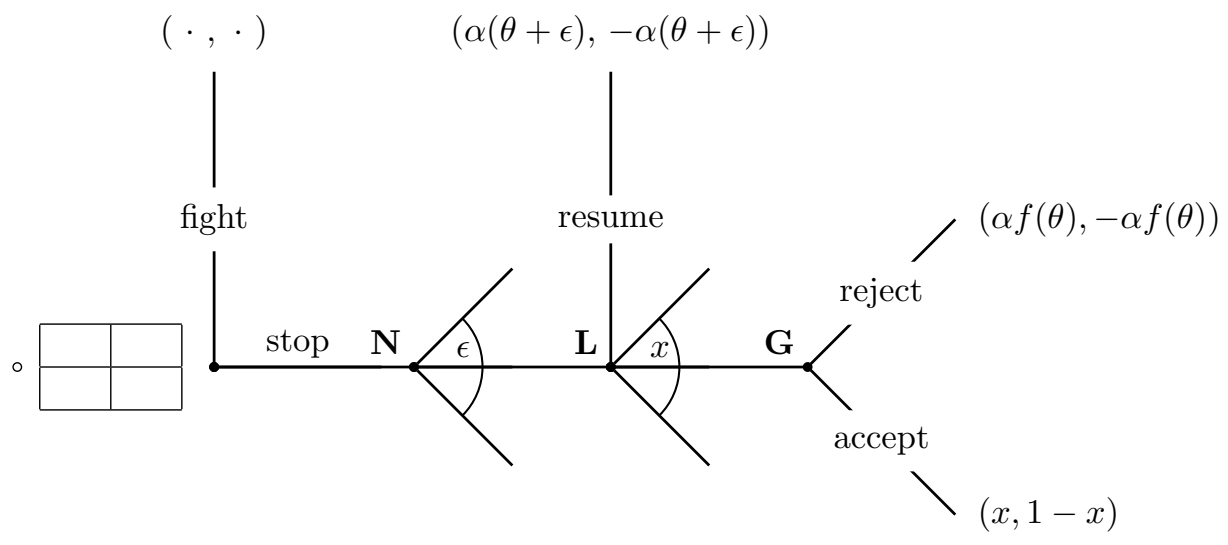

Figure 2.4: A Full Model: The Sequence of Moves

temporal, whereas $f(\theta)$ denotes her long-term growth of power. The initial growth may be affected by accidental events such as disrupted transportation. However, the error by accident $(\epsilon)$ is sooner or later canceled out and her growth converges to the true value $f(\theta)$. To put it differently, players may wait until her growth returns to the true value. Therefore, the component $\epsilon$ is irrelevant in the long-run.

In addition to these properties, I introduce a variation in power growth caused by the natural characteristics of resources, which is expressed by the functional form of $f(\theta)$. Not all resources can be converted into military power in the same way. Some resources are such that any groups or countries can easily exploit their benefits. Such resources include strategic territories of which anyone is able to take advantage by simply occupying them as well as so-called "lootable" resources, including diamonds, timber and some drugs such as coca. In contrast, only capable owners can reap the fruits of other sorts of resources. For instance, owners must be capable of investing money and labor in political and economic institutions to industrialize newly gained territories. Even if an occupied region is economically developed, the owners must make investments to sustain productivity. Among natural resources, bauxite and oil are particularly less lootable because they require investment and technology for exploitation.

To capture this variation, I assume that the gainer's power growth $f(\theta)$ has either increasing or decreasing marginal returns in her capability. Resources with decreasing marginal returns are similar to the concept of "lootable resources" in the sense that any group or country can easily convert them into military power. However, the benefit of one unit increase in the gainer's capability diminishes as the capability increases, that is, even a very capable gainer is unable to procure a significantly 
larger benefit from resources such as strategic territories and timber. In other words, her capability is not fully rewarded when she possesses such resources. This group of resources is denoted by $\hat{f}(\theta)$ where $\frac{\partial^{2} \hat{f}}{\partial \theta^{2}}<0$ and $\lim _{\theta \rightarrow \infty} \hat{f}^{\prime}(\theta)=0$. In contrast to this group of resources, a capable gainer, such as the U.S., is able to generate more and more profits from resources with increasing marginal returns in capability, such as a potential colony. This type of resources is denoted by $\check{f}(\theta)$ where $\frac{\partial^{2} \breve{f}}{\partial \theta^{2}}>0$. The rest of the game is identical to the basic model.

\subsubsection{Outcomes and General Mechanisms}

I first define an equilibrium of the game and describe the mechanisms of ceasefire, renegotiation and conflict resumption under uncertainty. The comparison of the full-model and the basic model allows me to highlight the role of uncertainty. Remember that in the basic model, conflict never resumes if terminated. Keeping the result of the basic model in mind, I proceed to the solution of the full model. I first present the equilibrium of the full model. As in the previous section, $\sigma^{G}$ denotes a set of pure-strategies of the gainer, and $\sigma^{L}$ denotes those of the loser.

Definition $\underline{f}(\theta) \equiv \theta+\frac{1}{\alpha}-\frac{1}{2 e}, \bar{f}(\theta) \equiv \theta+\frac{1}{\alpha}+\frac{1}{2 e}, f^{*}(\theta) \equiv \theta+\frac{1}{\alpha}+\frac{1-\sqrt{16 e(\theta-1)+1}}{4 e}$, and $\Lambda \equiv f(\theta)-\theta-\frac{1}{\alpha}$

Lemma 2 The following pair of strategies constitutes the pure-strategy SPE:

1. When $\theta>1+\frac{1}{2 e}, \sigma^{G}=\{$ settle, accept $\}$ and

$$
\sigma^{L}= \begin{cases}\{\text { settle, } \alpha f(\theta)\} & \text { if } f(\theta)<1+\frac{1}{\alpha} \\ \{f i g h t, \alpha f(\theta)\} & \text { if } 1+\frac{1}{\alpha} \leq f(\theta)<\underline{f}(\theta), \text { or } \underline{f}(\theta) \leq f \theta<\bar{f}(\theta) \text { and } \epsilon>\Lambda \\ \{\text { fight, resume }\} & \text { otherwise. }\end{cases}
$$

2. When $\theta \leq 1+\frac{1}{2 e}, \sigma^{G}=\{$ settle, accept $\}$ and

$$
\sigma^{L}= \begin{cases}\{\text { settle, } \alpha f(\theta)\} & \text { if } f(\theta)<\underline{f}(\theta), \text { or } \underline{f}(\theta) \leq f(\theta) \leq f^{*}(\theta) \text { and } \epsilon>\Lambda \\ \{\text { fight, } \alpha f(\theta)\} & \text { if } f^{*}(\theta)<f(\theta)<\bar{f}(\theta) \text { and } \epsilon>\Lambda \\ \{\text { settle, resume }\} & \text { if } \underline{f}(\theta) \leq f(\theta) \leq f^{*}(\theta) \text { and } \epsilon \leq \Lambda \\ \{\text { fight, resume }\} & \text { otherwise. }\end{cases}
$$

Proof See the appendix. 
The equilibrium of the full-model involves four paths: (1) ceasefire is achieved, and the agreement is successfully renegotiated; (2) they continue to fight to avoid costly renegotiation of ceasefire; (3) ceasefire is achieved, but fighting resumes later; (4) they continue to fight because they anticipate that fighting will resume. Which path is realized depends on a set of parametric values. Before discussing the impact of parameters, I present three implications derived from the comparison between the basic and the full models.

Remark 4 Conflict resumes only if the gainer's expected capability is sufficiently small or involves large uncertainty.

The first part of Lemma 2 describes a situation in which the gainer's capability $\theta$ is anticipated to be high or in which there is little uncertainty. When these conditions hold, the players' strategies are quite similar to those in the basic model. Ceasefire is achieved only if the gainer's power growth $(f(\theta))$ is quite small, such that post-conflict peace is maintained through renegotiation for certain and a revised deal is not too expensive. Otherwise, the loser never terminates the initial conflict either because he does not want to wage another conflict with the strong gainer or because the renegotiation with such a gainer costs too much. Therefore, as in the basic model, conflict never resumes in this case. Thus, the gainer's capabilities must be sufficiently small or involve large uncertainty in order for adversaries to resume fighting.

Remark 5 Post-conflict peace breaks down because of the loser's opportunistic behavior, rather than his preventive incentive.

The second part of the equilibrium strategies describes a situation where the gainer's capability is expected to be sufficiently small or there exists large uncertainty. I graphically present the loser's strategies under these conditions in Figure 2.5. The bold line in the middle shows the value of the gainer's post-conflict power growth $f(\theta)$. The line at the bottom presents the loser's choice in the post-conflict phase. Let me start with analyzing the loser's behavior in the post-conflict stage, assuming that ceasefire is achieved. The figure shows that the loser always chooses to renegotiate if the gainer's post-conflict power growth is sufficiently small. If it is sufficiently large, however, he always resumes fighting because it is too costly to strike a bargain with such a strong gainer. If the value of $f(\theta)$ falls into the middle range, uncertainty and its resolution play a crucial role, i.e., the loser's choice between renegotiation and conflict resumption depends on the revealed value of $\epsilon$. He chooses renegotiation if $\epsilon$ turns out to be sufficiently large, that is, the gainer's ex post growth 


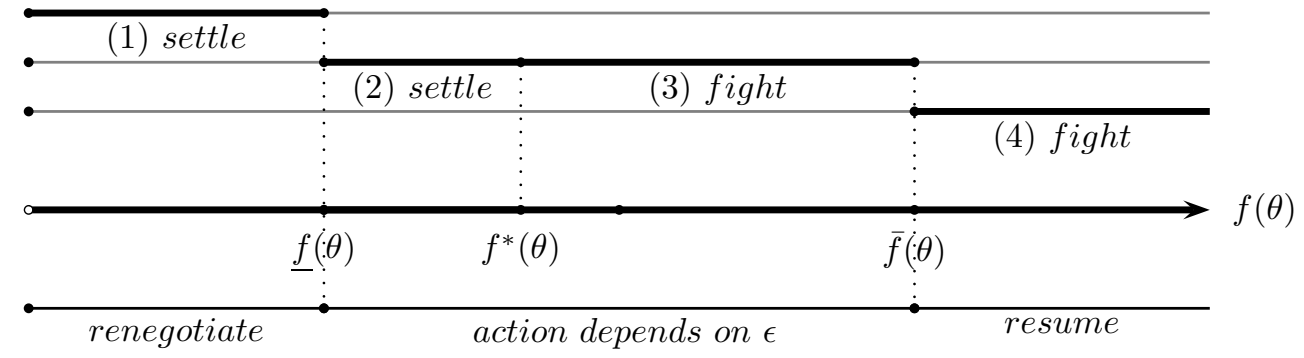

Figure 2.5: The Loser's Strategies in A Full Model

$\alpha(\theta+\epsilon)$ is sufficiently larger than the ex ante expectation. Conversely, if her initial growth turns out to be less than expected, the loser resumes fighting rather than renegotiates.

Although preventive war caused by shifting power has attracted much attention from scholars and policy makers, the model implies that peace breaks down when one-side of the adversaries fails to grow as expected. When the loser returns to fighting, he is not motivated by fear of the gainer's growth. If his opponent's initial power growth is larger than anticipated, he proceeds to renegotiation so that he can retain the gain expected at the moment of the ceasefire. As is clarified in the basic model, the gainer's post-conflict growth per se does not give an incentive for the loser to wage another conflict. ${ }^{5}$ He resumes fighting when he realizes that his opponent is less threatening than expected at the moment of the ceasefire. He learns that he made too much of a concession in the ceasefire and wants to seize some resources before his opponent fully utilizes the acquired resources.

One may wonder whether the gainer can appease the loser's opportunistic behavior by giving up some of the gained resources. The model shows that appeasement is unable to prevent the loser from taking opportunistic behavior. Recall that the model allows the loser to make an offer and that he asks the gainer to give up some resources. Although it is equivalent to appeasement, the model demonstrates that there still exists cases where the loser resumes conflict. This is because he knows that his position is deteriorating while the new deal is arranged and seeks to improve his gain at once. In other words, the gainer is unable to credibly commit to appeasement even if she is sincerely willing to give up some resources.

I next proceed to the analysis of the ceasefire phase. In Figure 2.5, the three disjointed bold lines on the top show the loser's choice in the initial conflict when the gainer's capability is sufficiently small or there is large uncertainty, i.e., $\theta \leq 1+\frac{1}{2 e}$. As in the basic model, only the loser's decision is

\footnotetext{
${ }^{5}$ Recent theoretical works also claim that growth of power does not result in preventive war (ex. Powell, 2012)
} 
binding to achieve ceasefire. First, players agree to ceasefire if post-conflict renegotiation is achieved for sure. Second, they never terminate the initial conflict if post-conflict peace certainly breaks down. When they are unsure about what will happen in the post-conflict phase, they may or may not stop fighting, depending on the value of parameters. Generally stated, the loser decides to settle when the gainer's post-conflict power growth $f(\theta)$ is sufficiently small so that he is presumably unlikely to be in a very bad situation regardless of the consequence of settlement. Hence, he takes the risk of potentially unstable ceasefire, knowing that the consequence of settlement may or may not be better than expected, which is determined by an external shock $\epsilon$.

Remark 6 There are a set of parametric values where uncertainty regarding the gainer's capability allows players to settle under a situation under which they are unable to agree to end conflict with complete information.

Proof See the appendix.

The model proves that there are a set of parametric values where players agree to a ceasefire in the full model even under conditions where they do not in the setting of the basic model. Precisely, this occurs when the capability of the gainer $\theta$ is very small and uncertainty involved is very small, i.e. $e$ is very large. Under this condition, the loser takes the risk of entering a potentially unstable ceasefire due to his opportunistic wish that drives peace that would not have been attainable without uncertainty. ${ }^{6}$

This finding is novel because it proves that uncertainty contributes to lasting peace under certain conditions, although most existing studies stress its negative effect. Thus, in this model, uncertainty has both negative and positive effects: it causes adversaries to resume fighting, but there exists a case where it also has them achieve a stable ceasefire under a situation where they never do without uncertainty.

\subsubsection{Analysis: Resumption of Fighting}

In this section, I highlight the determinants of post-conflict stability, given that ceasefire is achieved. Precisely, I analyze what parameters affect the likelihood of conflict resumption and how.

Proposition 1 The likelihood that fighting resumes is weakly increasing in $\alpha$.

Proof See the appendix.

\footnotetext{
${ }^{6}$ His opportunistic behavior could be deterred to some extent if the gainer has no dominant strategy.
} 
Fighting is more likely to resume if the gainer acquires more resources in the initial conflict. The logic behind the lemma is straightforward: the loser must give up more and more resources to appease the gainer who possesses a large amount of resources from which she can extract military power. Then, the loser bears a greater incentive for waging another conflict to avoid the costs of maintaining peace through renegotiation.

This proposition suggests that ceasefire following conflict ending with one side's decisive victory, if achieved, is more likely to break down. Although conventional wisdom maintains that an overwhelming victory of one side leads to stable settlement, this may not be the case if post-conflict power growth is taken into account. The model shows that a decisive victory may result in an unstable ceasefire because it gives rise to the loser's opportunistic behavior. An illustrative case is the Six-Day War in 1967, the successive so-called War of Attrition and the October War in 1973. In the Six-Day War, Israel acquired a great amount of new resources, including the Sinai Peninsula and the Gaza Strip from Egypt, the Golan Height from Syria, and the West Bank from Jordan. However, this decisive victory did not nurture peace between Israel and the Arab nations. Shortly after the settlement, a series of small military confrontations emerged around the newly established de facto border. Eventually the Arabs were driven into another war in 1973. The model implies that the Arabs had an incentive to resume war before Israel could fully utilizes the gains from the previous war.

Proposition 2 The likelihood that fighting resumes is weakly increasing in $\theta$.

Proof See the appendix.

Fighting is more likely to resume if the gainer is more capable. It may sound counter-intuitive that the loser is more likely to restart fighting with a more capable gainer, considering that he would suffer from more destruction in warfare with such a gainer. In deriving the lemma, her capability plays a role through two paths. On the one hand, it makes resumed warfare more destructive for the loser. On the other hand, it makes maintaining peace more expensive because the loser must concede more to satisfy a more capable gainer in renegotiation. Hence, the loser faces a trade-off between costly fighting and expensive peace. Because the marginal cost of maintaining peace is larger than that of restarting fighting, the loser is more likely to restart fighting to avoid expensive renegotiation. Remember that in resuming fighting on the equilibrium path, the loser decides to do so for an opportunistic purpose. Thus, if the gainer becomes more capable, he bears a stronger opportunistic incentive and avoids engaging negotiation with an even-stronger gainer. 
This may explain why "weak" states restart fighting against "strong" states. As Sechser (2010) explores, it is quite puzzling that strong states often fail to coerce considerably weak states. It may not be a mere coincidence that the Winter War in 1938 between the USSR and Finland, which Sechser (2010) provides as an illustrative case, is also an example of war that has been resumed by a loser. The Winter War resulted in a decisive victory by the Soviet Union who acquired control over Karelia, Salla, the Kalastajansaarento Peninsula, islands in the Gulf of Finland, and Hanko Island. Those ceded territories exceeded $10 \%$ of the pre-war Finnish territory and included its industrial center and important ports. Moreover, the GDP of the Soviet Union was almost four times as large as that of Finland in the year of war termination. That is, a very capable gainer acquired a large amount of new resources. This did not deprive Finland of mettle for fighting, however. Following the German invasion of the USSR in 1941, Finland fought back and started the so-called Continuation War. Of course, Finland aimed to win back Karelia, its pre-war industrial center, as a primary goal. This story corresponds with the mechanism the model illustrates. After the defeat in the Winter War, Finland was not discouraged from fighting another war with the USSR. On the contrary, Finland resumed fighting all the more because it anticipated that the Soviet Union would grow too strong to face in the future and because it found an opportunity to gain a resource back from the Soviet Union following the German invasion. Simply stated, "strong" gainers are less capable of committing to post-conflict peace, which gives the loser an incentive to diverge from settlement.

Finally, I examine the impact of the nature of post-conflict resource consumption on the likelihood that fighting resumes. Recall that the nature of resources is represented by the functional form of $f(\theta)$ : $\hat{f}(\theta)$ with diminishing marginal returns signifies resources that any gainer can easily exploit, such as diamonds or strategic territories; $\check{f}(\theta)$ with increasing marginal returns is regarded as resources that require high capability $\theta$ for full usage, such as colonies or new military technology. Similarly, ^ ${ }^{\wedge}$ and ${ }^{`}$ on other parameters denote the same relationship.

Definition Define $\theta^{*}$ such that $\hat{f}\left(\theta^{*}\right)=\check{f}\left(\theta^{*}\right)$.

Proposition $3 \check{p} \leq \hat{p}$ if $\theta \leq \theta^{*}$, and $\hat{p}<\check{p}$ if $\theta^{*}<\theta$.

From the set of assumptions on $\hat{f}(\theta)$ and $\check{f} \theta$, it is directly derived that there exists unique $\theta^{*} \in(1, \infty)$ such that $\hat{f}\left(\theta^{*}\right)=\check{f}\left(\theta^{*}\right)$ and that $\check{f}(\theta) \leq \hat{f}(\theta)$ if $\theta \leq \theta^{*}$.

Given that the gainer is sufficiently capable of exploiting resources, a ceasefire, if achieved, is no less likely to break down when resource exploitation has an increasing marginal return. This is because such a gainer grows more powerful and will be too expensive to appease in the future. If 
so, the loser does not miss an opportunity to restart fighting when it turns out that the gainer's initial growth is not enough to deter him from doing so. In contrast, provided that the gainer is not very capable of utilizing resources, ceasefire is more likely to break down if resource consumption has diminishing marginal returns because even an incapable gainer can utilize such resources.

Suppose there are two types of resources: strategic territories and colonies. Suppose also that there are two types of gainers: high and low. The high-type gainer is able to invest more resources in newly gained territories than the low-type is. This could be because the low-type just lacks the capital to invest or the technology to exploit resources. The model predicts that ceasefire is more likely to fail if the high-type gainer possesses colonies as opposed to strategic territories. In contrast, if the low-type obtains new resources, strategic territories are more detrimental to peace than colonies. The low-type gainer obtaining potential colonies is not very threatening because she is unable to fully develop the colonies and her opponent knows it. Remember that Proposition 2 indicates that the high-type is more threatening than the low-type in general.

Thus, the likelihood that conflict resumes is affected by the nature of resources conditional on the characteristics of the gainer. The literature on the "resource curse" has stressed the detrimental effects of "lootable" resources in civil war. Along with it, this model introduces heterogeneous types of gainers and demonstrates that it is important to investigate "who gets what."

\subsubsection{Analysis: Achievement of Ceasefire}

This section specifies conditions under which the initial conflict is terminated in the shadow of an (un)stable post-conflict situation. Each player chooses to terminate the initial conflict if their expected utility from a ceasefire exceeds the payoff from prolonged fighting. Because settle is the gainer's dominant strategy, I will focus on the loser's choice in the following analysis. Important conditions for the loser to choose settlement are derived from Lemma 2 as follows. See the Appendix for the details.

\section{Remark 7}

$$
s_{1}^{L}=\text { settle, if } \begin{cases}f(\theta)-\theta-\frac{1}{\alpha}<0 & \text { and } \theta>1+\frac{1}{2 e} \\ f(\theta)-f^{*}(\theta) \leq 0 & \text { and } \theta \leq 1+\frac{1}{2 e} .\end{cases}
$$


The remark defines the range of parametric values in which ceasefire is achievable. To investigate the impacts of parameters on the likelihood of armistice, we need take only the partial derivative on the left-hand side of the inequalities.

Proposition 4 The likelihood of ceasefire is weakly decreasing in $\alpha$.

This suggests that ceasefire becomes less likely when the gainer seizes more resources during conflict. According to Proposition 1, large resource transfer during conflict causes an unstable postconflict relationship. Knowing this, players are less likely to terminate the initial conflict in the first place. This proposition is quite counter-intuitive, indicating that decisive victory may prevent adversaries from agreeing to a ceasefire. This is because such a massive victory in any case leads to an unstable post-conflict situation and makes post-conflict peace, if maintained, quite expensive, which discourages the loser from agreeing to armistice in the first place.

Proposition 5 The likelihood of ceasefire is weakly decreasing in $\theta$.

The same logic of self-selection into a ceasefire can be observed with respect to varying levels of $\theta$. The following proposition demonstrates that a ceasefire is less likely to occur if the gainer is more capable of exploiting resources during the ceasefire. Just like in the case of $\alpha$, this is because a ceasefire is more likely to break down as $\theta$, increases and the players know that.

Propositions 4 and 5 provide empirically testable hypotheses regarding why some conflicts last longer than others. Prolonged conflict has been a theoretical puzzle for scholars because informational theory, such as in Fearon (1995), predicts that conflict ends shortly because a small battle is enough to convey credible information. Recent theoretical studies about persistent violence mainly claim that commitment problems prevent adversaries from agreeing to ceasefire (Leventoğlu and Slantchev, 2007; Powell, 2012). In line with this literature, the propositions clarify factors that cause such commitment problems, and the implications are empirically testable.

Proposition 4 implies that decisive victory by one side may cause a long conflict. In fact, there are historical cases where conflict was prolonged even after one side definitely prevailed. For example, Japan never agreed to terminate World War II until two atomic bombs were dropped on Hiroshima and Nagasaki, although it was apparent that Japan was losing the war and the Allies had offered war termination. Germany made the same decision. Eventually, both countries did not surrender until they were completely defeated and disarmed. Although their decisions seem irrational at a first glance, Proposition 4 suggests that they were consequences of rational decision-making because 
peace with the Allies would have been unacceptably expensive for the leaders of Japan and Germany. Thus, they kept fighting not because they hoped to win some resources back, but because the shadow of undesirable post-war peace made them desperate. As the war become prolonged, Allied forces acquired more and more territories and resources from Japan and Germany, which unfortunately discouraged them from agreeing to war termination.

Proposition 5 explains why "strong" powers often fail to defeat small powers quickly. Strong powers such as the U.S. are more likely to seize a great amount of resources and are more capable of investing resources for future use. Because such gainers are less capable of committing to postconflict peace, as is shown above, small parties tend to keep fighting back even if they know they will eventually lose. Otherwise, they are to face even stronger gainers in the aftermath of conflict. This may also explain why democracies, especially the United States, tend to fight long absolute wars, as was seen in World War II, the Afghanistan War and the Second Iraq War. Some claim that the American ideal or so-called "creed" motivates the US to demand unconditional surrender or absolute victory involving regime change (ex. Hunt, 1987). Others, such as Bueno de Mesquita et al. (2003), highlight institutional features of democracies that encourage them to make greater efforts in war. The proposition here provides another causal mechanism: democracies such as the US tend to fight a long war because they are less capable of committing to post-conflict peace.

Now, I examine the impact of "who gets what" on the likelihood of a ceasefire denoted by $q$.

Proposition $6 \hat{q} \leq \check{q}$ if $\theta \leq \theta^{*}$, and $\check{q}<\hat{q}$ if $\theta^{*}<\theta$.

The proposition suggests that ceasefire is more likely to be achieved when resources with an increasing marginal return are at stake, given that the gainer is not much capable of utilizing them and that armistice is more likely to occur when resources with diminishing marginal returns are at stake, given that the gainer is highly capable of exploiting them. Using the example of colonies and strategic territories, fighting is no less likely to terminate when a low-type gainer possesses potential colonies as opposed to strategic territories. A ceasefire is more likely to be achieved when a high-type gainer acquires strategic territories rather than colonies. The logic directly follows from Proposition 3, demonstrating that post-conflict peace is more stable in the cases above. Thus, the loser is discouraged from agreeing to a ceasefire if he anticipates that he is likely to restart fighting later.

A contrast between World War I and World War II well illustrates this logic. In the early 20th century, great powers were expected to and did invest great amounts of resources in new military 
technologies, including tanks, aircraft, and submarines. They also committed to training soldiers recruited from ordinary citizens to fight the total war, which eventually enabled offensive maneuvers such as the "blitzkrieg" (Biddle, 2004; Van Evera, 1998). Therefore, it can be said that resource exploitation after WWI gave increasing marginal returns. The fear of increasing post-conflict power growth prevented great powers from reaching ceasefire, which explains why WWI lasted more than four years, while people at that time had expected it would end shortly.

At the termination of WWII, European countries installed a scheme to mitigate the devastating effects of post-conflict resource exploitation. Notably, France, West Germany, Italy, and the Benelux countries signed the Treaty of Paris in 1951 which established the European Coal and Steel Community (ECSC). French foreign minister Robert Schuman declared that in order for "the elimination of the age-old opposition of France and Germany, [...] Franco-German production of coal and steel [be placed] under a common 'high authority'." He continued that "[t]he solidarity in [coal and steel] production thus established will make it plain that any war between France and Germany becomes not merely unthinkable, but materially impossible" (Schuman, 1950). ${ }^{7}$ This proposal was important in the sense that the gainer proposed the scheme, which restricted her capability of using natural resources that could be acquired from Germany. As the model predicts, the gainers in WWII realized that they had to moderate the impact of the exploitation of natural resources, especially in the resource-rich Ruhr.

The model also suggests why the participating countries successfully maintained the framework of the ECSC. The institution of the ECSC per se is not a direct cause of peace, considering that any agreement must be self-enforcing under the international anarchy. Rather, the low capabilities of the participants in the aftermath of WWII enabled the ECSC to survive. In the 1950s, the participants in the ECSC were not fully capable of investing in coal and steel production due to the disastrous war. In fact, the High Authority of the ECSC in 1954 had to ask for a loan from the United States because "this need will be urgent in the early years of the common market in connection with the modernization and development of the natural resources of the Community" and "the High Authority deems it necessary at this time to obtain credits outside the Community to assist in making investments for the modernization and development of the natural resources of the Community" (Swatland, 1954). The model predicts that ceasefire is likely to be maintained in such a case.

\footnotetext{
${ }^{7}$ I am thankful to Dr. Phill Wilkin for his support for my archival research at the Archive of European Integration (AEI), University of Pittsburgh.
} 


\subsection{Summaries and Implications}

To analyze why adversaries dishonor ceasefires, this chapter provided a game-theoretic model which has several key components. First, players are allowed to determine whether to terminate conflict, resume fighting, and renegotiate the terms of ceasefire. In other words, termination and resumption of conflict are treated as a continuous process.

Second, those decisions are made in the shadow of post-conflict resource usage by the gainer. Once they reach a settlement of the initial conflict, the gainer starts utilizing the newly obtained resources and both of the adversaries know it at the moment of the settlement.

Third, a stochastic component is involved in the post-conflict phase. This is because, ex ante, even the gainer is unable to precisely predict how much power can be extracted from the new resources. That is, the players are unable to solve such uncertainty through communication. The theory shows that adversaries' choices in the post-conflict phase largely depend on such an external shock.

Finally, heterogeneous types of resources and adversaries are introduced. Some gainers can effectively utilize newly gained resources using their economic and technological prowess. Similarly, some resources are easily exploited by anyone, whereas others require large efforts and investments to consume. The combination of resources and adversaries played a key role in achieving and maintaining a stable ceasefire.

With these settings, I investigated a mechanism through which a ceasefire is achieved, renegotiated and maintained in the shadow of uncertain post-conflict resource exploitation. To begin with, the basic model, which involves no uncertainty, demonstrates that fighting never resumes if terminated. Once uncertainty comes into play in the full model, players agree to a ceasefire and then resume fighting under certain conditions.

Precisely, post-conflict peace may break down because of the loser's opportunistic behavior. When the ex post growth of the gainer is less than the ex ante expectation, the loser seeks to resume conflict to gain some resources back before the gainer further grows. Thus, uncertainty enables fighting to resume because it renders an opportunistic incentive of the loser.

Moreover, the models present conditions under which players agree to settle the initial conflict. In general, they never agree to a ceasefire if they anticipate that it will certainly break down in the future. However, there are cases where they do not agree to a ceasefire even if post-conflict peace is maintained. This is because the loser does not choose a ceasefire when it is too costly to appease 
the growing gainer in the future. In other words, adversaries prolong conflict not only because the loser fears resumption of conflict, but also because he is afraid of achieving undesirable peace.

A comparison of the basic and full models shows that, under certain conditions, uncertainty enables belligerents to achieve settlement in situations where they would not otherwise. Because uncertainty gives an opportunistic motivation to the loser, it also incentivizes him to take more risks of terminating fighting, hoping that the gainer's post-conflict growth will turn out to be low.

Thus, uncertainty has both negative and positive impacts on peace. On the one hand, it enables conflict to resume. Because adversaries never choose to resume fighting under complete information, uncertainty is a necessary condition for fighting to restart. On the other hand, uncertainty allows adversaries to achieve armistice even under the situation in which it is otherwise unattainable. This is a remarkable result because it demonstrates that uncertainty combined with shifts in power, i.e., with a commitment problem, may contribute to peace, while existing studies emphasize the negative impacts of uncertainty.

The prospect of post-conflict peace as well as achievement of a ceasefire significantly depends on factors such as resource allocation in the initial conflict, the gainer's capability, and the nature of the resources. If the gainer acquires more of the good in the initial conflict, a ceasefire becomes less likely and fighting becomes more likely to resume. Likewise, if the gainer becomes more capable in exploiting newly obtained resources, a ceasefire becomes less likely and fighting becomes more likely to resume. If the gainer is sufficiently capable, a ceasefire becomes less likely and fighting becomes more likely to resume when she obtains resources with increasing marginal returns, such as potential colonies as opposed to resources such as strategically important territories or diamonds. If the gainer is insufficiently capable, the relationship reverses, that is, strategically important territories or diamonds are more detrimental to peace than potential colonies.

How can we apply the theory to the real world? I first clarify the scope of the theory. First, players in the model can be countries or sub-national groups. Therefore, the model can be applied to both international conflict and civil war, although this study primarily focuses on international conflict. Second, although I often referred to territorial change as an example, resources are not limited to territories and natural resources. Resources can be anything that potentially increases the military power of the new owner. In this sense, some policy concessions in addition to the acquisition of territories and natural resources fit the model. Finally, the theory may not fit cases such as purely humanitarian intervention, where parties are unlikely to gain valuable resources though conflict. 
With the implications and limitations in mind, I provide empirically testable hypotheses derived from the model. Note that in the hypotheses I interpret the gainer's capability as her economic wealth and political institutions, assuming that a wealthy democracy has more capital, technology and willingness to convert acquired resources into military power.

- Given that a ceasefire is achieved, fighting is more likely to resume if:

1. the initial conflict ends with one side's decisive victory but short of absolute war.

2. the gainer is a wealthy democracy.

3. a wealthy democracy obtains resources such as potential colonies, oil and bauxite as opposed to "lootable" resources such as diamonds, timber and drugs such as coca.

4. a poor autocracy obtains "lootable" resources or strategically important territories as opposed to resources such as potential colonies.

- Adversaries are less likely to settle fighting if:

1. one side acquires more, but not all, goods at stake during conflict.

2. a wealthy democracy obtains exploitable resources.

3. a wealthy democracy obtains resources such as potential colonies, oil and bauxite as opposed to "lootable" resources such as diamonds, timber and drugs such as coca.

4. a poor autocracy obtains "lootable" resources or strategically important territories as opposed to resources such as potential colonies.

- Terms of settlement are irrelevant in predicting the consequence of ceasefires.

Some of the implications are tested in the following chapters. 
Chapter 3

\section{Explain the Duration of Ceasefires}

This chapter examines the empirical validity of the theory presented in the previous chapter through statistical tests using data on ceasefires between 1946 and 1997 and territorial change that occurred during this period. The game-theoretic model in Chapter 2 ensures that the theory is coherent in its logic. This, however, does not spontaneously ensure that the implications of the theory are consistent with actual observations. To show the general validity of the theory, I examine whether the theory explains what happened after wars that were terminated between 1946 and 1997.

The theory in Chapter 2 demonstrated that uncertainty regarding the degree to which resources acquired during conflict empower the gainer determines the stability of post-conflict peace. Adversaries often seize territory or natural resources in conflict. Such new resources presumably increase the gainer's power, while the level of growth largely depends on "who gets what." Although adversaries expect post-conflict shifts in power, they are not always certain about how much power the gaining party will extract from the obtained resources. Even the new owner itself is unsure how it can utilize the resources until it actually starts utilizing them. Therefore, uncertainty causes instability of a ceasefire because the opponents possibly seek to renege on the initial agreement when the growth of the gaining party turns out to be less than expected at the moment of settlement and the relatively declining party seeks an opportunity to seize some resources back.

To investigate the explanatory power of this argument, I first analyze whether a ceasefire breaks down more quickly if resources are transferred between adversaries in the preceding conflict. Specifically, I examine whether acquisition of new territories through conflict shortens the duration of a ceasefire. Territory is presumably the most typical example of resources that are acquired through international conflict. Some territory includes strategically valuable locations, such as ports, and 
may enhance the gainer's ability to project power. Another is industrial centers that may increase the gainer's economic power. Thus, territorial change potentially causes significant shifts in the balance of power between adversaries. Assuming that uncertainty is inherent in such territorial change, I expect that the duration of a ceasefire following war with territorial change is shorter than that without territorial change.

Having said that uncertainty stemming from resource transfer causes a ceasefire to break down, the theory also demonstrated that the effect of uncertainty is reinforced or modified by such factors as the amount of transferred resources, the nature of the resources and the characteristics of the gaining side. This is because fighting is more likely to resume when the post-conflict growth of power is potentially large but temporarily stalled, because the declining party, ceteris paribus, has a greater incentive to act opportunistically in such cases.

This logic suggests three more hypotheses regarding the duration of a ceasefire. One hypothesis is that a ceasefire is shorter if a greater amount of resources is exchanged through conflict. In the analysis, I examine if the duration of a ceasefire decreases as the area of transferred territory becomes larger.

Another hypothesis is regarding the nature of resources, i.e., territory. Given that countries are sufficiently capable of exploiting resources, resources, such as colonies, generate a greater value of benefit to the new owner, whereas the benefit of resources, such as strategic location, does not increase even if the capable gainer acquires them. Therefore, I analyze what effect more populated territory, i.e., presumably colonies, has on the duration of a ceasefire.

The other hypothesis is that the durability of a ceasefire largely depends on "who gets what" through conflict. Specifically, the theory predicts that the duration of a ceasefire shortens if wealthy democracies acquire more populated territory, i.e., colonies, compared with cases where poor autocracies are on the gaining side. Wealthy democracies are considered more capable of exploiting benefits from colonies. Colonies are resources that require countries to have technology, capital, and innovative capacity to extract wealth and power from them. Economic wealth provides capital and technology to develop colonies. Democratic institutions incentivize political leaders to provide more public goods. Autocratic leaders, in contrast, tend to consume resources to buy off a small number of elites in a form of private rewards similar to feoffment. Because national security is a quintessential public good, wealthy democracies are committed to converting new resources into military capability, which motivates the losing party to resume fighting. 
Finally, the theory predicts that the terms of settlement are mostly inconsequential to postconflict peace because adversaries are able to renegotiate the initial agreement when revisionist wishes arise. The terms of settlement result from countries' strategic choices, and not vice versa. Therefore, this chapter reassesses the claim of Fortna (2004), which argues that strong agreements contribute to stable post-war peace.

I examine these five hypotheses in the analytic and empirical contexts of the two seminal studies by Fortna (2004) and Werner and Yuen (2005). The theory is evaluated against the data on ceasefires since World War II, which are compiled and made available by Fortna. ${ }^{1}$ To assess the effect of resource transfer, I combine Fortna's dataset with data on territorial change provided by the Correlates of War Project. A more detailed description of data is provided in the next section.

The following analysis confirms the explanatory power of the theory. It shows that territorial change during conflict has a significantly negative effect on the duration of a ceasefire. Territorial change has a disturbing effect even if territory is not the primary issue at stake. It also demonstrates that resource transfer leads to varying consequences, depending on the characteristics of exchanged territories and of the gainer. Furthermore, territorial change has a more devastating effect on postwar peace when wealthy democracies acquire larger and more populated territories.

\subsection{Dataset on Ceasefires}

Fortna's dataset consists of 48 ceasefires following 26 full-scale interstate wars ending between 1946 and $1997 .^{2}$ All cases are listed in the appendix. In the dataset, a ceasefire is defined as "an end to or break in the fighting, whether or not it represents the final end of the war" (p.45). Therefore, a ceasefire requires neither formal agreements nor minimum duration to be identified. For instance, Turkey and Cyprus agreed to a ceasefire at the end of July 1974 after Turkey conquered important strategic bases in northern Cyprus. Two weeks later, the settlement broke down with another Turkish offense in which it acquired almost $40 \%$ of Cyprus. Although the ceasefire was obviously short-lived, it is counted as a ceasefire that separates the Turco-Cypriot War into two distinct cases.

Each case identifies a pair of countries involved in a conflict, separating multilateral wars into several cases of "principal belligerents." For example, four principal belligerents (the United States

\footnotetext{
${ }^{1}$ I greatly appreciate that Dr. Fortna makes her dataset available online. The data set can be downloaded from her website at http://www. columbia.edu/ vpf4/research.htm.

${ }^{2}$ The source of the original data is Correlates of War (COW) Inter-State War Data, 1816-1997 (v3.0) (Singer and Small, 1972; Small and Singer, 1982).
} 
and South Korea vs. China and North Korea) are singled out in the Korean War, which originally yields 28 dyads. Thus, the Korean War renders four ceasefire cases.

Cases that are generated from iterated conflicts between the same pair of countries or from the same multilateral war are treated as a group. For instance, Turkey and Cyprus engaged in repeated fighting. Therefore, ceasefires between them may not be independent of each other. A similar problem arises when multilateral wars yield more than one case, as did in the Korean War. In the empirical analysis, such interdependence between cases is addressed by treating those cases as a group, following the procedure of Fortna. All cases among Arabs and Israel, including UK-Egypt and France-Egypt in the Sinai War, are considered to belong to Arab-Israeli conflicts. Likewise, wars over Kashmir and the Bangladesh War are grouped as Indo-Pakistani conflicts. Technically stated, I calculate robust standard errors by clustering cases by conflict to control for the problem of spatial autocorrelation.

Each case yields a series of observations that represents each year or less after a ceasefire so that time-varying covariates are included in analysis. In total, 48 ceasefires generate 876 observations. For instance, the truce between Israel and Egypt after the Six Day War in 1967 renders three observations per year (June 10th, 1967 - January 1st, 1968; January 1st, 1968 - January 1st, 1969; and January 1st 1969 - March 6th, 1969) until the War of Attrition starts in March 1969.

This setting allows me to take into account change in variables over time. Among factors affecting the duration of a ceasefire, the number of battle deaths and territorial consequences of war do not vary over time once the value is realized during war. Other so-called time-varying covariates, such as military capability, do change over time. Thus, by breaking each case into annual observations, effects of such time-varying factors can be fully examined.

The duration of post-war peace, i.e., the dependent variable of the analysis, is "measured from the date of the ceasefire to the start of another COW war between the same two belligerents, if there was one" (Fortna, 2004, p.48). Among 48 ceasefires, war resumed in 22 cases, such as the First Kashmir War and the First Turco-Cypriot War. In the other 26 cases, such as the Football War between El Salvador and Honduras, peace lasts beyond the time horizon of the analysis.

Such 26 cases are treated as right censored in 1998. This does not necessarily mean that those 26 cases are inherently more durable than other 22 cases. It may be that war did not restart simply because those ceasefires did not have enough time to experience failure. For example, the SinoVietnamese War ended in 1987 faced only 11 times of risks of resumption, whereas the settlement of the Korean War had 45 chances to fail in the setup of this dataset. In fact, Indo-Pakistan and 
US-Iraq experienced other conflicts after 1999. A problem revolving around censored cases will be addressed later.

I did not extend the analytic time beyond 1997, although new wars occurred and some ceasefires broke down since then. According to Gleditsch (2004), five full-scale wars took place between 1998 and 2004, including the Badme Border War between Eritrea and Ethiopia, the War for Kosovo, the Kargil War, the Afghanistan War and the Invasion of Iraq. Two ceasefires broke down between 1998 and 2004: one between India and Pakistan and another between the United States and Iraq. These cases between 1998 and 2004 are not included in the following analysis because some independent variables coded by Fortna as well as Werner and Yuen are unavailable for the new cases. All new ceasefires and failure are listed in the appendix.

\subsection{Measurement of Violent Resource Transfer}

\subsubsection{Territorial Change}

Hypothesis 1 (Occurrence of Resource Transfer) Post-war peace is less durable if territorial change occurs during war. TERRITORIAL CHANGE has a positive effect on the hazard ratio.

The first part of the analysis investigates the effect of violent resource transfer on post-war peace, that is, how acquisition of new territories affects the duration of a ceasefire. Territory is presumably the most typical example of resources transferred through interstate war. Some territories may include strategically important sites, such as ports, and others may become the gainer's source of industrial production. New territories have the potential to alter dramatically the balance of power between adversaries. Therefore, the dynamics of war resumption revolve around newly obtained territory. Thus, the duration of a ceasefire following territorial change is predicted to be shorter than it would be without territorial transfer.

Each ceasefire is checked to determine whether its preceding war causes any territorial change. Then, a binary variable TERRITORIAL CHANGE is created and coded as 1 if any violent territorial change is associated with the ceasefire and 0 , otherwise. I identify violent territorial change using the territorial change dataset of the Correlates of War Project (COW) (Tir et al., 1998). The territorial change dataset lists all territorial changes involving at least one nation-state and covers the entire period of the ceasefire dataset. Violent territorial change is identified if the dyad in the ceasefire dataset experiences territorial transfer as a result of the corresponding war. 
Two caveats must be added. First, some territorial changes are recorded before or after the date of their corresponding ceasefires because the dataset uses "the date of a treaty as the date when the territorial change actually occurred." Moreover, "[i]f no treaty was involved in the change, then the date (a) when action to take the territorial ceased, (b) a plebiscite occurred, or (c) an act of annexation took place is used as the date of transfer" (Tir et al., 1998, p.91). Thus, the date of territorial change may not match the date of the ceasefire of the same conflict.

Second, territorial change is identified only if the territorial change dataset acknowledges it as a result of conflict. That is, a peaceful change in border as a part of a ceasefire agreement is not recognized as territorial change. Because the theory treats renegotiation of settlement as a consequence of the initial allocation of war spoils, only initial territorial transfer as a result of violent conflicts is relevant in this empirical testing.

Three cases need special attention. First, the war of Israeli independence is associated with its territorial acquisition from the United Kingdom. Because the United Kingdom had controlled the disputed territory before Israeli independence, the dataset does not code that Israel gained the land from Arab countries. Yet, it is considered that Israel acquired new territory and that Arab countries lost territories that could be potentially acquired through war.

The second case is the Turco-Cypriot Wars I and II. Although Turkey occupied northern Cyprus in the first war that terminated in July 1974 and then conquered more in the second war that started in August 1974, the territorial change dataset codes no record for the first war. This is presumably because the dataset treats the two wars as one conflict due to the very short duration of the interwar armistice. Referring to historical accounts, I record territorial changes for both wars (ex. Camp, 1980).

Finally, the war between Azerbaijan and Armenia over Nagorno-Karabakh is also coded as experiencing territorial change in 1992, although this territorial change is not recorded in the original territorial change dataset. Azerbaijan and Armenia declared independence when the Soviet Union collapsed and soon engaged in the conflict over Nagorno-Karabakh, which had been under Azerbaijan's control despite its mostly Armenian population. Armenia immediately took control over the urban area of the region. It is considered that the region is under de facto administration of Armenia to date, although Nagorno-Karabakh declared its internationally unrecognized independence (Young and Kent, 2004, p.631). Considering that Armenia gained control over territory that it had not previously controlled and that Azerbaijan lost its control, I consider that the first Azeri-Armenian War caused territorial change. 
For a closer examination of the causal logic of the theory, I take into account whether the issue at stake in each war was territory and show that territorial change affects the duration of peace because of uncertainty stemming from it, but not because of adversaries' willingness to fight for territory. If the analysis shows that territorial change has an effect on the duration of ceasefires, it does not necessarily mean that the logic of the theory is correct. The results can be interpreted in two ways: (1) territorial change causes a fragile ceasefire because of uncertainty inherent in it; (2) territorial change causes a fragile ceasefire because adversaries are strongly resolved to fight for such valuable resources. In fact, Goertz and Diehl (1992) argues that territorial disputes are more likely to escalate to war. Tir (2003, p.62) also argues that "leaders of countries involved in territorial changes are likely to use force to seek territorial revisions when they can expect notable domestic and/or international payoffs from such actions."

The theory, on the other hand, highlights the effect of uncertainty that is inherent in territorial change. To distinguish these two arguments, I add a variable that identifies dispute in which territory is the primary issue at stake. This allows us to explore the sole effect of territorial change, assuming that territory is not the primary issue at dispute. To this end, TERRITORY AT STAKE from Fortna's dataset is added in the analysis. ${ }^{3}$

I also control for post-war CHANGE IN RELATIVE CAPABILITIES ${ }^{4}$ to show that conflict resumption is caused by uncertainty stemming from resource transfer and not by post-war shifts in relative power per se. The causal mechanism of the theory revolves around divergence from expectation rather than the magnitude of resource exploitation, whereas shifts in relative power presumably affect the durability of ceasefires as Werner (1999) demonstrates. Addition of CHANGE IN RELATIVE CAPABILITIES, thus, allows me to highlight the effects of territorial exchange, holding the material consequences of territorial transfer constant.

\subsubsection{Characteristics of Territorial Change}

The second part examines if the effect of resource transfer depends on "who gets what" in war, taking into account the area and density of exchanged territory in addition to the economic wealth and political institutions of the gainer. That is, the second analysis highlights variation among territorial changes and their consequences. ${ }^{5}$ The theory argues that the effect of uncertainty stemming from

\footnotetext{
${ }^{3}$ The source of the original data is "gravity of value threatened (GRAVCR)" in International Crisis Behavior (ICB2) data (Brecher and Wilkenfeld, 1992), reordered by Gelpi (1997).

${ }^{4}$ Fortna generates this variable following Werner (1999, p.923, fn.7). Note that this variable changed over time following settlement.

${ }^{5}$ To understand variation among territorial change, Tir (2003) serve as a very useful reference, showing that the prospect of conflict after either peaceful or violent territorial transition largely depends on the "tangibility" of
} 
territorial change is reinforced or modified by such factors as the amount of transferred resources, the nature of the resources and the characteristics of the gaining side. Fighting is more likely to resume when the post-conflict growth of power is potentially large but temporary stalled because the declining party, ceteris paribus, has a greater incentive to act opportunistically in such cases.

Hypothesis 2 (Size of Territory) Post-war peace is less durable if larger territories are transferred as a result of war. AREA OF EXCHANGED TERRITORY has a positive effect on the hazard ratio.

The first factor to be investigated is the area of exchanged territory. The theory predicts that larger resource transfer leads to less durable peace. Therefore, I add AREA OF EXCHANGED TERRITORY into the analysis (Tir et al., 1998, "Area of Unit Exchanged in Square Kilometers"). AREA is simply defined by the natural log of the land area obtained by a new owner as a result of war. Zero is assigned to cases where territorial transfer does not happen.

I add caveats to three cases: the First Kashmir War, the Turco-Cypriot Wars and the first Azeri-Armenian War. According to the territorial change dataset, both India and Pakistan acquired new territory in the first Kashmir War terminated in 1949. India obtained more land and greater population. To combine these territorial acquisitions, I simply subtract the area and the population of the Pakistani side from the equivalents on the Indian side.

The Turco-Cypriot Wars involved a dynamic process of territorial change. It is well known that Turkey occupied northern Cyprus in the first war and acquired more of the island in the second war. Yet, the territorial change dataset marks no record in the first war because it treats the two wars as one conflict. I divide the data on population and area into two and assign the obtained values to the first and second wars, respectively. When dividing the data, I rely on the historical account, which claims that Turkey acquired approximately $3 \%$ of the island in the first war and $38 \%$ in the second war (Camp, 1980).

Another difficult case is the first Azeri-Armenian War, whose territorial transfer was not coded in the dataset. As noted above, Armenia took control over the urban area of Nagorno-Karabakh during the war, and the region has been under de facto administration of Armenia to date. I add the data

exchanged territory (value) conditional on the balance of power between parties (power). However, the purpose of his study is different from that of this study in important respects. First and foremost, Tir studies the effects of territorial change on the prospect of conflict, whereas I examine the duration of ceasefires with and without territorial change. Second, Tir highlights (potential) adversaries' evaluation of territory and their power to seize it, whereas I focus on the natural characteristics of territory and the gainer's capability of consuming territory at hand. The former theory pertains to parties' military capabilities, while the latter elaborates on the gainer's political institutions as well as economic and technological capabilities. 
on population and area of Nagorno-Karabakh to the dataset by referring to the official statistics of the internationally unrecognized Nagorno-Karabakh Republic (The National Statistical Service of NKR, N.d.). ${ }^{6}$

Hypothesis 3 (Nature of Resources) Post-war peace is less durable if more populated territories are transferred as a result of war. DENSITY OF EXCHANGED TERRITORY has a positive effect on the hazard ratio.

Territories vary in their utility, and countries seek territory for strategic purposes, natural resources and market expansion. During the Russo-Turkish War between 1768 and 1774, the Russian Empire extended its de facto control over the Crimean Peninsula, which had been administered by a vassal state of the Ottoman Empire, and eventually annexed the area in 1783, resulting in the second Russo-Turkish War in 1787. The peninsula was particularly valuable for Russia because of ports facing the Black Sea that gave easy access to the Mediterranean Sea. Occupying the peninsula, the Russian Empire immediately built a naval base for its Black Sea Fleet in Sevastopol, which is located in the southwestern region of the Crimean Peninsula. The Spanish Empire built the colonial city of Potosi in Bolivia to mine its abundant silver. Just before World War II, the militarist regime in Japan conquered Manchuria and installed a puppet state to expand its colonial holdings.

The theory implies that colonies, i.e., more dense areas, are more likely to cause war resumption if the new owner's capability is sufficiently large. DENSITY OF EXCHANGED TERRITORY is assumed to represent the nature of territory exchanged. More dense regions are likely to include cities or resource fields that the new owner can exploit. Less dense areas presumably involve strategically important sites, considering that belligerents will never fight over territory without population, resource, or strategic value. Therefore, a less dense territory presumably gives strategic advantage to a new owner.

DENSITY is calculated by dividing the population residing in exchanged territory by the area of the corresponding territory (Tir et al., 1998, "Area of Unit Exchanged in Square Kilometers" and "Population of Unit Exchanged"). Then, I take the natural log of density to adjust its diminishing marginal effect. I assign zero to cases in which no territorial change occurred.

Hypothesis 4 ("Who Gets What") Post-war peace is less durable if wealthy democracies acquire larger and more populated territories through war. TERRITORIAL CHANGE INDEX has a positive effect on the hazard ratio.

\footnotetext{
${ }^{6}$ For population, I took the value from 1989.
} 
The theory indicates that the devastating effects of resource transfer depends on "who gets what" through conflict and that the effects are greater if the new owner is capable of fully exploiting the obtained territory. It is even more so if the territory is a potential colony and if larger territory is transferred because such territories require more investment for usage. Countries are different in their capability to exploit new territories, as the fate of a twin city of Nogales tells us. Through the Gadsden Purchase in 1853, half of Nogales was incorporated to the United States while the remainder remained in Mexico. In the U.S. side, American capitalists and settlers passionately developed silver mines, extended railroads, and opened up ranches. The Mexican side of the city suffered from lack of capital, turmoil with Native Americans and political instability, which undermined spontaneous economic development. Since then, the two areas of essentially the same city have followed divergent paths of economic and political development. Even today, the average income of a household in the Mexican side of Nogales remains one-third of average income on the American side of Nogales (Acemoglu, Robinson and Woren, 2012, p.7).

To test this hypothesis, a composite measurement, TERRITORIAL CHANGE INDEX, is created whose value increases as the gainer becomes more capable, the territory is more populated, and the gainer obtains a larger area. INDEX consists of the following factors: occurrence of territorial change, density of exchanged territory, area of exchanged land, GDP per capita of a new owner, and political institution of a new owner. This measurement allows us to investigate both the characteristics of territorial changes across cases and their consequences.

Before I proceed to detailed description of the INDEX, I offer a clarification of why I employ a composite measurement to analyze the effect of "who gets what," rather than just add each variable or an interaction term. Simply stated, I chose this strategy because it is difficult to identify the gainer in cases where no territorial change occurred. To create an interaction term, the capabilities of the gainer must be determined for all observations in the dataset. It is easy to identify the gainer in territorial change so long as historical records are available. However, who is "the gainer" in cases where territorial change did not take place? It is almost impossible to decide who the gainer in such cases is because no one acquired territory. This is true even more when no clear victor in the sense of a military outcome exists. In the case of the Six Day War, for instance, it is straightforward to identify the capabilities of the gainer, i.e., Israel. On the other hand, I have difficulty in coding the gainer's capabilities in the Iran-Iraq War terminated in 1988 in which no territorial change occurred and no clear victor exists. For this reason, I employ a composite measurement instead of an interaction term. 


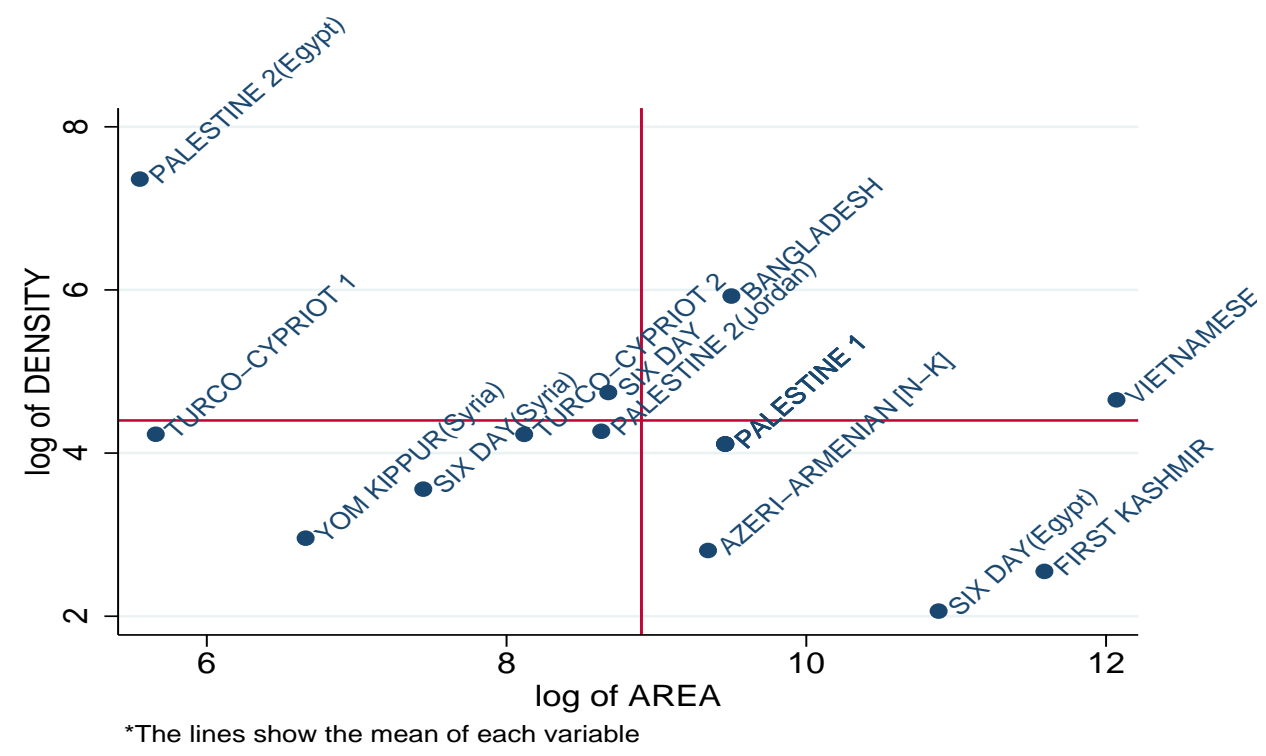

Figure 3.1: Density and Area of Exchanged Territories

INDEX is created in the following manner. First, a case gains one point if the war involves territorial change. Therefore, cases without territorial transfer are assigned zero points. As described above, density of exchanged territory represents the nature of transferred land. I first categorized all cases of territorial change into five groups in ascending order according to density so that each group contains a roughly equal number of observations. Those cases earn from zero to four points, depending on their assigned group. For instance, the least dense region is in group 0 and is assigned zero points, whereas the most dense territory earns four points. I repeat the same procedure for the data of surface area exchanged. The relationship between the density and the area in observed cases is plotted in Figure 3.1. The lines in the middle of each axis refer to the mean value of each variable.

Two more components are added to INDEX to capture the capability of a new owner: GDP per capita and POLITY score. GDP per capita directly captures the economic capability of countries. Wealthy countries are usually equipped with technology and capital for exploiting new territory. Although this may not be the case if a county's economy relies on oil production, no large oilproducing state is included as a gainer of territory in the dataset. I take the value of one year before a ceasefire is achieved to assert that GDP causes exploitation of territory and not vice versa. The data are obtained from the Maddison Project, and missing values are filled with values from the closest year (Bolt and van Zanden, 2013). Then, I categorize the values into five groups in 
ascending order and assign from zero to four points to each observation, following the procedure described above.

POLITY score is also added to INDEX because a country's capability of converting gained territory into military power also depends on its political institutions. More public goods are provided under inclusive political institutions, whereas resources are largely used for private transfer among political elites under exclusive institutions. Because security is a quintessential public good, a country with inclusive institutions is more threatening when it obtains new territories. It is well known that medieval feudal kings and emperors often distributed conquered territory among landlords in exchange for their war efforts. In contrast, the United States did not divide Japanese territory among soldiers after the end of World War II. Rather it advanced land reforms and the dissolution of the zaibatsu to achieve less unequal distribution of wealth, aiming for political stability and economic development. To capture these dynamics revolving around political institutions, I assign each observation from zero to four points, using lagged values of POLIY IV data (Marshall, Gurr and Jaggers, 2013).

INDEX, therefore, is composed of five factors and ranges from 0 to 17: the occurrence of territorial change (0-1), density of transferred territory (0-4), surface area of exchanged land (0-4), GDP per capita of a new owner (0-4), and POLITY score of a new owner (0-4). All cases without territorial change are assigned zero points. Among cases with border change, the observed value ranges from 7 to $14 .^{7}$ One case that obtained the highest point is Israel-Jordan in the Six Day War, when Israel obtained the West Bank. Although the area is not very large geographically, it was densely populated and, above all, Israel was a wealthy democracy that had effectively established control over the area. The ceasefire between Israel and Jordan broke down in October 1973.

\subsubsection{Terms of Settlement}

Hypothesis 5 (Inconsequentiality of Agreement) Terms of settlement are inconsequential in explaining post-war peace. INDEX OF AGREEMENT STRENGTH has no significant effect on the hazard ratio.

Finally, the theory implies that terms of settlement at the moment of war termination are inconsequential. Even if terms of settlement become obsolete or unsatisfactory, countries are able to

\footnotetext{
${ }^{7}$ One may be concerned with the large numerical gap between non-territorial cases and territorial change cases with the minimum index point (from 0 to 7 ), which is likely to cause a biased estimation of INDEX's impact. I checked the robustness of results by rescaling the measurement so that no large numerical jump exists. The finding remained unchanged. See the results of robustness checks in the appendix.
} 
renegotiate them peacefully. In the model, countries do reach new terms of settlement through renegotiation under certain conditions. Moreover, considering that a ceasefire is achieved with countries' explicit or implicit agreement, terms of settlement are a result of countries' calculation regarding a post-war situation, and not vice versa. They choose optimal terms of settlement, anticipating what will happen in the future. Thus, countries may choose a strong agreement in one context and a weak settlement in another. If so, the agreement per se is not a cause of war resumption. Rather, there are factors that cause countries to install a weaker settlement than necessary and that make such misperception more detrimental to peace. Specifically, these factors relate to the nature of violent resource transfer, according to the theory.

\subsection{Alternative Hypotheses}

Three alternative hypotheses are also tested.

Hypothesis 6 (Fortna) Post-war peace is more durable if a strong ceasefire agreement is installed. INDEX OF AGREEMENT STRENGTH has a negative effect on the hazard ratio.

Fortna (2004) highlights the effect of strong agreements on the durability of peace. Agreement strength is measured by adding the number of peacekeeping mechanisms implemented. These mechanisms include the following: formality of an agreement, withdrawal of forces, a demilitarized zone, arms control measures, third-party involvement and so forth. The measurement takes a value from 0 to 10 , and the larger number means the stronger agreement. The value of each ceasefire may vary over time if a follow-up agreement is achieved or peacekeeping mechanisms are added or dropped.

Hypothesis 7 (Werner\&Yuen I ) Post-war peace is less durable if battle outcomes in the preceding war are consistent. BATTLE CONSISTENCY has a positive effect on the hazard ratio.

Hypothesis 8 (Werner\&Yuen II ) Post-war peace is less durable if a third-party interrupts the process of a ceasefire. INTERRUPTED WAR has a positive effect on the hazard ratio.

Werner and Yuen (2005) demonstrate that consistent battle outcomes significantly reduce the risk of war resumption by revealing reliable information regarding the opponent's military capability. Likewise, peace is less durable if it is somewhat imposed by the interruption by a third-party because such settlement is likely to break down once the third-party withdraws her commitment to peace. 
They create two variables, BATTLE CONSISTENCY and INTERRUPTED WAR, to test these hypotheses. BATTLE CONSISTENCY is measured "as the duration of the last tide of the war before the ceasefire as a proportion of the total duration of the war." The tide is considered to continue as long as "one side is consistently wining battles" (p.274). Thus, BATTLE CONSISTENCY takes values between 0 and 1. INTERRUPTED WAR is identified "when (1) there is clear evidence of significant third-party pressure to ceasefire, and (2) the ceasefire is invoked before the parties negotiate the final settlement" (p.273). INTERRUPTED WAR takes either 0 or 1.

They also control for the following variables that affect the duration of post-war peace. War which ends with a military TIE leads to less durable post-war peace. ${ }^{8}$ The variable is coded 1 if war ends with a tie and 0 , otherwise. A ceasefire following costly war is more likely to fail. The COST OF WAR is measured by the natural log of the total number of battle deaths. ${ }^{9}$ Post-war peace is less durable if a dyad has a HISTORY OF CONFLICT, which is measured by the number of militarized interstate disputes between the dyad divided by the number of years that the dyad has existed in the interstate system at the time the war started. ${ }^{10}$ Moreover, peace is less durable if existence was at stake in the previous war (EXISTENCE AT STAKE) and if adversaries are CONTIGUOUS. ${ }^{11}$ These variables take 1 if yes and 0, otherwise. More detailed accounts are offered by Fortna (2004)

The descriptive statistics of all variables and the correlations between them are reported in the appendix.

\subsection{A Statistical Model}

Using the duration model, I analyze both how long a ceasefire takes until war resumes and what factors affect the ceasefire's duration. The model is a class of statistical analysis that has been developed for a study of duration. The analysis is also called event history model in sociology, survival analysis in biometrics, and hazard model elsewhere. Duration model examines how long a subject exists before it fails. For instance, a biometrician often studies the survival time until subjects who are exposed to certain medication literally fail, or die. In the case of post-war peace, we are interested in the duration until a ceasefire fails, or war resumes.

\footnotetext{
${ }^{8}$ The original data are drawn from Stam (1996).

${ }^{9}$ The original data are drawn from the Correlates of War (COW), v.3.0 (Singer and Small, 1972; Small and Singer, 1982).

${ }^{10}$ The source of the original data is the Militarized Interstate Disputes (MID), v.2.1 (Daniel M. Jones and Singer, 1996).

${ }^{11}$ The source of the original data on EXISTENCE is ICB2 (Brecher and Wilkenfeld, 1992). Contiguity is seemingly calculated with EUGene (Bennett and Stam, 2000).
} 
An issue in analyzing duration arises when some cases do not fail within the period of analysis. Some patients may survive beyond the last point of experimental observation. Some ceasefires, such as the Football War, did not experience war resumption by 1999. The problem is that those cases provide no information regarding failure. Because researchers are unable to observe their failure, no information regarding failure can be extracted from those observations. Those cases are called right-censored because their history becomes unobserved after the period of analysis. A standard regression analysis is unable to handle those cases properly. Therefore, researchers employ duration analysis, which can take into account the fact that censored cases contribute information only regarding survival and not regarding failure.

A concept of particular interest is the hazard function, i.e., the instantaneous probability of failure at a certain point in time conditional on survival up to that time. How likely is a patient to die at a given point in time, if she survives up to that time? How likely is a war to restart after 10 years have passed since settlement, assuming that a ceasefire is maintained for 9 years? Those probabilities may increase, decrease or remain constant over time. A natural guess is that a patient's probability of death increases over time as she grows old. Thus, the probability is expressed as a function and called the hazard function. Again, the hazard function gives a probability that a patient dies at a given time if she lives to that time, or that war resumes at a given time if a ceasefire is maintained up to that time.

Those probabilities are systematically influenced by various factors, such as age, sex or medical history in the case of life expectancy, and outcome of war or history of territorial change in the case of a ceasefire. Duration analysis allows researcher to analyze how various factors affect such probabilities.

One assumption must be made regarding the baseline dynamics of failure. For instance, it was natural for the case of medication to assume that the baseline prospect of death continues to increase as time passes. What about a ceasefire? In this chapter, I assume that the baseline probability of war resumption is monotonically changing as time passes, following the procedure of Fortna, Werner and Yuen. That is, the baseline probability continues to increase or continues to decrease as time goes on. I need not assume the direction of shift. This particular form of duration analysis is called the Weibull model. ${ }^{12}$

\footnotetext{
${ }^{12}$ Results using the Cox Model are also reported in the appendix.
} 


\subsection{Results}

\subsubsection{Resource Transfer Causes Unstable Peace}

I first replicate the analyses of existing studies to evaluate the hypotheses within their framework. Column 1 of Table 3.1 reports replicated results of Fortna (2004, p.170, Column 2 of Table 5.3) ${ }^{13}$ and Column 2 shows those of Werner and Yuen (2005, p.276, Column 2 of Table 1). I successfully replicate their analyses. ${ }^{14}$ Fortna's analysis shows that a ceasefire lasts longer if belligerents agree to a stronger agreement when terminating war. Additionally, a ceasefire is more likely to be maintained if the preceding war was costly. Moreover, belligerents are more likely to restart fighting if the preceding war ended with a military tie, they have a history of conflict, their existence was at stake in the dispute, they are geographically contiguous, or the post-war balance of power greatly changes. Werner and Yuen also show that a ceasefire is maintained if the tide of battles in the preceding war is consistent and settlement is not interrupted by a third-party.

Territorial change as a result of war has significant negative effects on post-war peace, as is shown in Column 3 of Table 3.1. If either or both adversaries acquires new territory as a result of war, they are more likely to restart fighting and settlement becomes less durable. In all analyses, territorial change significantly decreases the duration of post-war peace. These results are interpreted directly from Column 3 of Table 3.1. Coefficients reported in the table show the effect of variables on a hazard function that is the instantaneous probability of failure at a certain point in time conditional on survival up to that time.

Negative coefficients in the hazard function mean an increase in the variables reduces the hazard rate of a ceasefire, i.e., the probability that a ceasefire fails at a given time if it is maintained up to that time. In other words, factors with negative coefficients make war less likely to resume and thus tend to prolong the duration of a ceasefire. If variables have positive coefficients, an increase in those variables raises the probability that a ceasefire fails at a certain point in time. Positive coefficients mean that those factors make war more likely to resume and make post-war peace less durable. The value $p$ indicates whether the hazard rate is increasing or decreasing. If the value $p$ is great than one, the probability of war resumption increases as time passes. If the value is less than one, the probability decreases as time goes on. If it is equal to one, post-war peace breaks down with the same probability at any point in time.

\footnotetext{
${ }^{13}$ Note that Fortna reports hazard ratio instead of coefficients. Cases of joint democracies are not dropped, following Werner and Yuen's procedure.

${ }^{14}$ Although some results are slightly different from the original, they seem negligible.
} 
Table 3.1: Replications and the Effect of Territorial Change

\begin{tabular}{|c|c|c|c|c|c|c|}
\hline & $\begin{array}{l}(1) \\
\text { Fortna } \\
\text { coef. }\end{array}$ & $\begin{array}{c}(2) \\
\mathrm{W} \& \mathrm{Y} \\
\text { coef. }\end{array}$ & $\begin{array}{l}(3) \\
\text { TC } \\
\text { coef. }\end{array}$ & $\begin{array}{c}(4) \\
\text { TC } \\
\text { coef. }\end{array}$ & $\begin{array}{l}(5) \\
\text { TC } \\
\text { coef. }\end{array}$ & $\begin{array}{c}\text { (6) } \\
\text { hazard ratio }\end{array}$ \\
\hline TERRITORIAL CHANGE & & & $\begin{array}{l}1.27^{*} \\
(0.50)\end{array}$ & $\begin{array}{l}1.27^{* *} \\
(0.49)\end{array}$ & $\begin{array}{c}2.57^{* * *} \\
(0.70)\end{array}$ & 13.04 \\
\hline $\begin{array}{l}\text { INDEX OF AGREEMENT } \\
\text { STRENGTH }\end{array}$ & $\begin{array}{c}-0.21^{* *} \\
(0.07)\end{array}$ & $\begin{array}{l}-0.38^{*} \\
(0.15)\end{array}$ & & $\begin{array}{l}-0.13 \\
(0.11)\end{array}$ & $\begin{array}{l}-0.35 \\
(0.23)\end{array}$ & 0.70 \\
\hline BATTLE CONSISTENCY & & $\begin{array}{c}-5.48^{* *} \\
(2.09)\end{array}$ & & & $\begin{array}{l}-7.31^{*} \\
(2.85)\end{array}$ & 0.00 \\
\hline INTERRUPTED WAR & & $\begin{array}{c}4.17^{* * *} \\
(0.91)\end{array}$ & & & $\begin{array}{c}6.94^{* * *} \\
(0.95)\end{array}$ & 1031.07 \\
\hline TIE & $\begin{array}{c}3.49^{* * *} \\
(0.21)\end{array}$ & $\begin{array}{l}2.62^{*} \\
(1.06)\end{array}$ & $\begin{array}{c}3.92^{* * *} \\
(0.87)\end{array}$ & $\begin{array}{c}3.83^{* * *} \\
(0.84)\end{array}$ & $\begin{array}{c}4.52 \\
(2.81)\end{array}$ & 92.28 \\
\hline COST OF WAR & $\begin{array}{c}-0.65^{* * *} \\
(0.17)\end{array}$ & $\begin{array}{c}-0.96^{* * *} \\
(0.24)\end{array}$ & $\begin{array}{c}-0.65^{* * *} \\
(0.18)\end{array}$ & $\begin{array}{c}-0.59^{* * *} \\
(0.17)\end{array}$ & $\begin{array}{c}-0.87^{* * *} \\
(0.13)\end{array}$ & 0.42 \\
\hline HISTORY OF CONFLICT & $\begin{array}{c}0.95^{* * *} \\
(0.22)\end{array}$ & $\begin{array}{c}0.39 \\
(0.28)\end{array}$ & $\begin{array}{l}0.96^{*} \\
(0.38)\end{array}$ & $\begin{array}{l}0.88^{*} \\
(0.41)\end{array}$ & $\begin{array}{c}0.60 \\
(0.62)\end{array}$ & 1.82 \\
\hline EXISTENCE AT STAKE & $\begin{array}{c}2.05^{* * *} \\
(0.43)\end{array}$ & $\begin{array}{c}3.92^{* * *} \\
(0.68)\end{array}$ & $\begin{array}{c}0.76 \\
(0.61)\end{array}$ & $\begin{array}{c}1.00 \\
(0.65)\end{array}$ & $\begin{array}{l}2.50^{*} \\
(1.22)\end{array}$ & 12.15 \\
\hline CONTIGUOUS & $\begin{array}{c}1.14^{* * *} \\
(0.25)\end{array}$ & $\begin{array}{c}0.99^{* * *} \\
(0.20)\end{array}$ & $\begin{array}{l}1.50^{*} \\
(0.59)\end{array}$ & $\begin{array}{c}1.60^{* * *} \\
(0.48)\end{array}$ & $\begin{array}{c}1.29 \\
(1.10)\end{array}$ & 3.65 \\
\hline $\begin{array}{l}\text { CHANGE IN RELATIVE } \\
\text { CAPABILITIES }\end{array}$ & $\begin{array}{c}0.85^{* * *} \\
(0.19)\end{array}$ & $\begin{array}{c}1.03^{* * *} \\
(0.20)\end{array}$ & $\begin{array}{c}1.06^{* * *} \\
(0.14)\end{array}$ & $\begin{array}{c}1.02^{* * *} \\
(0.14)\end{array}$ & $\begin{array}{c}1.29^{* * *} \\
(0.31)\end{array}$ & 3.64 \\
\hline TERRITORY AT STAKE & & & $\begin{array}{l}-2.08^{*} \\
(0.92)\end{array}$ & $\begin{array}{l}-1.76 \\
(0.99)\end{array}$ & $\begin{array}{c}-3.53^{* * *} \\
(0.66)\end{array}$ & 0.03 \\
\hline Constant & $\begin{array}{c}-5.96^{* *} \\
(1.88)\end{array}$ & $\begin{array}{c}-4.38^{* *} \\
(1.35)\end{array}$ & $\begin{array}{c}-7.68^{* * *} \\
(2.03)\end{array}$ & $\begin{array}{c}-7.85^{* * *} \\
(1.94)\end{array}$ & $\begin{array}{c}-9.87^{* *} \\
(3.49)\end{array}$ & \\
\hline$p$ & $\begin{array}{c}0.81 \\
(0.12) \\
\end{array}$ & $\begin{array}{c}1.06 \\
(0.17)\end{array}$ & $\begin{array}{c}0.89 \\
(0.16)\end{array}$ & $\begin{array}{c}0.92 \\
(0.16) \\
\end{array}$ & $\begin{array}{c}1.39 \\
(0.17)\end{array}$ & \\
\hline Observations & 770 & 770 & 770 & 770 & 770 & \\
\hline Number of subjects & 48 & 48 & 48 & 48 & 48 & \\
\hline $\mathrm{BIC}$ & 152.6 & 152.1 & 153.5 & 159.4 & 130.0 & \\
\hline
\end{tabular}

Standard errors in parentheses. Standard errors are clustered by conflict.

${ }^{*} p<0.05,{ }^{* *} p<0.01,{ }^{* * *} p<0.001$ 
The devastating effect of territorial change is quite robust and distinct from that of territorial disputes. It is argued elsewhere that territorial disputes are difficult to resolve. Yet, the ex post effect of territorial change is distinct from that of territorial issue. Issues at stake, of course, influence the fate of post-war peace because they determine how much countries are willing to pay. The effect of actual territorial change can be theoretically distinguished from such a mechanism because resource transfer works through countries' post-war capabilities, rather than their willingness. The analysis in Column 3 demonstrates that territorial change causes an unstable post-war situation even if territory is not a primary issue of the dispute. Thus, the effect of actual territorial change is distinct from that of territorial dispute. Moreover, a territorial war ended without territorial change is considerably less likely to resume. Even if territory is the primary concern of adversaries, they are likely to maintain peace unless actual territorial change devastates their post-war power balance. Furthermore, the performance of TERRITORIAL CHANGE does not change whether TERRITORY AT STAKE is included or excluded from analyses.

Territorial change has a disturbing effect on a ceasefire regardless of actual shifts in power, as the theory predicts. Remember that conflict resumption is not caused by post-war shifts in relative power per se in the theory. Rather, the fate of post-war peace hinges on accidental events whose consequences increase or decrease depending on the nature of resources and others. Although acquisition of new resources of course leads to shifts in post-war capabilities, this study focuses on another causal mechanism distinct from post-war power shift. Specifically, the theory claims that the loser resumes war if the gainer's power growth is less than expected. This causal mechanism revolves around divergence from expectation rather than the magnitude of resource exploitation. It should be emphasized that the actual growth of power is not a primary focus in this study, but the gap between ex post realized power and ex ante expectation is. Addition of CHANGE IN RELATIVE CAPABILITIES, thus, allows me to highlight the argument of this theory by controlling for actual shifts in power. The results show that territorial change decreases the duration of a ceasefire even if its material effects, i.e., shifts in power, are held constant. The effect of TERRITORIAL CHANGE remains unchanged even if I exclude CHANGE IN RELATIVE CAPABILITIES from the analysis in Column 3.

Territorial change exhibits consistent effects across different model specifications. I add TERRITORIAL CHANGE to Fortna's model in Column 4 and to Wener and Yuen's model in Column 5. In all analyses, territorial change significantly decreases the duration of post-war peace. 


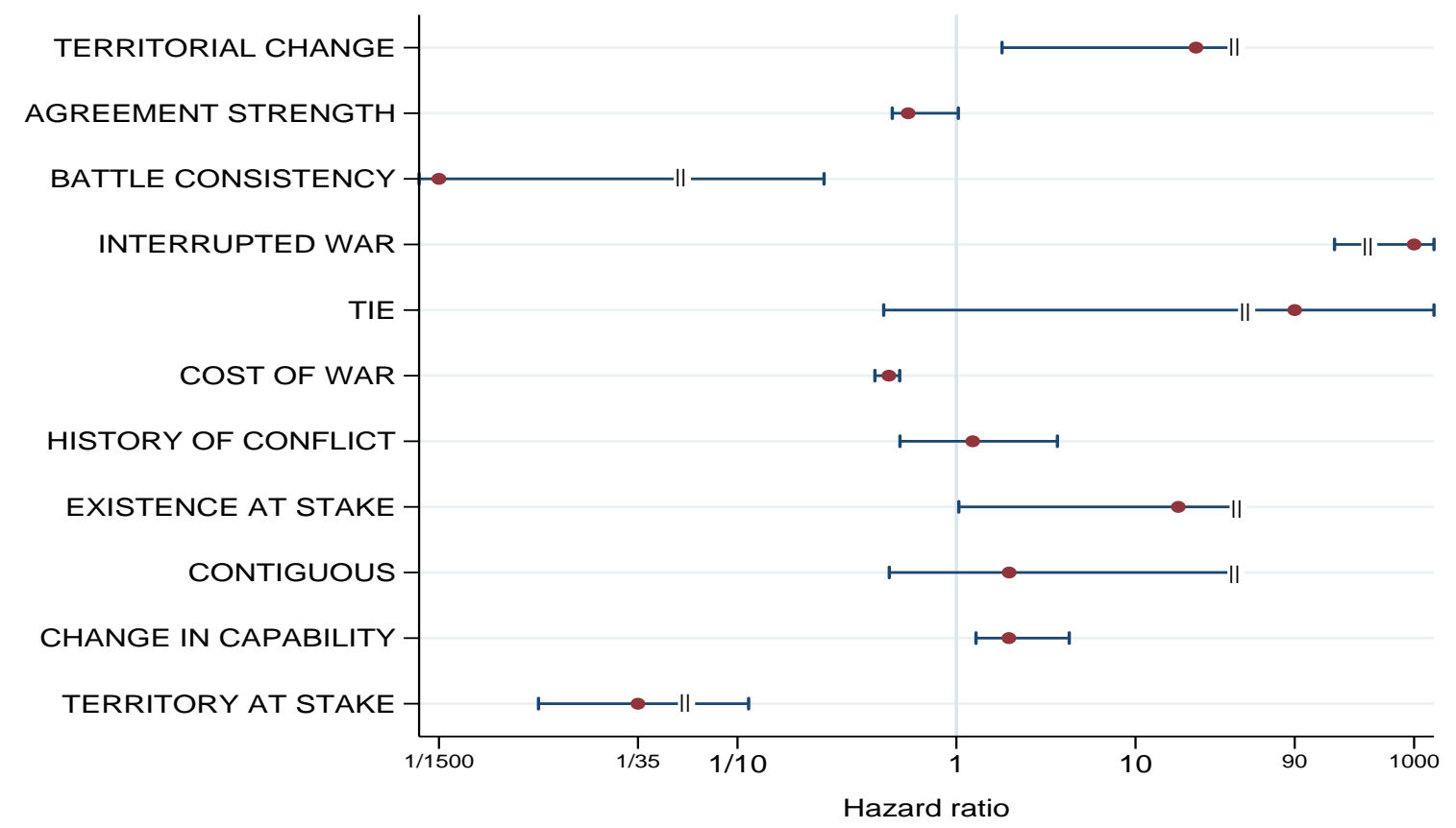

Figure 3.2: Effects on the Likelihood of War Resumption (Model 5 in Table 3.1)

The effect of territorial change is not negligible in substance. Column 6 of Table 3.1 shows the hazard ratio of each variable calculated from the full model in Column 5. If territorial change happens during war, the possibility of war resumption at a given time is thirteen times as high as the case of no territorial change, ceteris paribus. An interpretation of a hazard ratio is straightforward. If a hazard ratio is greater than one, the factor will cause a ceasefire to fail more quickly. If a ratio is equal to 2 , for instance, one unit change in the factor gives a ceasefire twice the chance of failure at a certain point in time, given that it survives up to that time. If a ratio is 0.5 , in contrast, one unit change causes a ceasefire to have a one-half the chance of breakdown, hence, to last longer. Because TERRITORIAL CHANGE is a binary variable, the value of its hazard ratio can be understood as the difference between cases with and without this factor.

When territorial change is taken into account, the effect of agreement strength becomes obscure. Although agreement strength still shows a negative effect on the probability of war resumption, we cannot refute the possibility that the relationship is observed by chance. In Columns 1 and 2, agreement strength may capture a part of the effects of territorial change through demilitarized zones. Alternatively, strong agreements are achieved in cases of territorial change, as Fortna argues that strong peacekeeping devices are installed in difficult cases. 
Battle consistency and third-party interruption exhibit consistent effects on the duration of postwar peace even when territorial change is included in the analysis. Inconsistent battle tide and thirdparty involvement increase the likelihood of war resumption, independent of territorial alteration. The effect of these factors is quite large. The model predicts that if one side of adversaries continues to prevail in combat, the war seldom restarts if terminated. If settlement is achieved under the pressure of third parties, the likelihood of war resumption is more than a thousand times as great as that of autonomous settlement. However, the model alone is unable to unfold the dynamics between third-party intervention and post-war peace. It may be the case that particularly unstable settlements attract a third-party's involvement, and not vice versa.

Bayesian Information Criterion (BIC) is reported to compare the validity of different model specifications. It is not easy to identify a model which best explains variations in observed data because we can improve the precision of model prediction by adding an infinite number of explanatory variables. Yet, such a model is not necessarily the best model to demystify the causal relationship among factors. Bayesian Information Criterion (BIC) is useful for the purpose here because it allows us to compare the precision of model prediction across different model specifications, while taking into account an addition of explanatory variables. That is, BIC penalizes overfitting due to an increase of predictors. We do not substantively interpret the values of BIC but compare the values across models. In general, a model with a lower BIC is better than one with a higher BIC.

It is apparent from Table 3.1 that adding TERRITORIAL CHANGE considerably improves model fitness. The lowest BIC in Model 5 indicates that TERRITORIAL CHANGE explains a substantial portion of variation in the duration of post-war peace. Moreover, an increase in BIC in Model 4 implies that the explanatory powers of TERRITORIAL CHANGE and INDEX OF AGREEMENT STRENGTH overlap, and I overfit in Model 4 by adding both variables to the analysis. As mentioned above, the two variables tend to explain the same variation in observed cases. This implies that INDEX OF AGREEMENT has little explanatory power.

Effects of the factors calculated from the full model in Column 5 are visually presented in Figure 3.2. The circle dots indicate the magnitude of each predictor's effect on the probability of war resumption. The horizontal solid lines around the dots show the confidence interval. If a dot is located to the right of the vertical line of one, the factor causes war reatrting to be more likely. A larger value implies a more devastating effect on post-war peace. The value 10 means that the factor will cause a ceasefire ten times the chance of failure. A dot placed on the left of the vertical line of one indicates that the factor discourages adversaries from resuming war. The value $1 / 10$ suggests 
that the risk of war resumption at a given time is ten times higher without the factor (or without one unit increase in the factor). Note that the scale of the graph is adjusted so that the behavior of all variables is substantively and visually understandable in one figure. I scaled down the right and left tails of the horizontal axis so that large numbers are included. Curtailed parts are denoted by the vertical double lines. I also scaled up the left part of the horizontal axis to make substantive interpretation easier. The modified axis places 10 and 1/10 at the same distance from 1 because the substantive magnitude of their effects is equivalent in opposite directions.

Territorial change and third-party interruption are particularly detrimental to post-war peace. Although TIE seems to have a huge effect, the horizontal line crossing the vertical line of one suggests that the association between TIE and the duration of post-war peace may be observed by chance. Consistent battle outcomes greatly contribute to post-war peace. A substantive effect of this factor must be interpreted with caution, however. BATTLE CONSISTENCY is measured by the share of the last tide of battles in the entire fighting and varies from 0 to 1 . The value of hazard ratio represents an effect when BATTLE CONSISTENCY shifts from 0 to 1, comparing war in which one side persistently prevails with one where either side excels only at the last minute. Thus, the graph and the hazard ratio in the Table show the maximum effect of the variable. COST OF WAR also contributes to post-war peace. Because it is measured by a natural log of total battle deaths, the graph can be interpreted, for instance, as an effect when total number of casualties increases from 2980 to 8100 battle deaths.

\subsection{2 "Who Gets What" Matters}

Remembering that the first analysis proves the effect of territorial change in general, the next analysis investigates variation among territorial change using AREA OF EXCHANGED TERRIORY, DENSITY OF EXCHANGED TERRITORY, and TERRITORIAL CHANGE INDEX. The test above divides all cases into two groups according to the occurrence of territorial change; hence, all ceasefires involving territorial transfer are assumed to have the same effect. Yet, the theory argues that the effect of territorial change varies across cases, depending on the nature and the size of territory as well as the characteristics of the new owner.

Three hypotheses are tested. First, a ceasefire is expected to be of short duration if larger area is exchanged between adversaries. The second hypothesis is that a ceasefire is less durable when more dense territory is transferred because such territory is considered as potential colonies, which enables the new owner to increase its military power given that her capability is sufficiently large. 


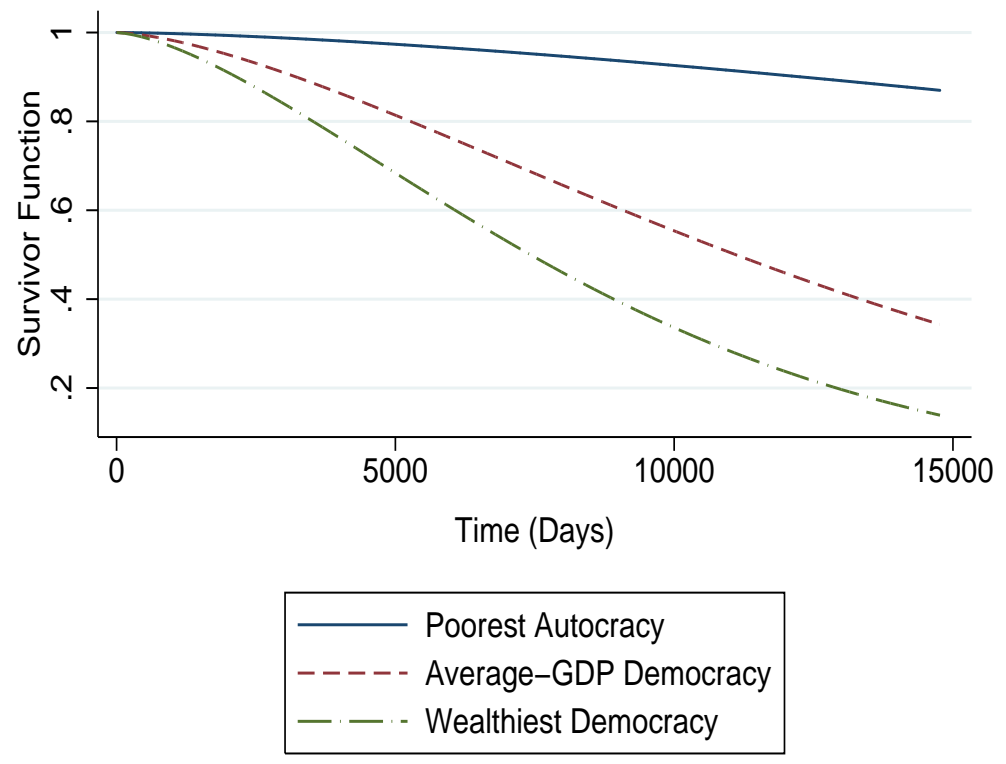

Figure 3.3: Characteristics of the Gainer and Survival of Post-War Peace (Model 3 in Table 3.2)

Third, a ceasefire is more likely to break down when the new owner of territory is more capable, the territory is more exploitable, and larger land area is transferred.

As shown in Table 3.2, all three variables behave as predicted. Column 1 shows that post-war peace is short-lived if larger area is transferred from one to the other as shown in Column 2. This may be counter-intuitive because it is often said that decisive victory leads to more stable post-war peace. The analysis indicates that larger territorial acquisition remaining short of absolute victory causes unstable peace. Absolute war is defined as one in which one adversary fights until she completely defeats or disarms its opponent. ${ }^{15}$ Although Lo, Hashimoto and Reiter (2008) demonstrate that absolute war, particularly post-war regime change, positively contributes to post-war peace, this study indicates that the size of victory influences peace in a non-monotonic way. Larger victory often results in a non-durable settlement, although its effect may turn to positive as its value exceeds a certain threshold.

Column 2 demonstrates that war is more likely to resume if more dense territory is exchanged as a result of war. This is consistent with the theory's claim that a country is able to extract additional military power from an acquired land if it includes a large city or industrial center and, hence, causes a larger opportunistic motivation of the loser for war resumption.

\footnotetext{
${ }^{15}$ The Vietnam War between North and South Vietnam was the only absolute war in this data set. South Vietnam was integrated into North Vietnam and disappeared from the international system as of the war termination in 1975. The data set treat this case as censored quickly after the ceasefire.
} 
Table 3.2: Characteristics of Territorial Change and Post-War Peace

\begin{tabular}{|c|c|c|c|c|c|c|}
\hline & \multicolumn{2}{|c|}{ (1) } & \multicolumn{2}{|c|}{$(2)$} & \multicolumn{2}{|c|}{ (3) } \\
\hline & coef. & haz.ratio & coef. & haz.ratio & coef. & haz.ratio \\
\hline $\begin{array}{l}\text { AREA OF EXCHANGED } \\
\text { TERRITORY }\end{array}$ & $\begin{array}{l}0.29^{* *} \\
(-0.11)\end{array}$ & 1.33 & & & & \\
\hline $\begin{array}{l}\text { DENSITY OF EXCHANGED } \\
\text { TERRITORY }\end{array}$ & & & $\begin{array}{l}0.38^{*} \\
(-0.16)\end{array}$ & 1.47 & & \\
\hline $\begin{array}{l}\text { TERRITORIAL CHANGE } \\
\text { INDEX }\end{array}$ & & & & & $\begin{array}{c}0.33^{*} \\
(-0.15)\end{array}$ & 1.39 \\
\hline $\begin{array}{l}\text { INDEX OF AGREEMENT } \\
\text { STRENGTH }\end{array}$ & $\begin{array}{c}-0.32 \\
(-0.23)\end{array}$ & 0.73 & $\begin{array}{c}-0.37 \\
(-0.29)\end{array}$ & 0.69 & $\begin{array}{l}-0.42 \\
(-0.27)\end{array}$ & 0.66 \\
\hline BATTLE CONSISTENCY & $\begin{array}{c}-7.69^{* * *} \\
(-2.03)\end{array}$ & 0.00 & $\begin{array}{l}-6.78^{* *} \\
(-2.08)\end{array}$ & 0.00 & $\begin{array}{l}-6.4^{* * *} \\
(-1.68)\end{array}$ & 0.00 \\
\hline INTERRUPTED WAR & $\begin{array}{l}7.13^{* * *} \\
(-1.67)\end{array}$ & 1247.2 & $\begin{array}{l}6.02^{* *} \\
(-1.85)\end{array}$ & 413.13 & $\begin{array}{l}7.53^{* * *} \\
(-2.14)\end{array}$ & 1869.88 \\
\hline TIE & $\begin{array}{l}4.17^{*} \\
(-1.70)\end{array}$ & 64.95 & $\begin{array}{l}4.40^{*} \\
(-1.97)\end{array}$ & 81.55 & $\begin{array}{l}5.44^{*} \\
(-2.27)\end{array}$ & 231.19 \\
\hline COST OF WAR & $\begin{array}{l}-0.87^{* * *} \\
(-0.17)\end{array}$ & 0.42 & $\begin{array}{c}-0.94^{* * *} \\
(-0.19)\end{array}$ & 0.39 & $\begin{array}{c}-0.85^{* * *} \\
(-0.19)\end{array}$ & 0.43 \\
\hline HISTORY OF CONFLICT & $\begin{array}{c}0.68 \\
(-0.47)\end{array}$ & 1.98 & $\begin{array}{c}0.73 \\
(-0.54)\end{array}$ & 2.09 & $\begin{array}{c}0.78^{*} \\
(-0.40)\end{array}$ & 2.19 \\
\hline EXISTENCE AT STAKE & $\begin{array}{c}2.45 \\
(-1.47)\end{array}$ & 11.56 & $\begin{array}{c}2.6 \\
(-1.92)\end{array}$ & 13.51 & $\begin{array}{c}2.19^{*} \\
(-1.02)\end{array}$ & 8.97 \\
\hline CONTIGUOUS & $\begin{array}{c}1.10 \\
(-1.47)\end{array}$ & 3.01 & $\begin{array}{c}1.60 \\
(-1.74)\end{array}$ & 4.93 & $\begin{array}{c}0.99 \\
(-1.45)\end{array}$ & 2.69 \\
\hline $\begin{array}{l}\text { CHANGE IN RELATIVE } \\
\text { CAPABILITIES }\end{array}$ & $\begin{array}{l}1.24^{*} \\
(-0.63)\end{array}$ & 3.46 & $\begin{array}{c}1.33^{*} \\
(-0.59)\end{array}$ & 3.77 & $\begin{array}{c}1.19^{*} \\
(-0.60)\end{array}$ & 3.26 \\
\hline TERRITORY AT STAKE & $\begin{array}{l}-3.84^{* *} \\
(-1.30)\end{array}$ & 0.02 & $\begin{array}{l}-2.96 \\
(-1.57)\end{array}$ & 0.05 & $\begin{array}{l}-3.29^{* *} \\
(-1.16)\end{array}$ & 0.04 \\
\hline Constant & $\begin{array}{l}-9.59^{* *} \\
(-3.40)\end{array}$ & & $\begin{array}{l}-8.29^{*} \\
(-3.76)\end{array}$ & & $\begin{array}{l}-12.25^{*} \\
(-4.90)\end{array}$ & \\
\hline$p$ & $\begin{array}{c}1.38 \\
(-0.19)\end{array}$ & & $\begin{array}{c}1.3 \\
(-0.26)\end{array}$ & & $\begin{array}{c}1.52 \\
(-0.34)\end{array}$ & \\
\hline Observations & 770 & & 770 & & 770 & \\
\hline Number of subjects & 48 & & 48 & & 48 & \\
\hline $\mathrm{BIC}$ & 150.15 & & 154.32 & & 147.2 & \\
\hline
\end{tabular}

Standard errors in parentheses. Standard errors are clustered by conflict.

${ }^{*} p<0.05,{ }^{* *} p<0.01,{ }^{* * *} p<0.001$ 
Finally, Column 3 shows that a ceasefire is more likely to fail at a given time if wealthier democracies acquire a larger and denser colony. The effect of TERRITORIAL CHANGE INDEX is graphically presented in Figure 3.3. The graph shows the probability that a ceasefire is maintained, or survives, a given time. A steeper line means that a truce fails more quickly. The probability is calculated using Model 3 of Table 3.2 and holding all variables but TERRITORIAL CHANGE INDEX at mean values.

The figure compares three scenarios. The solid line represents a case where a poorest autocracy acquires a new land which has average density and size. More specifically, the top solid line is derived by keeping the value of TERRITORIAL CHANGE INDEX at 5.55, which is composed of the occurrence of territorial change (1pt.), average density (2.29pt.), average size of land (2.26pt.), lowest GDP per capita (0pt.), and lowest Polity score (0pt.). The dashed line depicts a case where a new owner of land is switched to a full democracy (4pt.) that has average GDP per capita (2.15pt.). The dash-dotted line in the bottom is a case where a wealthiest (4pt.) democracy obtains a region of average density and size.

The graph shows that change in capability exhibits considerable effect on the survival of a ceasefire. Supposing that 10 years have passed since war termination, the likelihood that war resumes by then is approximately $20 \%$ higher if a wealthiest democracy acquired territory, comparing with a case where a poorest autocracy occupied the same land. After 30 years, the possibility that a ceasefire is still maintained is only $30-40 \%$ if a wealthiest democracy is the gainer, while the probability remains as high as $90 \%$ if a poorest autocracy is the gainer.

As demonstrated in this graph, variation among territorial change is not negligible. One concern, however, is that the results are driven by the large numerical gap between non-territorial change cases and territorial change cases. As is noted in the previous section, all non-territorial change cases are assigned 0 points. The minimum value that territorial change cases obtain is 7 points because there are no cases which earn low points in all components. Considering the general effect of territorial change shown in the first analysis, it is possible that the effect of TERRITORIAL CHANGE INDEX is largely derived from the occurrence of territorial change (numerical jump from 0 to 7 ), rather than variation among territorial transfer (7pt. to $14 \mathrm{pt}$.). To examine this possibility, I run the same analysis replacing TERRITORIAL CHANGE INDEX with TERRITORIAL CHANGE INDEX 2 that reduces the numerical gap generated by the occurrence of territorial alteration. The result remains mostly unchanged; see the appendix for robustness checks. 


\subsection{Summary of Findings}

This chapter evaluated the theory in the context of important preceding studies and demonstrated its validity. Three core arguments of this study are examined: Post-war peace becomes more unstable if one side of adversaries obtains new exploitable resources as a result of war. The effect of violent resource transfer varies across cases, depending on the nature of resources, the size of transfer, and the characteristics of a new owner. Terms of settlement are inconsequential to the duration of a ceasefire.

The first analysis demonstrated that territorial change during war causes shorter post-war peace. A ceasefire after territorial change is substantially less durable than one without territorial transfer. Because a gainer of new territory grows stronger by exploiting the acquired land, the loser conceives that his power is relatively declining. Thus, the loser has a larger incentive for resuming war when an opportunity arises. The analysis confirms that territorial alteration has a devastating effect on post-war peace even if effects of a post-war power shift and territorial disputes are taken into account.

The second analysis showed that the effect of territorial change varies across cases. In particular, war is more likely to resume if wealthier democracies acquire more dense and larger territory. Wealthier democracies are more capable of producing wealth and power from colonies than are poor autocracies. Wealthy countries have technology and capital for industrial and military development. Democracies are more capable of providing public goods. such as national security. The analysis indicates that the negative effect of territorial change depends on "who gets what" as a result of war.

Finally, the effect of agreement strength more or less disappears if territorial change is taken into account. This may be because a strong agreement follows territorial change, considering that Fortna (2004) argues that stronger peacekeeping devices are installed in cases where the prospect of peace is not bright. In addition, I also reassessed the claims of Werner and Yuen (2005). As they claim, war with consistent battle outcomes results in more durable peace, and a third-party interruption in war termination causes an unstable post-war situation. Although the observed data show that interrupted conflicts are significantly less durable, the analysis here per se is unable to unfold the causal relationship because it may be the case that a third-party tends to intervene in particularly difficult disputes and not vice versa. 
$\Gamma_{\text {Chapter }}$

\section{Illustration: Sino-Vietnamese Conflict}

The statistical analysis presented in the previous chapter indicates that the duration of post-conflict peace is considerably affected by "who gets what" as a result of war. Post-conflict peace is significantly short-lived if territory is transferred through combat, and even more so if wealthy democracies seize the territory. The results indicate that the predictions of the theory in Chapter 2 are consistent with observed patterns. The large- $\mathrm{N}$ analysis, however, does not corroborate the causal mechanism of the theory. It does not fully account for countries' motivation to terminate and resume conflict. This chapter closely examines these causal chains though a detailed historical analysis and illustrates the causal mechanism of the theory. Because the general explanatory power of the theory was examined against alternative theses in the previous chapter, the analysis in this chapter focuses on how violent resource transfer fosters peace and violence after conflict.

This chapter studies the duration of ceasefires between China and Vietnam in the framework of the theory in Chapter 2. China and Vietnam have been involved in a number of armed confrontations, including two full-scale wars, along the land border and in the South China Sea. Although most of their disputes related to territorial sovereignty and have existed since the mid-1970s, the durability of ceasefires significantly varied across them. The ceasefire of the First Sino-Vietnamese War in 1979 broke down quickly, whereas post-war peace after the Second Sino-Vietnamese War in 1987 has been maintained to date. Contrasted with the fragile ceasefire at the land border during the 1970s and 1980s, ceasefires following incidents in 1979 and in 1988 in the South China Sea lasted longer. What explains the duration of these ceasefires?

I first show that the duration of the Sino-Vietnamese ceasefires largely depend on the nature of transferred resources conditional on the gainer's capabilities of utilizing the obtained resources. 
The theory presented in Chapter 2 demonstrates that uncertainty inherent in resource transfer has greater detrimental effects on post-conflict peace when the potential of post-conflict power growth is large. This is because if the potential of power growth is large, the losing party has a great incentive to seek resources whenever it can. Given that the capabilities of China and Vietnam remained unsatisfactory during the 1970s and 1980s, strategic sites along the border were more detrimental to peace than maritime resources in the South China Sea which require investment and technology for usage.

Moreover, I demonstrate that temporal stagnation of the gainer's resource usage causes a fragile ceasefire, motivating the losing party to renege on the initial settlement and to seek some resources back while it can. Specifically, the ceasefire after the First Sino-Vietnamese War in 1979 broke down quickly because during this period Vietnam obtained influence over Cambodia and hilltops along the land border, both of which are strategically important sites, but failed to fully control and utilize the resources. In contrast, China retained the hills through the Second Sino-Vietnamese War in 1987 and successfully utilized them, whereas Vietnam lost the resources that it had occupied by then. Similarly in the South China Sea, a conflict resumed in 1988 when China discovered a major field of maritime resource but failed to conduct actual production. The stability after the incident has been maintained while China's economy was rapidly rising, but broke down in 2014 when people start talking about slowing of China's economy.

Before proceeding, I clarify the usage of terms and limitations of the analysis. To begin with, a military confrontation is a situation in which both adversaries resort to armed force to achieve political goals, regardless of its intensity. All military confrontations are listed, to the limit of existing historical records, regardless of the intensity, size, or length of violent actions. In one case, China and Vietnam engaged in military incidents in the South China Sea in 1988, causing approximately 70 casualties. In another case known as the First Sino-Vietnamese War, China invaded across the land border with massive troops and withdrew in a month, causing 50,000 fatalities. Each of them is counted as a military confrontation.

Moreover, a ceasefire is minimally defined as non-existence of violent incident, without requiring any formal agreement or minimum duration. Although it is difficult to distinguish conceptually a ceasefire and truce between clashes with this definition, it is not substantively problematic because they are merely different interpretations of the same phenomenon. For instance, China and Vietnam engaged in a series of intensive clashes at the land border from 1983 to 1987. The hostility peaked in 1987, constituting what is often called the Second Sino-Vietnamese War. A question arises as 
to whether confrontations in 1983 were a part of the war. One understanding is that a conflict happened and terminated in 1983, resumed and ended in 1986, and resumed again in 1987. Another interpretation is that China and Vietnam fought a five-year war with periodical truces. The difference in these interpretations is not significant in the framework of the theory because unstable ceasefires and long wars are explained by the same causal mechanism; if a post-conflict situation is expected to be unstable, adversaries would not stop fighting to begin with, but would continue to engage in violent actions; hence, long war coincides with short ceasefires, and short war with durable ceasefires.

This study has several limitations. The biggest obstacle in the analysis stems from the limited availability of governmental documents. Because access to internal governmental documents is constrained in China and Vietnam, it is quite difficult to know what policymakers were thinking and discussing during the decision-making process. To overcome this problem, I tried to trace historical processes in detail, using various sources including scholarly research, governmental documents, newspapers and quantitative data.

Another problem is that China and Vietnam have engaged in oral accusations of each other, seemingly exaggerating facts and intentions. Researchers are not free from this problem because it is difficult for them to be completely "neutral" or "objective." Thus, I carefully examined the standing of the authors when I refer to governmental documents and scholarly research.

The analysis proceeds as follows: I first explain why the Sino-Vietnamese conflict is an appropriate case for this study. I then raise two puzzles regarding the duration of ceasefires. To solve the puzzles, I draw predictions from the theory in Chpater 2 and from other competing arguments. Specifically, this study highlights the roles of three core factors: the nature of resources transferred during conflicts, the level of economic and technological development of the country that obtained the resources, and the temporal stagnation of resource usage by the gaining party. Keeping these predictions in mind, I analyze the Sino-Vietnamese conflict in detail. The concluding section presents the summary of findings and predictions regarding the future of their bilateral relationship. Specifically, this chapter prospects that serious confrontations may occur if the economies of China and Vietnam stop growing in the future. Although scholars and policy makers have vocally discussed the effect of the rise of China, the real danger will emerge when China's economic boom is over. ${ }^{1}$

\footnotetext{
${ }^{1}$ Legro (2007) presents the same conclusion, arguing that the economic stagnation possibly results in the transformation of ideas among Chinese leadership. The decline of economic growth may cause the currently orthodox integrationist ideas to collapse and alternative thinking to consolidate as the next dominant idea. This argument and this study are mutually complementing because Legro focuses on the distribution of ideas among Chinese leadership while this study highlights the opportunistic incentives of China's counterpart, i.e., Vietnam.
} 


\subsection{Case Selection}

I study the Sino-Vietnamese conflict primarily because it has seen both durable and fragile ceasefires. Therefore, this case allows me to focus on key causal mechanisms offered by the theory and to disregard many potential explanations. Because I solely focus on the Sino-Vietnamese relationship, many factors can be held constant. For instance, contiguity does not change over time. The same historical legacies precede all incidents. Thus, I can disregard potentially important factors and highlight the causal mechanisms of the theory. Yet, I do not make an argument that the theory is the sole and complete explanation of the Sino-Vietnamese rivalry. Rather, the theory sheds light on interesting dynamics in the relationship between China and Vietnam.

Moreover, the Sino-Vietnamese rivalry, especially the two wars at the land border, is a case for which existing theories such as Fortna (2004) and Werner and Yuen (2005) have trouble offering comprehensive understanding. As described above, two full-scale wars broke out at the land border. The ceasefire following the First Sino-Vietnamese War in 1979 was quite unstable. Military confrontations persisted and eventually escalated to another full-scale war within a decade. Peace after the Second Sino-Vietnamese War has been relatively stable and maintained to date. These observations are not fully consistent with the predictions of existing theories. It is often said that a costly war is less likely to resume because adversaries want to avoid the heavy costs of another war. The first war was very costly, causing 50,000 fatalities. However, the ceasefire failed quickly. Likewise, no peace agreement was reached after the first as well as the second war. However, the second war was followed by stable post-war peace. Fortna (2004, p.155) says that "[t]he stability of peace between China and Vietnam between 1987 and the settling of the border dispute is not

well explained by my argument." Similarly, this conflict is not an ideal case for Werner and Yuen (2005) because the battle outcomes were inconsistent in both wars and no third-party was involved in either war. However, the consequences of the two wars were quite different. Thus, the SinoVietnamese rivalry presents an intriguing challenge to theories of post-war peace. I argue that the key to explaining the puzzle resides in "who gets what" through confrontations.

Another reason for investigating the Sino-Vietnamese rivalry resides in its contemporary implications. As mentioned above, the Sino-Vietnamese relationship has rapidly deteriorated in 2014, primarily due to resource exploitation in the South China Sea. Thus, the illustration in this chapter will shed light on the structure of the ongoing dispute and will provide foresight to deter escalation. 
Specifically, I argue that current conflicts in the South China Sea are caused not by the rise of China, but rather by the (relative) decline of China.

The implications of this case study may not be limited to the Sino-Vietnamese bilateral relationship. Since the end of the World War II, Asian countries and Russia have faced a similar type of unresolved territorial disputes. Russia and Japan have yet to achieve a mutually agreed settlement regarding the four islands called the Kuril Islands in Russia and the Northern Territories in Japan. Similarly, Japan, China and Taiwan have not agreed upon the territorial ownership of the Senkaku Islands, also known as the Diaoyu Islands, in the East China Sea. Japan also has a territorial issue with South Korea over certain small islets named Dokdo in Korean and Takeshima in Japanese. Those disputes are widely recognized as primary obstacles in maintaining peace and promoting cooperation in Asia. The analysis of the Sino-Vietnamese disputes will provide insights into these issues.

\subsection{Puzzles: Ceasefires between China and Vietnam}

The People's Republic of China (hereafter, China) and the Socialist Republic of Vietnam (hereafter, SRV or Vietnam) are known for their long-time rivalry, which was militarized at the land border and in the South China Sea. Their antagonism became clear by the mid-1970s when North Vietnam reunited Vietnam. Although both countries upheld communist ideology, this did not imply shared interests. Vietnam believed that its security was promoted by its influence over Indochina, whereas China was averse to the presence of a strong neighbor on its southern border. Since then, they competed over hegemony in Indochina.

Although all the conflicts between China and Vietnam shared some common traits, the durations of ceasefires varies strikingly across time and place, which yields questions to be answered in this chapter. Most conflicts between China and Vietnam related to territorial disputes and appeared on the surface in the mid-1970s. Therefore, the conflicts were of course mutually intertwined. However, the durations of ceasefires greatly differs across cases. Specifically, I present two puzzles.

Why did China and Vietnam fail to establish durable peace after the First Sino-Vietnamese War in 1979, but achieve a durable ceasefire after the Second Sino-Vietnamese War? The first puzzle stems from a comparison of ceasefires over time, holding the location constant. As mentioned above, the ceasefire following the First Sino-Vietnamese War was significantly shorter than that of the 


\section{SOUTHEAST ASIA}

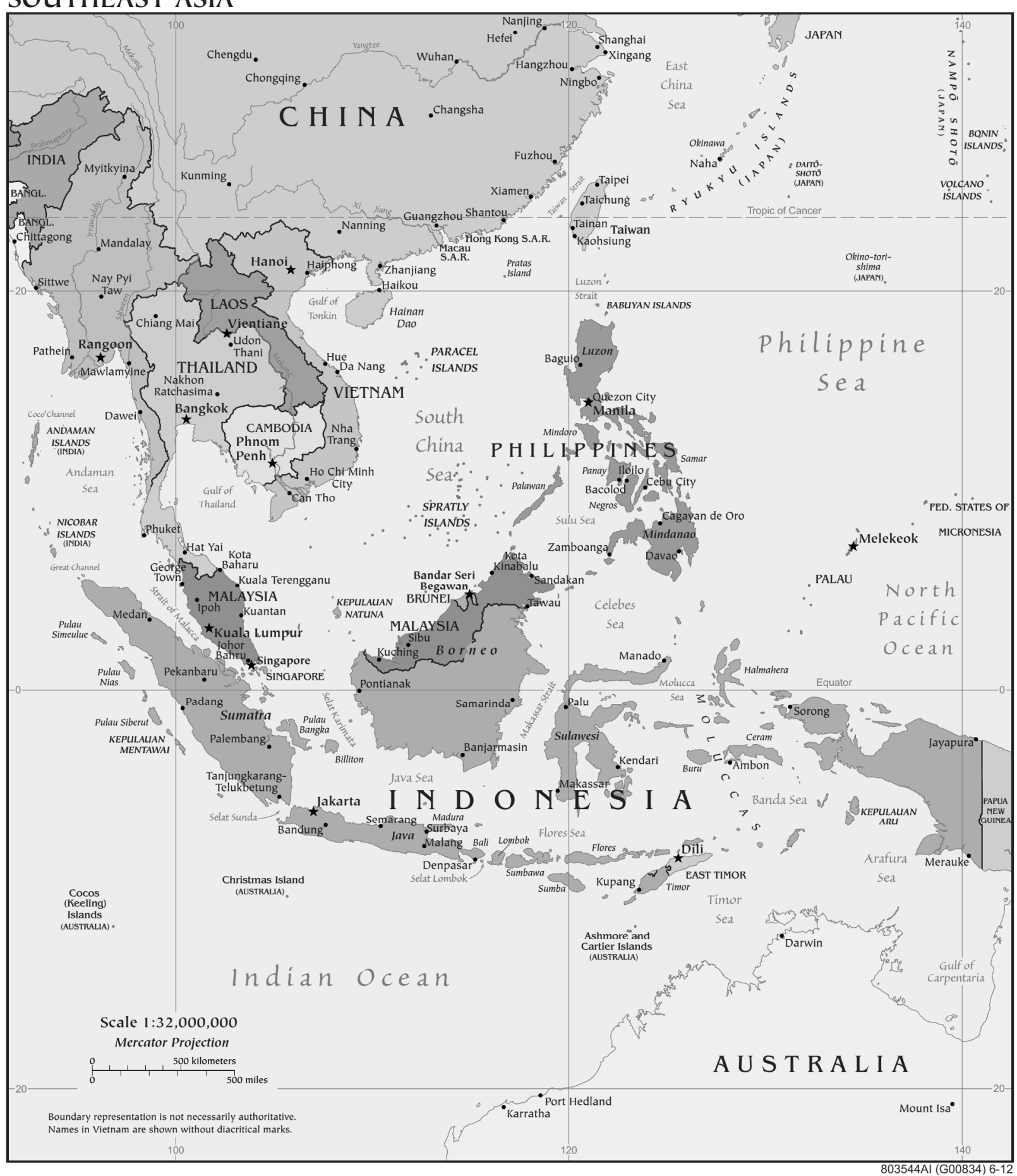

Figure 4.1: Map: Southeast Asia in 2012 (Central Intelligence Agency, 2012) 
Second Sino-Vietnamese War. This is even more intriguing, considering that the first war was very bloody.

Why did the ceasefire at the maritime boundary last longer than that at the land border? The second question arises from a cross-location comparison, holding the period of analysis roughly constant. China and Vietnam engaged in military confrontations along both the land border and the maritime boundary in the 1970s and 1980s. However, ceasefires at the maritime boundary lasted longer than those at the land border. What explains these variations?

\subsection{Theoretical Predictions and Competing Arguments}

The illustration in the following sections is provided with two theoretical predictions in mind. First, the theory predicts that temporal stagnation in the gainer's power growth causes resumption of fighting. According to the theory, conflict resumes if the ex post power-growth of the gainer turns out to be less than expected because such temporal stagnation encourages the losing party to act opportunistically. In the context of the Sino-Vietnamese conflict, fighting must resume when the gaining party's power is relatively decreasing, not when it is rapidly increasing.

Second, the theory predicts that the devastating effects of the temporal stagnation are amplified by the nature of the transferred resources conditional on the levels of economic development. A resource transfer is more disturbing when the new owner can extract more power from the obtained resources because in such a case, the losing party reacts more sensitively to the temporal stagnation of the gainer's resource usage, and then seeks to seize some resources back while it can. A ceasefire is durable if a relatively incapable state seizes resources that require economic and technological capabilities to extract them because it is unable to effectively utilize the resources. Given that the gainer does not have sufficient capitals or technologies, the post-war situation will be volatile if it obtains strategically valuable territories because even an incompetent gainer can take advantage of such territory. In the following analysis, therefore, I pay close attention to "who gets what" in the Sino-Vietnamese disputes.

These theoretical predictions are tested against competing arguments. The analysis in this chapter mainly speaks to historical accounts because existing theories on post-conflict peace has trouble explaining the puzzles. However, let me revisit the arguments of existing studies before I proceed. As mentioned previously, existing theories argue that a ceasefire is durable under the following conditions: (1) when the preceding conflict is costly, (2) when a strong formal treaty is 


\begin{tabular}{lccccc}
\hline & 1st War & 2nd War & SC Sea & SC Sea & SC Sea \\
& 1979 & 1987 & 1979 & 1988 & 2014 \\
\hline Actual observations & a few months & 26 years & 9 years & 26 years & $?$ \\
(1) Cost of war & $\bigcirc$ & $\bigcirc$ & $\times$ & $\times$ & $\times$ \\
(2) Formal treaty & $\times$ & $\times$ & $\times$ & $\times$ & $\times$ \\
(3) Battle consistency & $\times$ & $\times$ & $\bigcirc$ & $\bigcirc$ & $\bigcirc$ \\
(4) Third party intervention & $\bigcirc$ & $\bigcirc$ & $\bigcirc$ & $\bigcirc$ & $\bigcirc$ \\
(5) "Lock-in" & $\triangle$ & $\times$ & $\triangle$ & $\times$ & $\times$ \\
\hline
\end{tabular}

Note: $\times$ short, $\triangle$ intermediate, $\bigcirc$ long.

Table 4.1: Predictions of Existing Theories

installed, (3) when the battle outcomes in the previous conflict are consistent, (4) when there is no third-party involvement, and (5) before parties are "locked-in" the enduring rivalries.

If the first argument was applicable to the Sino-Vietnamese conflict, we would observe durable ceasefires along the land border and fragile post-conflict peace in the South China Sea, considering that the first war caused 50,000 fatalities whereas the incident in the Paracel Islands resulted in approximately 70 casualties.

If the second theory was right in the context of the Sino-Vietnamese rivalry, we would observe no significant difference between the first and second wars as well as between the land and maritime borders because no formal treaty was signed shortly after the termination of these conflicts.

If the third theory was correct, we would observe no difference between the first and second wars in which battle outcomes were not consistent. In contrast, all incidents in the South China Sea must have been followed by durable ceasefires, considering the very short and seemingly consistent fighting there.

Fourth, no explicit intervention was made in all incidents, which fails to explain the difference between the first and second wars. However, the implicit threats from the Soviet Union could have affected the duration of ceasefires. I will elaborate on this argument in the following analysis.

Finally, although it is often conceived that parties are locked in a spiral of violence after a few confrontations, the Sino-Vietnamese hostility did not necessarily cumulate, considering that a stable situation has persisted after the second war. The predictions of these theories are roughly summarized in Table 4.1 .

One of the most plausible accounts highlights the pressure from the Soviet Union. Although the Soviet Union refrained from explicitly intervening in the Sino-Vietnamese conflict, Vietnam was its 
important protégé in Asia and a recipient of economic and military aids. Thus, we can easily imagine that adversaries took into account the possibility of Soviet's intervention when they terminated and resumed conflict.

Two hypotheses are drawn from the Soviet factor. The first hypothesis argues that the intervention by the USSR prevented China and Vietnam from achieving a durable ceasefire because such third-party intervention yielded a settlement that is inconsistent with underlying material conditions. As Werner and Yuen (2005) argue, China may have been more likely to renege on the initial settlement if the Soviet's threats forced it to make concessions in achieving the original settlement. If this explanation is right, we would observe that when threats existed, China conceded gains in conflict that it could otherwise obtain.

Conversely, the second possibility is that the presence of the Soviet Union contributed to stability between China and Vietnam, discouraging both parties from waging military conflict. If this argument is correct, we would observe that a ceasefire becomes fragile as the USSR weakens its commitment to Vietnam. I will elaborate on the role of the USSR in the following analysis.

Another factor is the importance of the issues at stake. It may be that China and Vietnam engaged in recurrent conflicts in some cases because the issues at stake were very valuable to them. If it is correct, we would observe that China and Vietnam resumed fighting when they perceived great value in issues at stake. However, it is difficult to identify how they evaluated issues ex ante of fighting. We must avoid a tautological inference, such as "adversaries fought because the issue at stake was important and we know that the issue was important because they fought for it." It is all the more difficult to identify their evaluation of issues because China and Vietnam were inclined to exaggerate their concerns in oral accusation. In the analysis, I will infer the value of stakes from the external environment in which the two parties interacted.

\subsection{Comparison over Time}

This section examines why China and Vietnam failed to establish durable peace after the First Sino-Vietnamese War in 1979, but successfully achieved a durable ceasefire after the Second SinoVietnamese War. A following explanation will be derived from a detailed examination of historical facts. Through the first war and the following incidents, Vietnam obtained strategically important asset, including Cambodia, but failed to fully utilize it, which motivated China to resume fighting, resulting in the very fragile ceasefire. When China underwent economic reform and acquired the 
strategic hills and when Vietnam lost control over Cambodia in the second war, however, Vietnam did not find an opportunity to fight back against rapidly rising China.

Along the land border, China and Vietnam experienced the most intensive confrontations. Approximately 796 miles of land border separates the two countries, starting at the tripartite point with Laos and extending toward the east, ending at the Gulf of Tonkin as shown in Figure 4.1. The western side of the border from Laos to Lao Cai is a high plateaus whose elevation exceeds 6,000 feet. Eastward of Lao Cai on the Red River continues to be characterized by mountains and hills, although their elevations are considerably lower than that of the western region. Then, rice paddies spread over a small plain field near the Gulf of Tonkin. The area along the boundary is inhabited essentially by ethnic minorities, except for the far-eastern region near the gulf (Hood, 1992, pp.111-114).

China and Vietnam disputed where the land border is actually located, although both of them agreed to uphold the Sino-French treaty in 1887 that designated the border and set a principle of Sino-Vietnamese negotiations thereafter. Territorial disputes arose because the border line was designated by 300 stone border markers which were few and far between. Another problem stemmed from the fact that there were ethnic Chinese living on the Vietnamese side of the boundary and Vietnamese living on the Chinese side.

Although no effective state control had been established over the land border until the mid-1970s, they started severely disputing the issue when their relationship soared. SRV became a potential competitor of China when North Vietnam conquered Saigon in April 1975 and reunited Vietnam after the long Vietnam War. Although China was forced to celebrate the communists' triumph over the West as its official stance, it sensed troubles to come with the Soviet-backed regime because Beijing had parted ways with Moscow by then (Hood, 1992, pp.114-117).

\subsubsection{Road to the First Sino-Vietnamese War}

A number of violent confrontations occurred along the land border during the mid-1970s. A Chinese source reported that more than 400 incidents took place mostly between border guards and local residents in 1975 and that the number exceeded a thousand in 1978 (Xinhua News Agency, 1979a, p.21). The official Vietnam-News Agency also accused China of sending divisions "equipped with thousands of artillery pieces, hundreds of tanks and armored cars, and hundreds of fighter planes" (Mathews, 1978). 
Through confrontations prior to the First Sino-Vietnamese War, Vietnam seized strategically important hills along the border, which caused recurrent confrontations afterwards. "Vietnam reportedly had seized a number of strategic hills hundreds of meters inside Chinese territory and had begun shelling Chinese villages with mortar fire" by mid-December of 1978 (Chang, 1986, p.50).

Considering that Vietnam's economic and military capabilities remained underdeveloped in this period, the strategic hills were very attractive resources for offering the upper hand in conflict. Vietnam's economic performance was very unsatisfactory during this period due to the long Vietnam War, poor administrative capacities, and corruption among political elites. Its economic and military capacities mostly depended on assistance from the Soviet Union (Hood, 1992, p.66). In China, similarly, the economy and society at large were devastated because of the Cultural Revolution from 1966 to 1977. Although the situation started changing in 1978, when Deng Xiaoping took leadership and conducted economic reform, more than half of the population still lived below the poverty line in 1981 (Ravallion and Chen, 2007). Thus, the hills were valuable and exploitable resources for both parties, which explains why confrontations recurred and eventually led to a full-scale war. A historical account claims that "the territorial dispute was a major contributing factor to the Sino-Vietnamese border war in February 1979" (Chang, 1986, p.53).

Another important strategic resource, influence over Cambodia, arose as an issue during the days leading up to the first war, which further intensified the Sino-Vietnamese hostility in the area. Most historical studies claim that the first war was deeply entangled with the Sino-Vietnamese dispute over Cambodia (ex. Hood, 1992, p.58). In 1975, the Khmer Rouge backed by China gained control over Phnom Penh. Because the Pol Pot regime was strongly anti-Vietnam and anti-Soviet and repeatedly intruded into Vietnamese territory, it was a serious threat to Hanoi. Moreover, China and Vietnam believed that Cambodia would serve as a touchstone of their hegemony in Indochina. The Vietnamese authority asserted, in a secret document published in 1978, that China supported regimes in Cambodia and sought to overturn the government in Hanoi to dominate Southeast Asia. On the Chinese side, Li Xiannian, the Vice Chairman of the Communist Party of China, accused Hanoi of trying to colonize Cambodia (Hood, 1992, pp.45-46). Thus, Cambodia had great strategic value for each of them. However, neither party sought economic benefits from Cambodia, which had no significant industries or natural resources. 


\subsubsection{The First Sino-Vietnamese War}

On February 14, 1979, China finally invaded Vietnam from 26 points simultaneously on the borderline.

[E]ight army corps (about 20 divisions) in addition to support units were concentrated near the border. Total PLA [People's Liberation Army] forces available probably numbered about 300,000 soldiers, 700-1000 aircraft, about 1000 tanks, and at least 1500 pieces of heavy artillery. Most of the maneuver forces (essentially tanks and infantry) and all of the aircraft were held in reserve and never committed. The initial attack was made by six or seven divisions, which were later joined by perhaps four more. At the climax of the fighting, in early March, there were roughly 80,000 Chinese soldiers inside Vietnam, with the large majority of them committed to the battle for Lang Son (Jencks, 1979, p.807). ${ }^{2}$

During its initial offense, China aimed at five provincial capitals including Lai Chau, Lao Cai, Ha Giang, Cao Bang, and Lang Son (Jencks, 1979, p.809). In the beginning of the war, "Chinese forces moved six miles into Vietnamese territory within four days, fifteen miles within six days, and finally twenty-five miles deep within nine days" (Hood, 1992, p.52).

However, the People's Liberation Army "did not, and could not, occupy and pacify a solid zone of control behind its leading elements" (Jencks, 1979, p.809). The Vietnamese force "initially had only about 75,000-100,000 border troops and militia. These proved to be much better trained, equipped, and led than anyone expected" (Jencks, 1979, pp.807-808).

The war was terminated when China seized Lang Son on March 5 and announced its withdrawal from the occupied territory, announcing that "[w]e do not want a single inch of Vietnamese territory but neither will we tolerate incursions into Chinese territory" (Xinhua News Agency, 1979b).

The USSR refrained from explicitly intervening in the war. However, China presumably took into account the possibility that the USSR would join the Vietnamese side. Vietnam joined COMECON that is the economic bloc led by the Soviet Union in the summer of 1978. Through COMECON, a greater amount of aid and technical help became available to Vietnam. By the late summer, the USSR provided weapons to Vietnam, in addition to economic assistance from COMECON. Moreover, Vietnam and the Soviet Union signed the Treaty of Friendship and Cooperation in early

\footnotetext{
${ }^{2}$ Original footnotes are dropped by the author.
} 
November, stating mutual defense in a possible crisis (Hood, 1992, pp.46-47). The Soviet's threat certainty contributed to China's "self-restraint" in terms of territorial acquisition in the war.

Historical accounts disagree on who won the war. Some suggest that "[i]t was a total defeat for China" (Bercovitch and Jackson, 1997, p.189). Others claim that "Vietnam perhaps 'lost' the war in terms of sustaining massive property damage" (Hood, 1992, p.59).

An undeniable fact, however, is that the war imposed tremendous costs on both sides. More than 50,000 soldiers lost their lives and 500,000 people were killed in the war, although contradictory figures are provided by various sources (Bercovitch and Jackson, 1997, p.189; Hood, 1992, p.xv). It is also reported that Chinese troops destructed $80 \%$ of the infrastructures and ruined cities in occupied areas (Hood, 1992, p.55). A research describes the destruction as follows.

In Lao Cai city, the Chinese border infrastructure was severely damaged as a result of the invasion and the bridge that connected Lao Cai to Hekou, China was completely destroyed. In Muong Khuong district, the Chinese had laid many landmines along the border near the Muong Khuong crossing point as well as on the roads that lead to the border. The presence of so many bombs and landmines near the border prompted one state official in Muong Khuong to say that the border region was inaccessible for ten years following the attack (Schoenberger, August 2006, p.75). ${ }^{3}$

What did both adversaries acquire in the war? About this time, Vietnam expanded its influence over Cambodia. In December 1978, Heng Samrin stood up to challenge the Pol Pot regime in Cambodia, organizing the Kampuchean National United Front for National Salvation. This internal power struggle in Cambodia gave a legitimate pretext for Hanoi's further intervention against the Khmer Rouge. Vietnam eventually invaded Cambodia on the Christmas day of 1978. On January 7, 1979, the Vietnam-backed Kampuchean National United Front for National Salvation marched into Phnom Penh. The pro-Vietnam regime was installed, placing Heng Samrin as a puppet leader of the country. Five weeks after Vietnam's seizure of Phnom Phnh, China eventually invaded Vietnam and the First Sino-Vietnamese War broke out. Yet, Vietnam successfully retained its influence over Cambodia even after the war.

China reportedly seized sites of which the other claimed ownership. During the war, China claimed that it did not want "an inch of Vietnamese territory." In fact, China withdrew from most of the territories that it had occupied during the war and refrained from establishing permanent

\footnotetext{
${ }^{3}$ Original footnotes are deleted by the author.
} 
control over the disputed areas (Chang, 1986, p.55). However, some report that Chinese troops continued to stay in territory as large as 38 square miles over which Vietnam had claimed ownership (Hung, 1979, p.1040).

\subsubsection{Fragile Ceasefire}

Despite the tremendous costs of the war, the ceasefire did not last long. Beijing and Hanoi started peace negotiations immediately after the war terminated in April 1979. In response to Chinese military withdrawal, Radio Hanoi commented that the Vietnamese government would be willing to join negotiation with China at the deputy ministers' level. It was "evident that both sides were willing to end the hostilities and were relieved that the war was winding down" (Hood, 1992, p.55). However, they failed to reach any meaningful settlement.

The fighting resumed when it became apparent that Vietnam failed to fully control Cambodia, although the ceasefire was maintained for a few months and "[a]s late as early December 1979, China exercised considerable restraint in its order to the border security forces that 'absolutely banned' the use of weapons in dealing with Vietnamese armed incursions" (Chang, 1986, p.49). In the beginning of its invasion of Cambodia, "Vietnam's intent was to strike a quick fatal blow to the Khmer Rouge leadership in Cambodia and take Phnom Penh in a matter of a week or so, and place their man, Heng Samrin, at the head of the puppet government." Hanoi remained optimistic for a while after its victory in Phnom Penh. "Though meeting unexpected resistance, the Vietnamese still found it relatively easy to gain ground against the weaker Cambodian forces" (Hood, 1992, p.50). Although Vietnamese military took control over the area occupied by the Khmer Rouge by the winter of 1980, it failed to completely defeat the guerrillas. "This meant the Chinese had a small victory under their belt in slowing down the Vietnamese military machine" (Hood, 1992, p.64). During the winter dry season of 1981, the Khmer Rouge desperately defended the highlands while more grounds fell into Vietnamese hands (Hood, 1992, p.65). Vietnam's stagnation in Cambodia motivated China to act opportunistically.

Another important resource that caused periodical heavy clashes between 1980 and 1987 was a strategic hill from which adversaries shelled the opponent. The first large-scale artillery exchange occurred in July 1980, and a similar one took place in November 1980 when the two sides clashed for several days. Confrontations following the war, particularly after 1980, "often took the form of artillery duels and involved battalion or even regiment-sized units numbering several thousand mend on each side." It was reported that the number of violent incidents committed by the Chinese 
exceeded 4,000 cases by February 1981. During the 14 months after the end of the war, China accused Vietnam of instigating more than 2,000 armed provocations and the killing of 240 Chinese. Then, "the fiercest and most prolonged fighting took place in mid-1981 when the two sides engaged several thousand troops and fought almost continuously for two months from May to July over a few hills in the Fakashan area of Chana's Guangxi region less than one square meter in area that Vietnam had reportedly seized" (Chang, 1986, pp.79-80).

As fierce confrontations continued, China took over the hilltops in 1984. Chang (1986, pp.80-81) describes the situation as follows:

The [Sino-Vietnamese] clashes [at the border] reached a new peak in April and May 1984, when Chinese and Vietnamese troops once again engaged each other in fierce artillery exchange and ground fighting almost continuously for two months, resulting in heavy casualties and property damage for both sides. During the sustained fighting, Chinese troops proceeded to seize a couple of hilltops that China claimed to be inside Chinese territory but which had been occupied by Vietnam since the war and repeatedly used to shell Chinese border villages for five straight years. This action apparently triggered the unprecedented division-level attack launched by Vietnam against China in early July, in an attempt to recapture the strategic high grounds that Hanoi claimed were inside Vietnamese territory. [...] By late November 1984, the two sides continued to exchange heavy artillery fire in several populated border areas.

What about the role of the Soviet Union? The threat of the USSR did exist in the first war. One argument is that such third-party interruptions create a fragile ceasefires because adversaries are more likely to dishonor such imposed settlements. This hypothesis is consistent with what happened during this period. Another argument is that the pressure from the USSR forced adversaries to maintain peace, credibly indicating that the Soviet Union would intervene if necessary. This thesis seems to be inconsistent with the reality, considering that the Soviet's threats did not deter China from engaging in persistent fighting at the border.

The other alternative argument highlights the issue at stake and argues that the adversaries fight for valuable goods, which is moderately consistent with what occurred between China and Vietnam. It was apparent that Cambodia was a very important issue for both China and Vietnam, which may be why the ceasefire after the first war broke down quickly. However, the argument does not fully 
explain why the border confrontations emerged to the surface the mid-1970s, before the dispute over Cambodia intensified.

\subsubsection{The Second War and Post-War Peace}

Vietnam continued to struggle in Cambodia largely due to "poor economic planning and corruption in the Vietnamese system that was sapping money intended for construction projects." In fact, "[t]he Soviets pointed to poor administration, bad bureaucratic attitudes, general inefficiency, and corruption as factors leading to Vietnamese problems in Cambodia." Therefore, "Moscow pushed for a reorganization of the Vietnamese economy more along Soviet lines and encouraged the dismissal of older economic planners in order to ensure consistency in planning." However, Hanoi did not respond to the Soviet's demand and stuck to existing political and economic systems (Hood, 1992, p.66). Therefore, Vietnamese troops in Cambodia continued to suffer from poor moral and material capabilities. Although they seized areas previously controlled by the Khmer Rouge, some of those locations were retaken (Hood, 1992, p.74).

In early 1985, Vietnam conducted the most intensive offensive maneuvers in Cambodia since the first Sino-Vietnamese War, hoping to seize highlands from the Khmer Rouge. Although the operations inflicted severe damage on the Khmer Rouge, Vietnam failed to defeat it. After almost six years had passed since the invasion, Vietnam, as well as its puppet leader in Cambodia, admitted that they would not win total victory soon (Hood, 1992, p.74).

In addition to the failure of the offense in 1985, internal leadership changes weakened Vietnam's commitment to Cambodia. In December 1986, existing leaders, including Premier Pham Van Dong, Secretary Troung Chinh, and party strategist Le Duc Tho, were purged and replaced by new leadership under Nguyen Van Linh who was believed to be a reformer (Hood, 1992, p,78). At the 6th Congress of the Vietnamese Communist Party, Vietnam officially turned away from a centrally planned economy to a market economy, a process called "Doi Moi (economic renovation)."

Vietnam's weakened commitment in Cambodia caused intensive battles along the land border in January 1987, in a conflict called the Second Sino-Vietnamese War. The incidents marked the highest point of Sino-Vietnamese hostilities since the war in 1979. Confrontations lasted until March 1987, which caused as many as three thousand, mostly Chinese, fatalities (Bercovitch and Jackson, 1997, p.216).

After the ceasefire, the focus of the Sino-Vietnamese territorial disputes shifted from the land border to the South China Sea. Vietnam reduced armed forces deployed along the boundary, and 
completely withdrew field army troops from the border by May 1989 (Womack, 1994, p.499). The border was reopened for trade in November 1988, followed by normalization of Sino-Vietnamese relations in 1991. On 30 December 1999, China and Vietnam signed an agreement to negotiate border issues, although the exact location of the border was left uncertain. Nine years later, they eventually completed demarcation of the boundary (Turner, 2010, pp.278-279).

Seen in the framework of the theory, a contributing factor to post-war stability was the rapid growth of China's economy. As mentioned previously, China underwent economic reform under the leadership of Deng Xiaoping throughout the 1980s. This economic growth in China, which was on the gaining side, discouraged Vietnam from waging another fight to gain the disputed territory. When China and Vietnam signed the border agreement, some Vietnamese individuals "suggested that the agreement had been rushed and that perhaps their government had made too many concessions" (Turner, 2010, pp.279-280). It was reported that Vietnam lost approximately 700 square kilometers [270 square miles] of its potential territory (Shoji, 2006, p.59), which indicates that China, in the 1990s and the 2000s, successfully coerced Vietnam to make concessions and to uphold the deal without resorting to violent means.

The resolution of the issue in Cambodia does not provide a comprehensive explanation for peace following the second war. From the viewpoint of highlighting the issue at stake, it may be conceived that the resolution of the issue in Cambodia led to a durable ceasefire after the war. However, this statement assumes that Cambodia was the vital issue and the territorial issue was not, which contradicts the fact that military confrontations recurred at the land border as early as the mid1970s, that is, a few years before Vietnam extended its influence to Cambodia.

Similarly, the Soviet Union did not play a vital role in preserving the ceasefire following the second war. The USSR maintained its presence in Vietnam at the moment of ceasefire. The New York Times reported in March 1987 that the U.S. Pacific Fleet commander, Adm. James A. Lyons said that "[t]he Soviets have [had] quadrupled the facilities at Cam Ranh and are using it as a major operating base to threaten stability in the region" (Trainor, 1987). It was not until the end of 1988 that the USSR hinted at reducing its commitment to Vietnam. In other words, the Soviet's influence and commitment had been high at the moment of the war's termination and then decreased. If the Soviet's interruption had destabilized the ceasefire as Werner and Yuen argue, the ceasefire after the second war should have been fragile. On the contrary, if the Soviet's commitment had contributed to peace, we should have observed instability after the Soviet's withdrawal.

The summary of key explanatory variables and confounding factors is provided in Table 4.2. 


\begin{tabular}{lccccc}
\hline & 1st War & 2nd War & SC Sea & SC Sea & SC Sea \\
& 1979 & 1987 & 1979 & 1988 & 2014 \\
\hline Actual observations & a few months & 26 years & 9 years & 26 years & $?$ \\
Predictions of theory in Ch.2 & $\times$ & $\bigcirc$ & $\triangle$ & $\bigcirc$ & $\times$ \\
$\quad$ Stagnation & Yes & No & No $\rightarrow$ Yes & No & Yes? \\
$\quad$ Nature of Resources & strategic locations & \multicolumn{2}{c}{ maritime resources } \\
Capabilities & Yes & Yes & No & Moderate & Yes \\
Third party interruption & $\times$ & $\times \rightarrow \bigcirc$ & $\times$ & $\bigcirc$ & $\bigcirc$ \\
Third party enforcement & $\bigcirc$ & $\bigcirc \rightarrow \times$ & $\bigcirc$ & $\times$ & $\times$ \\
$\quad$ Soviet's commitment & high & high $\rightarrow$ low & high & low & no \\
Issue at stake & $\times$ & $\triangle$ & $\triangle$ & $\times$ & $\times$ \\
\hline
\end{tabular}

Note: $\times$ short, $\triangle$ intermediate, $\bigcirc$ long.

Table 4.2: Theoretical Predictions: the Duration of Ceasefires

\subsection{Comparison across Locations}

Although China and Vietnam engaged in violent confrontations in the South China Sea in 1979 and 1988, no serious confrontations occurred between 1979 and 1988. Why did the ceasefire for the maritime boundary last longer than that for the land border? I will demonstrate that the resource transfer in the South China Sea did not lead to a fragile ceasefire because both countries lacked the capabilities to exploit the maritime resources that they obtained. Stability broke down in 1988 when China announced that it had discovered oil fields in the area but failed to achieve actual production. However, military confrontation did not resume until 2014, despite the growing demand for oil because of China's rapid economic development during the 1990s and 2000s.

China and Vietnam also had disputes over the maritime boundary in the South China Sea, particularly for two disputed areas: the Paracel Islands and the Spratly Islands (See Figure 4.1 and 4.2). The Paracel Islands are located 150 miles southeast of Hainan Island. They are also known as Xisha Islands in Chinese and Hoang Sa Islands in Vietnamese. The area consists of 15 islets and a number of major sand banks and reefs. China, Taiwan and Vietnam claim territorial sovereignty over the archipelago.

The other disputed area is the Spratly Islands, which are located 400 miles east of the mainland Vietnam and 60 miles west of Palawan Island of the Philippines. Currently, seven islands of the Spratlys are under Vietnam's control, six islands are under the Philippians' control and Itu Aba Island is under Taiwan's control. The Philippines, Vietnam, China, Brunei and Taiwan have claimed ownership over the islands and surrounding water (Hood, 1992, pp.119-121). 
The Paracel Islands

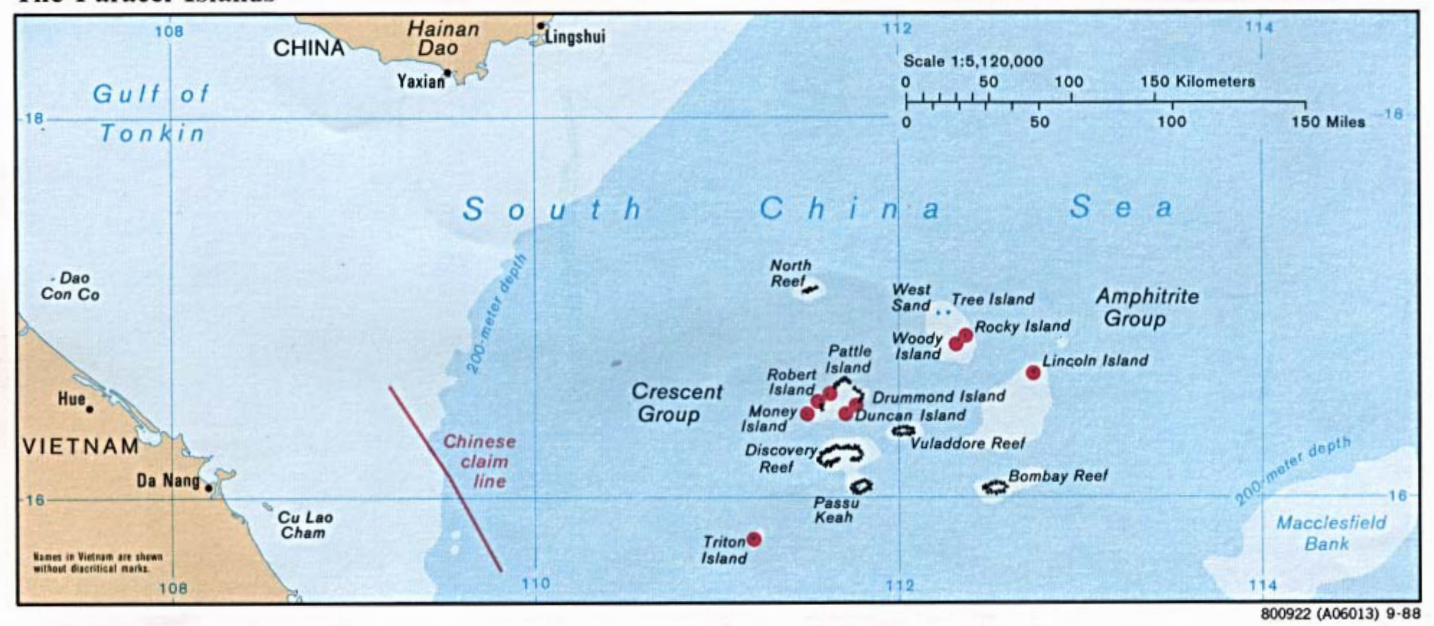

The Spratly Islands

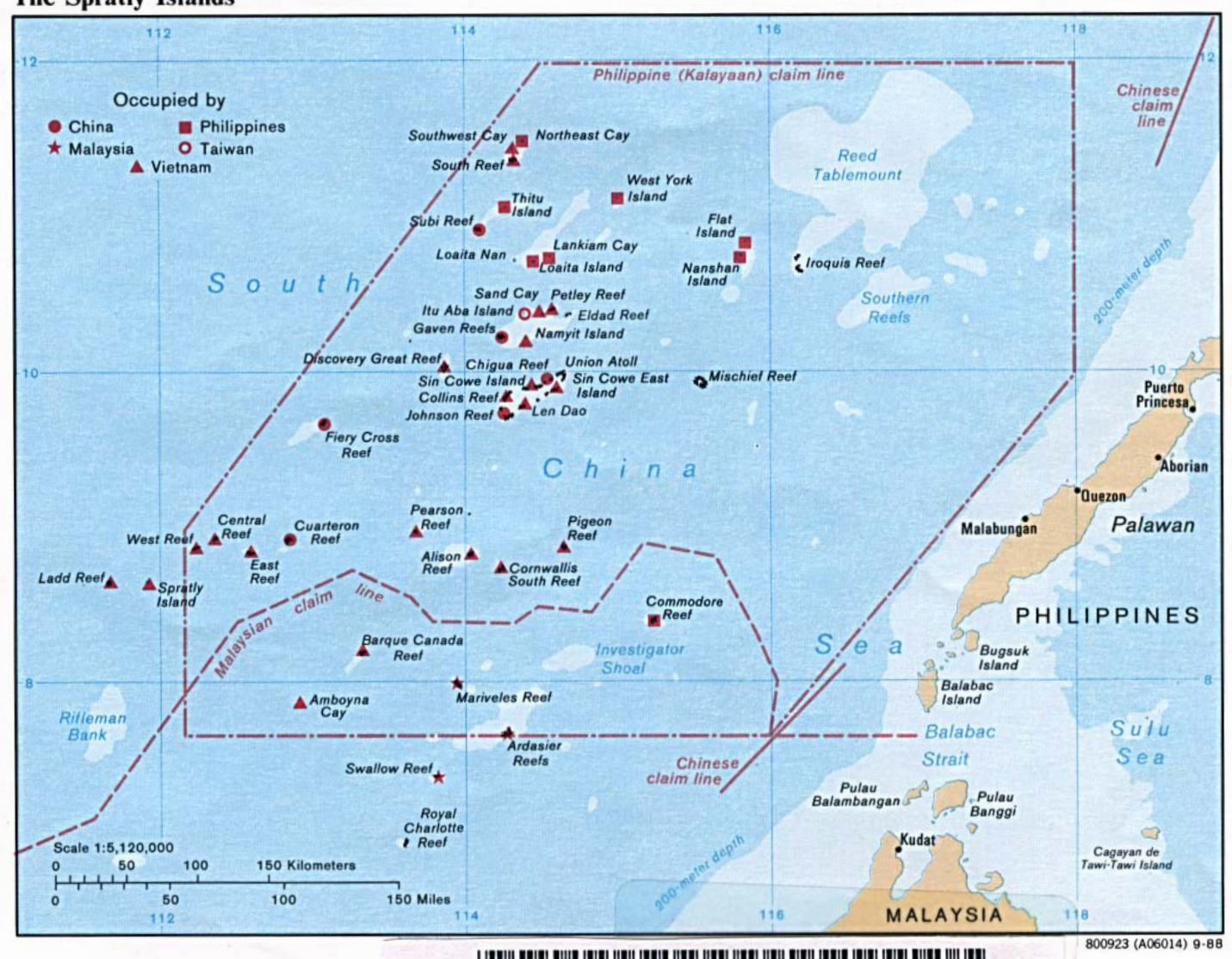

Figure 4.2: Map: South China Sea (Central Intelligence Agency, 1988) 


\subsubsection{Between 1974 and 1988}

A major confrontation in the South China Sea occurred between China and South Vietnam in January 1974. China seized the entirety of the Paracel Islands, and South Vietnam, in turn, occupied a part of the Spratly Islands. The confrontation over the Paracels was not limited to navel clashes but rather escalated to land fighting, which caused twenty to thirty fatalities. In this incident, China seized the part of the Paracel Islands that had been controlled by South Vietnam and hence occupied the entirety of the Paracels (Bercovitch and Jackson, 1997, p.151). In retaliation, Saigon deployed troops to occupy six islands of the Spratlys in February 1974 (Chang, 1986, p.25). Since then, the Paracel Islands have been under China's de facto control and the six islands of the Spratlys have been under Vietnam's control.

The first incident between China and SRV occurred in 1979. Fighting was limited in intensity and did not resume for nearly a decade. Following the end of the Vietnam War, Hanoi took over the territorial claims and control from former South Vietnam. Hanoi reportedly "dispatched troops to occupy the six islands in the Spratly group that had been seized by South Vietnam." Moreover, "[b]y the end of May, the entire Spratly group was marked as part of Vietnamese territory in a Vietnamese map" (Chang, 1986, p.28). China and Vietnam, then, engaged in armed fighting in April 1979 when "China seized a Vietnamese reconnaissance boat allegedly conducting sabotage activities in the Paracels" (Chang, 1986, p.79).

The main resources at stake in the South China Sea were oil and mineral reserve under the seawater. Before maritime resources were discovered in the South China Sea, the main economy in the most of the disputed Islands in the South China Sea was guano (excrement of seabirds used for fertilizer), tropical fruits, lumber, fresh water, and commercial fishery (Hood, 1992, p.121). The islands also had strategic values "because of their control over the main sealanes between the Indian Ocean and the Pacific" (Chang, 1986, p.14). For instance, "[t]he Paracels provide China with an outpost to watch Soviet naval activities in the South China Sea by extending the Chinese presence an additional 200 miles from the mainland" (Hood, 1992, p.129). However, the archipelagos "have attracted new attention since the late 1960s when these areas became known as rich in undersea oil deposits" (Chang, 1986, pp.14-16).

Therefore, the confrontations between China and South Vietnam in 1974 and between China and SRV in 1979 were clearly motivated by their desires for maritime resources and caused a significant transfer of offshore resources. Their ambition for oil and minerals was fueled by the global trend at 
that time. In 1973, the Third United Nations Conference on the Law of the Sea was held in New York; countries discussed exclusive economic zones (EEZs), including the treatment of maritime resources. China claimed its ownership over the natural resources in the surrounding water immediately after its occupation of the Paracels, and Hanoi shared the same ambition. An expert asserts that "China was probably more concerned about its long-term interests in maritime rights in the South China Sea rather than any immediate needs" (Lo, 1989, pp.61-62). When SRV took over the islands in the Splatlys, "Hanoi reportedly had also started to conduct talks with foreign oil companies on the resumption of oil exploration and exploitation in areas adjacent to this archipelago" (Chang, 1986, p.28).

However, this resource transfer did not cause the ceasefire to fail quickly because both countries lacked the capabilities to exploit offshore oil fields by the mid-1980s. Oil exploration in the area was difficult because of the water depths around the Paracels and the Spratlys. The only area where China was able to exploit offshore oil was the shallow water in the Gulf of Tonkin (Lo, 1989, p.6061). According to Hood (1992, p.119), "[t]he water depth in the gulf ranges from around 60 feet to 300 meters, making it attractive for offshore oil exploration." Therefore, China naturally sought cooperation with foreign companies for exploration. Yet, large contracts with foreign companies in offshore oil search had been limited for internal political reasons by 1977.

When Mao Zedong died and the "Gang of Four" was purged, the new leadership, under its "open door" policy, decided to incorporate foreign companies into oil production (Lo, 1989, pp.125126). China established the China National Offshore Oil Corporation (CNOON) in 1982 and signed a number of contracts with foreign companies throughout the 1980s. By the end of 1982, China extended its focus to the South China Sea, announcing its plan for geological surveys around both the Paracels and the Spratlys (Chang, 1986, p.72). China installed "forty rigs in service in 1984, twenty-six in 1985, and thirty-two in 1986."

Despite these efforts, China had not been able to start actual oil production, even in the Gulf, until 1986 (Hood, 1992, p.132). Moreover, "[e]ven after the foreign companies had participated in China's plan for oil exploration in the South China Sea, by the early 1980s their activities were still limited to the shallow sea areas in the Tonkin Gulf and off Hainan Island" (Lo, 1989, p.61).

Similarly, Vietnam suffered from a lack of technological capabilities for extracting maritime resources. Although Vietnam with the Soviet Union reportedly installed three or four oil rigs in the Gulf as early as in 1975 and 1976, "it was learned that probably only two [of the rigs installed in the Gulf of Tonkin] were actually working" in 1984. Even in the shallow water of the Gulf, it was not 
until April 1986 that "the Vietnamese-Soviet drill crews discovered their first major producer [...] in the Bach Ho (White Tiger) field, seventy-five miles offshore, between the port of Vung Tau and Kon Dao Island." Disappointed by the result, Vietnam considered making a contract with Western companies because "[t]he Vietnamese felt the Soviets were unable to exploit rich reserves in the Tonkin Gulf because of poor technology and techniques," although the USSR did not allow Honoi to do so (Hood, 1992, pp.131-133).

If the lack of capabilities contributed to stability in the South China Sea, what occurred in the Gulf of Tonkin where they were capable of exploring? In fact, a couple of incidents took place between armed vessels and fishing boats during this period, which suggests that the negative effects of resources depend on the capacities of the gainer. In December 1978, the Vietnamese Navy fired on Chinese fishing boats in the Gulf of Tonkin, which resulted in the killing of Chinese fishermen (Chang, 1986, p.50). Another serious confrontation occurred in November 1981 when "four Chinese torpedo boats and 'hundreds' of Chinese fishing trawlers allegedly repeatedly intruded in the Vietnamese waters in the Gulf of Tonkin and off the coast of central Vietnam, apparently in the disputed sea areas." Likewise, "[i]n early March, 1982, Vietnamese gunboats fired upon three Chinese fishing trawlers operating at $108^{\circ} 50^{\prime}$ east and $17^{\circ} 40^{\prime}$ north in the Gulf of Tonkin [...]. As a result, 6 Chinese fishermen were injured and 19 were missing." Then, "[a] few days later Chinese gunboats seized a Vietnamese 'spy ship' allegedly operating near the Paracels, apparently in retaliation for the Vietnamese action." A similar confrontation occurred in mid-June when "Vietnam again attacked and seized a Chinese fishing boat in the gulf. In early July, another incident took place when 14 armed Vietnamese boats intruded into Chinese territorial waters in the Gulf of Tonkin and clashed with Chinese fishing trawlers." Next year, "[o]n August 31, 1983, Vietnamese gunboats again intercepted two Chinese fishing trawlers on the high seas in the Gulf of Tonkin and robbed the fishermen of their personal belongings. This was followed by another incident on September 4 when Vietnamese forces again fired at two Chinese fishing boats operating off the Chinese coast in the northern part of the gulf" (Chang, 1986, pp.76-77). Quarrels in the Gulf were clearly related to oil exploration in the area. "Hanoi warned that if China continued to search for oil in the disputed waters in the Gulf of Tonkin, companies which took up those concessions would have to bear the consequences" (Hood, 1992, p.132).

Another account for the stability is the threats of the Soviet Union. In early 1980s, "Vietnam granted the Soviet Union the right to use Hanoi's largest naval base at Cam Ranh Bay, which led to an immediate increase of soviet naval activity off the Vietnamese coast," including the South China 
Sea (Chang, 1986, p.73). As mentioned above, the Soviet's presence was persistently observed until 1988. Thus, it may be that the ceasefire was maintained under the credible threat from the Soviet Union. If this explanation were true, we would observe the ceasefire break down after the USSR weakened its commitment to Vietnam in December 1988.

\subsubsection{Resumption of Conflict in March 1988 and after}

The ceasefire in the South China Sea broke down in 1988, causing more than 70 casualties. In the 1980s, "[t]he Vietnamese troops stationed on two of them - Sinh Ton and An Bang - were specially commended for their determination to build the Spratlies into a 'steel-like archipelago'." Vietnam allegedly conducted military training, constructed a naval base, and "did not hesitate to fire on all unauthorized vessels in the area, including both refugee boats and pleasure yachts." Furthermore, "by April 1983, Hanoi had reportedly taken control of six additional islands in the archipelago" (Chang, 1986, pp.73-74). China, on the other hand, increased its military presence and settlements in occupied areas, conducted air and naval exercises in the disputed water, and instructed its garrisons stationed there to "fire at sight at any unauthorized vessels intruding in the area" (Chang, 1986, p.70-71).

A serious confrontation took place in March 1988 when a Chinese naval vessel went ashore in the waters of the Spratly Islands and attacked a Vietnamese gunboat. The incident caused more than seventy deaths of Vietnamese soldiers. In response, Vietnam strengthened its naval deployment in the area. China, then, announced that they would send marines to "maintain" its sovereignty over the area (Bercovitch and Jackson, 1997, p.233).

The incident was preceded by China's discovery of oil in the Spratlys and its failure to conduct immediate production in the area. As described previously, both countries lacked the capabilities needed to explore resources in the South China Sea, especially in the Spratly Islands, in the mid1980s. In fact, "[u]ntil late 1987, the Spratly potential was largely unknown and unexplored." The situation drastically changed in November 1987 when "China announced it had discovered rich oil and gas deposits under the Spratlys after a survey of 180,000 square kilometers." Despite the discovery, however, China made "no immediate announcement of China's plans to exploit the deposits" (Hood, 1992, p.132). In other words, China failed to show its full potential of extracting the oil and gas reserve. Such stagnation in resource extraction gave its opponent a great incentive to act opportunistically to gain some resources. 
The incident, however, did not result in recurrent fighting despite the adversaries' growing demand for oil. Considering that both China and Vietnam were rapidly developing and that China's onshore oil boom was ending, they should have found the maritime resources more valuable than before. If the value of the stakes solely explained the recurrence of conflict, we would observe conflict resumption in the South China Sea during the 1990s and 2000s. However, no serious confrontation occurred in the South China Sea or in the Gulf of Tonkin.

What explains the stability after March 1988? I argue that the rapid economic growth of China was the key to understanding peace on both the land and maritime borders after 1988. Because China and Vietnam experienced rapid economic growth during the 1990s and 2000s, no opportunity arose for them to seize resources from the opponent. During this period, China periodically indicated "joint development" of resources in the South China Sea and in the Gulf of Tonkin, although most plans for joint development failed. ${ }^{4}$ These actions suggest that China attempted to "appease" Vietnam in order to moderate its fear from the rising China. It must be noted that China experienced two periods of temporal stagnation due to Tienanmen Square in June 1989 and the financial crisis in 1997. Vietnam took no action on these occasions presumably because the Tienanmen incident coincided with Vietnam's withdrawal from Cambodia, which was completed in September 1989, and because Vietnam also suffered from the financial crisis in 1997.

The Soviet's contribution to the durable ceasefire was seemingly limited. As described above, the USSR maintained its high level of presence in the South China Sea until the end of 1988, that is, at the moment of the conflict termination. However, there was no indication that the USSR explicitly or implicitly intervened in the conflict. Moreover, the ceasefire did not fail even after the Soviet's commitment to Vietnam decreased after the end of 1988.

\subsubsection{Rise in Hostility in 2014}

The controversy reemerged on the surface in 2007 when "the [Chinese] government repeatedly warned foreign oil companies that continued cooperation with Vietnam in the disputed waters of the South China Sea would affect their business in China, reportedly causing some international companies to abandon drilling projects in Vietnam. These warnings coincided with enhance law enforcement patrols in disputed water." ${ }^{5}$

\footnotetext{
${ }^{4}$ The idea of "joint development" was publicly declared by Deng Xiaoping in 1984, as a new approach to resolve territorial disputes.

${ }^{5}$ Original footnotes are dropped by the author.
} 
In 2010, it was reported that China arrested nine fishermen, whom it accused of equipping with explosives near the Paracel Islands (The Associated Press, 2010). In 2011, Chinese vessels, escorted by Chinese law enforcement vessels, "severed the exploration cables of Petro Vietnam seismic surveillance vessels on two occasions." ${ }^{6}$ Vietnamese officials stated that this was "the most serious incident" between China and Vietnam since 1988 (International Crisis Group, 2012, p.5).

When Beijing installed oil-rigs in disputed waters of the Paracel Islands in May 2014, a number of serious confrontations occurred. Vietnam claimed that Chinese military as well as civilian ships harassed Vietnamese vessels with water cannons in the Paracels. Vietnamese officials said that China deployed more than 60 vessels in the area and "[t]hese vessels have intentionally hit and collided with Vietnamese law enforcement ships, including those of the maritime Police and Fisheries Control, causing dame in human and property" (Li, 2014).

Although the disputes were clearly motivated by desire for oil, it does not fully explain why several incidents took place in 2014, considering that such desire has existed since the 1990s. ${ }^{7}$ Rather, the incident in 2014 was caused by the prospects of a slowing Chinese economy. In 2014, experts has noted that "the economy has shown signs of slowing in recent years. Real GDP grew by $7.7 \%$ in both 2012 and 2013" (Morrison, 2014, summary). The International Monetary Fund (IMF), in 2014, also projected that the growth of China's real GDP will decrease to $6.5 \%$ on average between 2015 and 2019, whereas China has maintained a growth rate of more than $10 \%$ on average since the economic reforms were first enacted (International Monetary Fund, 2014, p.184). Considering the high stake in the South China Sea, as opposed to the land border, the slowing of China's economy gave Vietnam a great opportunity to regain some resources.

However, it should be noted that China seemingly took the initiative with the recent incidents, whereas the theory projects that Vietnam would exhibit opportunistic behavior under the conditions described above. One interpretation is that China had foresight, anticipating Vietnam's opportunistic actions in the near future. Another interpretation is that China attempted to seize more resources to increase its power, anticipating that its economic boom would slow down. It is difficult to determine which interpretation is correct because information on China's decision-making is limited. Nevertheless, an important implication of the theory is that the current situation in the South China Sea is extremely volatile and the hostility will remain high if the economy of China continues to slow.

\footnotetext{
${ }^{6}$ Original footnotes are dropped by the author.

${ }^{7}$ One explanation for this may be the wide-spread disappointment regarding offshore oil extraction.
} 


\subsection{Past and Future of the Sino-Vietnamese Relationship}

This chapter explained the duration of the Sino-Vietnamese ceasefires, highlighting three factors: the nature of the resources transferred through conflict, the levels of economic development among the adversaries, and temporal stagnation in resource usage.

At the land border, the strategically important resources combined with limited economic capacities of Vietnam in the 1970s and 1980s caused persistent confrontations after the First SinoVietnamese War in 1979. Specifically, Vietnam took two important resources by force from China during and following the war in 1979: influence over Cambodia and hilltops along the border. Both were territories for which the owner needed to make little investment to extract benefits. That is, a new owner could enjoy the value of the territories simply by occupying them. Since the economic, technological and administrative capabilities of Vietnam remained low until 1987, such easy-to-use territories were attractive to them during this period. After the first war, China resumed conflict when it observed that Vietnam had trouble establishing full control over Cambodia. Moreover, when Vietnam weakened its commitment to Cambodia in the end of 1987, China intensified its fighting, causing the Second Sino-Vietnamese War.

Throughout the second war, China retained the strategically important hills that it gained in 1984 and Vietnam lost its influence over Cambodia. Therefore, China was the gainer in the second war. The ceasefire following the second war was durable because the gainer, i.e., China, was rapidly growing its economic power, which discouraged Vietnam from acting opportunistically.

Confrontations in the South China Sea demonstrate the vital role of the capabilities of the gainer in understanding the stability of post-conflict peace. Although the Paracel and the Spratly Islands were considered resource rich, neither party was capable of effectively extracting resources in the deep water in these regions during the 1970s and the 1980s, which is why the occupation of the Paracel Islands by China in 1974 did not escalate into persistent confrontations. It may be true that Hanoi did not want to engage in serious conflicts with China right after the end of the Vietnam War. This account is not fully convincing, however, considering that Hanoi initiated a number of violent incidents in the Gulf of Tonkin during the same period. Hanoi knew that China was incapable of fully extracting resources in the South China Sea and hence violent incidents in the area did not resumed until 1988.

The ceasefire broke down when China discovered maritime resources in the Spratlys but failed to effectively utilize the resources. Vietnam took this opportunity to resume fighting, which re- 
sulted in more than 70 fatalities. Thereafter, however, Vietnam was discouraged from challenging China, which was rapidly rising. Conflict resumed after more than 20 years when China's economy reportedly started slowing.

Before concluding, I address a limitation of the theory, namely with regard to the temporal scope of the theory, which became clear through the analysis of this chapter. It may be that the explanatory power of the theory relatively decreases as time passes because many confounding factors emerge. Therefore, the theory may be less valid in 2014 than in the 1980s, considering that 40 years have passed since the violent resource exchange took place in 1974. In this sense, incidents in 2014 are not the best case to test the theory. Nevertheless, the theory should not be disregarded even after decades have passed since the original conflict, as long as there is a possibility that the loser can take back the resources. All in all, an interesting finding of the theory regarding the South China Sea is that the ceasefires lasted for moderately long periods of time because China and Vietnam were not fully capable of utilizing maritime resources.

This section demonstrates that the key to explaining the Sino-Vietnamese confrontations is "who gets what" through violent interactions. Scholars have paid great attention to each of the issues at stake and the power of adversaries in understanding international conflicts. They have addressed China's expansion in the South China Sea and the rise of China. However, this study shows that the combination of the two factors is vital to understanding the Sino-Vietnamese rivalry and recurrent conflicts in general. Although people tend to think that oil and mineral deposits always cause troubles among nations, the Sino-Vietnamese case indicates that is not the case if adversaries are incapable of utilizing such resources. If such countries are in dispute, strategically important locations are more detrimental to peace than natural resources, such as oil. Moreover, the analysis of this chapter indicates that post-conflict peace fails due to opportunistic behavior by the belligerent, rather than their fear for the rising opponent.

What does the theory project about the future of the Sino-Vietnamese rivalry? The theory predicts that China and Vietnam will possibly engage in violent confrontations if the economy of China or Vietnam stops growing and that they will occur in the South China Sea because the adversaries will find an opportunity to seize their rivals' maritime resources. Scholars as well as policy makers stressed on the rise of China and its positive and negative implications to peace in Asia and in the world. This study, however, suggests that the real danger will emerge if China stops growing. 


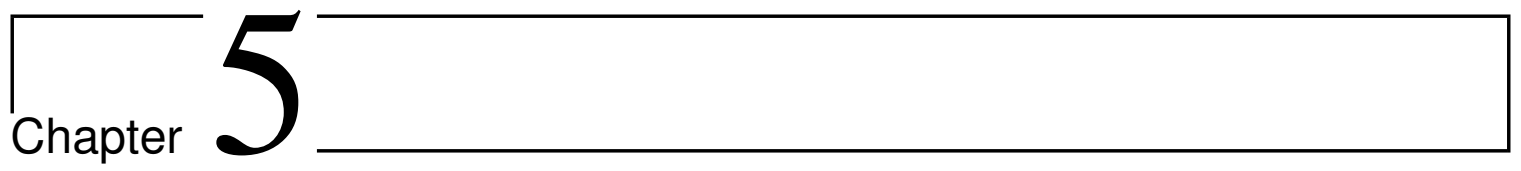

\section{Conclusion}

This project started with a theoretical, empirical and normative question: Why do adversaries often fail to construct peace even after bloody fighting? Some conflicts have led to stable peace, whereas others have resulted in another round of fighting. Between 1946 and 2004, more than 40\% of ceasefires broke down and many of them collapsed within a few years. Although most existing theories of conflict assume that fighting moderates fundamental causes of conflict, countries do resume brutal fighting within several years. Why do they resume conflict if the initial conflict truly modified the causes of confrontation? Why do they resort to force again rather than peacefully renegotiate when dissatisfaction regarding the initial conflict arises? Why do they terminate the initial conflict in the first place if they dishonor the settlement and resume fighting later? This study answered these questions by elucidating the general mechanism through which adversaries resume fighting and identifying factors that make some ceasefires to last longer than others.

In this concluding chapter, I first revisit the arguments and findings of this study, and then discuss the issues to be elaborated in future research. In the second section, I lay out the contributions of this research beyond post-conflict peace, suggesting four avenues of research for which this project may have implications. These include contemplation of multiple causes of conflict, heterogeneous types of resources, heterogeneous sources of power and the role of war. The final section provides policy recommendations to construct post-conflict peace. 


\subsection{Explaining Post-Conflict Peace}

\subsubsection{Why and Under What Conditions Does Fighting Resume?}

This study demonstrated that uncertainty regarding the degree to which resources acquired during conflict empower the gainer determines the stability of post-conflict peace. Conflict often causes adversaries to seize resources such as territory and policy concessions from the opponent. Resource acquisition during conflict presumably results in a post-conflict shift in power, while the extent of transition largely depends on "who gets what." Although the adversaries take into account such a shift in power when they decide whether to terminate fighting, they are not always certain about how much power the gaining party extracts from the obtained resources. Even the new owner is unsure how the resources can be utilized until they are actually exploited. Therefore, uncertainty brings instability into settlement of the initial conflict because the opponents possibly seek to renege from the initial agreement when the growth of the gaining party turns out to be less or more than expected at the moment of settlement.

Post-conflict peace breaks down precisely because of the losing partys opportunistic behavior, and not out of fear of the growing opponent. Observing the actual growth, they can revise the original agreement either through peaceful renegotiation or violent fighting. The theory showed that the losing party chooses to fight when it realizes that his opponent's resource extraction is less than expected because it seeks to gain some resources back before the opponent fully utilizes the resources. In contrast, when the losing party observes that the opponent's power growth is more than expected, it appeases the opponent through peaceful renegotiation rather than resumes conflict because it does not want to fight with the strong opponent.

The dynamics in the post-conflict phase greatly influence the adversaries' initial choices of terminating conflict. Adversaries never terminate fighting when conflict is expected to resume or it is too costly to maintain ceasefire through appeasement. The losing party agrees to settlement when it does not have to give up a great amount of resources to maintain post-conflict peace. Thus, the window of opportunity for settlement is quite limited when adversaries are interacting in the shadow of shifting power.

However, this study demonstrated that under certain conditions, uncertainty encourages them to agree to settlement in a situation where they would otherwise not, while uncertainty also causes opponents to resume fighting. In other words, uncertainty modifies the devastating effect of a commitment problem stemming from shifting balance of power. It should be remembered that the losing 
party has an incentive to take opportunistic behavior in the post-conflict phase. The same motivation encourages it to take the risk of accepting a potentially unstable ceasefire, hoping to gain some resources back later.

The impact of uncertainty is modified or reinforced by various factors such as the amount of resources transferred in the initial conflict, the capabilities of the gaining party, and the nature of resources. Although uncertainty is omnipresent in interaction among nations, there effects vary across cases, depending on the nature of conflict. Adversaries are more likely to prolong conflict and, if a ceasefire is reached, to resume fighting when the post-conflict power growth is large because the declining party, ceteris paribus, has a greater incentive to engage in opportunistic behavior in such cases.

First, a decisive victory by one side causes adversaries to prolong conflict and to return to fighting if a ceasefire is reached. If one party gains a great amount of resources in the initial conflict, settlement becomes hard to achieve because the losing party expects that it will be very expensive to maintain peace with the gainer who obtains so many resources to exploit. This explains why adversaries often prolong conflict even after the outcome of conflict becomes apparent, as Japan did in World War II. Although such a decision seems irrational, this study suggests that countries sometimes keep fighting merely because the shadow of expensive post-conflict peace made them desperate. The same logic explains why weak states often resume fighting against strong states. For instance, in 1941, Finland resumed fighting against the Soviet Union, which seized more than 10\% of Finlands territory in the preceding Winter War.

The second factor is the gaining party's capabilities of exploiting newly obtained resources. If the gainer becomes more capable, a ceasefire becomes less likely and fighting is more likely to resume. The capability of extracting resources is affected by economic wealth and political institutions. Wealthy countries have more capital and technology. Inclusive political institutions have political leaders who invest the benefit of resources in public goods, such as national security, whereas autocratic leaders tend to distribute the spoils of fighting among political elites. Thus, wealthy democracies are more effective in exploiting resources such as territory. In fact, because the town of Nogales was divided into the United States and Mexico in the 19th century, the American side has flourished, whereas the Mexican side has long remained underdeveloped due to a lack of capital and political instability.

This argument may help us to understand why democracies, particularly the United States, are likely to fight absolute war such as World War II, the Afghanistan War and the Iraq War in 2003. 
People claim that the United States is so "exceptional" that it imposes regime change upon total victory, which is upheld by the "American creeds." This study implies that wealthy democracies such as the U.S. are more capable of extracting resources, which discourages adversaries from agreeing to settlement in fear of post-conflict growth.

Finally, this study demonstrated that the durability of ceasefire largely depend on "who gets what" in conflict, that is, the nature of resource conditional on the gainer's capabilities. Suppose that there are two types of resources: potential colonies and "lootable" resources such as diamonds and timber. They differ in the extent to which an owner must invest to extract the benefit. Countries must invest in political and economic infrastructure to fully cultivate colonies, whereas almost anyone can easily exploit and consume "lootable" resources. Given that the gaining party is sufficiently capable of exploiting resources, a ceasefire becomes less likely and fighting is more likely to resume when the gainer obtains potential colonies as opposed to "lootable" resources. Provided that the gainer is insufficiently capable, the relationship reverses, that is, "lootable" resources are more detrimental to peace than potential colonies.

These implications suggest that conflict leads adversaries to another confrontation or durable post-conflict peace depending on the nature of conflict, but it is not an effective solution to all international disputes. In other words, the utility of violence in international relations, if any, depends on the nature of conflict. Conflict helps opponents effectively solve dispute when poor autocracies compete over potential colonies. In contrast, conflict is ineffective solution to international disputes when wealthy democracies are involved in disputes, particularly over potential colonies, and when poor autocracies fight over strategically important territories or "lootable" resources. This finding is consistent with literature claiming that "lootable" resources significantly cause civil war, which is usually fought by poor and weak political entities.

This argument may also complement literature on democratic peace, indicating that wealthy democracies are hardly able to solve their disputes through violence, which in turn may discourage them from resorting to forces to solve their disagreements to begin with.

\subsubsection{Findings of Empirical Analysis}

The theory renders a number of empirically testable implications, which were tested through quantitative and qualitative methods. Chapter 3 examined the core implications of the theory though statistical analysis, using data on ceasefires between 1946 and 1998 combined with data on territorial change. The analysis presented three important findings. 
First, it was demonstrated that resource transfer, i.e., territorial change, during conflict causes shorter post-conflict peace. The theory claimed that resource transfer in conflict causes an unstable ceasefire due to uncertainty inherent in such resource redistribution. As the theory predicts, a ceasefire after territorial change is 13 times more likely to resume than one without territorial transfer at a given time.

The effect of territorial change is distinct from that of territorial disputes. Although territorial disputes are often considered difficult to solve, territorial change has a negative impact on peace even if territory is not the primary issue at stake. On top of that, territorial disputes are more prone to peace if no territorial transfer takes place. That is, actual territorial change plays a key role in explaining the duration of a ceasefire, as the theory argues.

Moreover, territorial change has an effect on peace, independent of post-conflict shifts in power. Even if we hold the post-conflict power growth constant, territorial change exhibits a significant impact. Thus, territorial change leads to an unstable peace not because it causes shifts in power. This finding, along with the theory, suggests that power growth per se does not lead to resumption of fighting but uncertainty or external shock inherent in it does.

Second, the impact of territorial change is reinforced or modified by factors such as the amount of resources transferred and "who gets what" in conflict. As the theory expected, ceasefire is less durable when larger resource transfer takes place, i.e., larger territory is exchanged. Moreover, who acquires what type of territory matters significantly. Specifically, fighting is most likely to resume when wealthy democracies acquire large and densely populated territory. For instance, after 10 years of settlement, the likelihood that conflict resumes is approximately $20 \%$ higher if wealthy democracies acquire territory, compared with cases where poor autocracies occupy the same land. After 30 years, the possibility that a ceasefire is still maintained decreases to $30-40 \%$ if wealthy democracies gain territory, while the probability remains as high as $90 \%$ if poor autocracies are the gainers.

Finally, the analysis suggested that the terms of settlement are mostly inconsequential to postconflict peace. Although the terms of agreement sometimes help adversaries to modify uncertainty or clarify procedures, they do not force them choose a particular path because they can renegotiate and revise the terms if necessary. Previously research has indicated that the terms of settlement matter in explaining post-conflict peace. Yet, its effect more or less disappeared when the impact of territorial change is taken into account. This may be because a formal agreement is epiphenomenal 
to territorial change such that a demilitarized zone is likely to be installed when territorial change occurs.

The findings of statistical tests are complemented by a detailed examination of the Sino-Vietnamese rivalry in Chapter 4 . The Sino-Vietnamese confrontation took place at the land border and in the South China Sea. Conflicts in both locations involved territorial disputes and appeared on the surface in the mid-1970s. Yet, the duration of ceasefires greatly varies across time and places, although they were inevitably mutually intertwined.

Along the land border, China and Vietnam fought two full-scale wars in 1979 and 1987. Although the first Sino-Vietnamese War in 1979 inflicted considerable costs on both sides, China and Vietnam failed to achieve a stable peace following the war. A series of military confrontations persisted, and eventually escalated into another full-scale war in 1987. Since then, however, China and Vietnam have maintained a relatively stable situation along the border, which was confirmed by a formal agreement.

Comparing with the fragile ceasefire along the land border, the ceasefires in the South China Sea lasted longer while adversaries competed over very valuable resources, i.e., oil. After both China and (South) Vietnam seized a part of the archipelagos through armed operations in 1974, no serious military confrontations had happened in the area except for 1988 and 2014.

The case study explained the durability of the Sino-Vietnamese ceasefires, shedding light on "who gets what" and temporal stagnation in each conflict. At the land border, the strategically important resources combined with limited economic capacities of Vietnam in the 1970s and 1980s caused persistent confrontations after the First Sino-Vietnamese War in 1979. Specifically, Vietnam seized influence over Cambodia and hills along the border, both of which are strategically valuable resources. Since the economic, technological and administrative capabilities of Vietnam had remained low until 1987, such easy-to-use territories were attractive to them during this period. After the first war, fighting resumed when China observed that Vietnam had trouble establishing full control over Cambodia, that is, that Vietnam's resource usage was less than expected. Through the second war, China retained strategically important hills that it gained in 1984 and Vietnam lost its influence over Cambodia. Therefore, China was the gainer in the second war. The ceasefire following the second war was durable because the gainer, i.e., China, was rapidly increasing its economic power, which discouraged Vietnam from acting opportunistically.

Confrontations in the South China Sea demonstrate the vital role of capabilities of the gainer in understanding the stability of post-conflict peace. Although the Paracel and the Spratly Islands 
were considered to contain maritime resources, neither party was capable of effectively extracting resources in the deep water in these regions during the 1970s through the 1980s. Therefore the confrontation in 1974 and 1979 did not provoke successive violence. The ceasefire broke down when China discovered maritime resources in the Spratlys but failed to effectively utilize the resources in 1988. Vietnam took this opportunity to resume fighting, which resulted in more than 70 fatalities. Since then, however, it was discouraged from challenging to China that was rapidly rising. The conflict resumed after more than 20 years when China's economy reportedly started slowing.

\subsubsection{Future Avenue of Research}

This section discusses the future avenues to which the empirical and theoretical analysis of this research can be extended. Regarding the empirical tests, more extensive statistical analysis will be conducted to illuminate the full implications of this research. First, this research can serve as a study on the duration of conflict, in addition to the duration of post-conflict peace. Although this dissertation focused on the duration of ceasefires and the effect of resource transfer, the implications of the theory are not limited to them. Specifically, this project presents conditions under which fighting is terminated and conflict results in absolute war. Such implications will be empirically tested in future research.

Second, the analysis in Chapter 3 could be complemented with an examination of the duration of ceasefires following territorial conflict. In Chapter 3, I examined the core hypotheses of the theory, using data on ceasefires and essentially comparing ceasefires with and without resource transfer. To complement the analysis, it will be helpful to limit the population to ceasefires involving territorial change and then analyze whether "who gets what" well explains variation among resource transfer.

On the theoretical side, I propose three extensions that can be done in the future research. First, the theory can be extended so that it highlights the political-economic aspects of tactical choices in combat. The theory in Chapter 2 treats destruction in conflict as exogenously given for simplicity. Yet, if resource transfer has such a significant impact on post-conflict situations as this study suggests, adversaries may have incentives to choose targets of attack, taking into account what effect the targeted resources have on post-conflict peace. In fact, existing studies, such as Downes (2011) and Pape (1996) suggest that there exists significant variation in the selection of targets during conflict: Some attack civilians while others aim at the military. The framework of this theory will provide implications to such target selection during combat, analyzing adversaries' choices during combat in the shadow of post-conflict peace. 
Second, I can extend the theory by endogenizing political and economic institutions of opponents. The current theory assumes that countries' capabilities of extracting resources are exogenously given and that economic wealth and political institutions determine the capabilities in applying the theory to the real world. It will be helpful to explicitly model such institutions and actors' decisions of resource extraction for the purposes of clarifying the causal logic and generating more implications.

Finally, this research may speak to the democratic peace literature and to the decrease of international conflict if it includes conflict onset in analysis. In this research, I assumed that countries are at fighting in the beginning and did not analyze why they do. It may be interesting to analyze onset, termination and resumption of conflict as a continuous process. Such a framework may imply that countries refrain from initiating conflict when they anticipate that violence will result in an unstable post-conflict situation. In contrast, countries may resort to force more casually when they anticipate that fighting will not devastate their relationship, regardless of the result of conflict.

The theory in Chapter 2 suggests that wealthy democracies are less likely to resort to force in solving international disputes, knowing that the post-conflict situation will be quite unstable. This may provide a novel account for the democratic peace and the fact that the number of international conflicts, particularly territorial war, have decreased since the mid-20th century (Gleditsch and Pickering, 2014). World-wide development of technology and spread of democracy now enable many countries to exploit fruits from territories effectively, which prevents adversaries from achieving sustainable peace. This, in turn, may cause them to refrain from initiating conflicts over territories to begin with, in fear of being entrapped in ever-lasting confrontation.

\subsection{Implications for International Relations}

This study primarily explored why and under what conditions adversaries fail to construct durable peace after conflict. However, the framework of this study also speaks to five issues in international relations. First, this study offered an insight to the literature on war in general, demonstrating that multiple causes of conflict mitigate the detrimental impacts of each other. Existing studies argue that two important causes of war are uncertainty and a commitment problem often stemming from shifting power. Then, scholars have vigorously elaborated on how to moderate the negative impact of uncertainty, highlighting domestic institutional features (ex. Fearon, 1994; Goemans, 2000; Schultz, 1998, 2001; Smith, 1998; Ramsay, 2004), military strategies such as mobilization and alliance for- 
mation (ex. Fuhrmann and Sechser, 2014; Slantchev, 2005; Smith, 1998), and the roles of mediating devices (ex. Fang, 2010; Gilligan, Johns and Rosendorff, 2010; Kydd, 2003, 2006).

On the other hand, it has been a difficult issue for scholars what modifies the detrimental effect of shifting power, i.e., a commitment problem. Leventoğlu and Slantchev (2007), Reiter (2009), and Weisiger (2013) examined how war helps and does not help countries modify a commitment problem. On commitment devices under international anarchy, few studies have been developed but Ohtsuki (2013) which proves that democratization by external forces serves as a commitment mechanism that ensures a non-extractive relationship after war.

This project illustrated one of mechanisms through which the impact of a commitment problem is moderated. Precisely, uncertainty encourages adversaries to settle conflict even in situations that they are unable to uphold the agreement in the shadow of shifting power because uncertainty causes them to take more risks of terminating conflict in hope of obtaining a better deal in the future.

This suggests that informational and commitment problems do not always turn out to have bad chemistry. To date, few researchers apart from Wolford, Reiter and Carrubba $(2011)^{1}$ explicitly theorize the interaction between informational and commitment problems. ${ }^{2}$ Although they emphasizes the negative implications of multiple causes, this study offered conditions under which a lack of information enables countries to achieve peace in the shadow of shifting power.

Second, this study has relevance to literature on endogenous power shift. As mentioned above, shifts in power attracted scholarly attention as a cause of conflict (ex. Acemoglu and Robinson, 2000; Fearon, 1995; Powell, 2006). Most studies assumed that such shifts in power are exogenously driven and that some countries are inherently rising while others are doomed to relatively decline due to an uneven rate of industrialization, demographic growth and so forth (ex. Kim and Morrow, 1992; Organski, 1968; Organski and Kugler, 1980; Powell, 1996, 2006, 2012).

Shifts in power distribution, however, might be a result of actors' choice. For instance, decisions to settle conflict may put one party in a deteriorating position and the rising party may have an incentive to renege from the agreement. To the best of the author's knowledge, there are only two theories that allow players to decide whether to trade sources of power (Fearon, 1996; Schwarz and Sonin, 2008)..$^{3}$

\footnotetext{
${ }^{1}$ Although Wolford, Reiter and Carrubba (2011) assumes that shifts in power are externally driven, this study focuses on endogenous power transition.

${ }^{2}$ Powell $(1996,1999)$ analyze "the combined effects of a shifting distribution of power and of uncertainty about the extent of an adversary's ambitions (p.749)" but limit the scope to the situation where "the declining state's deteriorating position is expected to bottom out eventually" (p.750).

${ }^{3}$ Wagner (1994) also elaborates on this issue. Fearon (1996) formalizes "bargaining over objects that influence future bargaining power" and proves that war rarely occurs because countries are better off by making a series of small concessions rather than wage war unless resource transfer generates a significantly large change in the odds of winning
} 
Although these studies are mostly theoretical, this study contributed to the literature by providing empirically testable conditions under which an endogenous shift in power results in conflict and showing that the effect of endogenous power shift can be mitigated by uncertainty.

Third, this study explicitly introduced heterogeneous types of resources and illuminated their impacts on peace, although existing theories on international conflict pay relatively little attention to goods at stake as a cause of military confrontation. ${ }^{4}$ Scholars have elaborated on so-called "indivisible goods," 5 "tangible resources," and "cumulative resources" that affect future shifts in power. ${ }^{6}$ Empirical literature such as Goertz and Diehl (1992) also demonstrates that an increase in the size and population of exchanged territories makes war more likely and more frequent. Similarly, Tir (2003) shows that the "tangibility" of territories exchanged through peaceful or violent interaction significantly affects the prospect of future conflict.

Acknowledging these works, this project explicitly introduced heterogeneous types of resources in the analytic framework. Specifically, two types of resources are included in the theory: one, such as colonies, which requires investment to exploit but generates great benefits if developed by a capable owner; and the other, such as diamonds, which almost anyone can easily exploit but whose benefit does not increase considerably even if a capable owner exploits it. This approach not only elaborates on the important, but presently neglected, roles of goods at stake in disputes but also provides empirically testable implications.

In addition to heterogeneous type of resources, this study highlighted the effect of actors' abilities to convert resources into military power, which may elucidate a novel mechanism through which

in future wars. Then he implies that "offense-dominance" may cause such an unstable situation. Schwarz and Sonin (2008) also clarify conditions under which appeasement through a series of small concessions may not be feasible. Specifically, it could happen when players have decreasing marginal utility of consumption because more and more concessions are required to appease the gaining party as it receives more resource transfer. Yet the authors remain unclear as to how players with "decreasing marginal utility of consumption" can be identified in the real world.

${ }^{4}$ In contrast with the scarce attention to disputed goods in interstate conflicts, the nature of resources is an essential component of civil war literature, particularly since the publication of Collier and Hoeffler (2004) who link between primary commodity exports and the onset of civil war. For instance, Journal of Conflict Resolution publishes a special issue on primary commodities and civil war in 2005, in response to Collier and Hoeffler (2004). So far, empirical studies provide mixed results on whether primary commodities make civil conflicts more likely and persistent (ex. Fearon, 2005; Le Billon, 2001; Lujala, 2010; Ross, 1999, 2004a,b).

${ }^{5}$ Fearon (1995) suggests that indivisible goods may prevent adversaries from striking a bargain and some researchers suggest that sacred space may fall into that category (ex. Hassner, 2003). However, Powell (2012) asserts that indivisible goods per se do not cause war because if adversaries are able to credibly commit to follow through with an agreement, they will conduct a lottery in which either of them wins the whole goods with a certain probability and the dispute will be solved. Therefore, an essential problem resides not in indivisible goods but in adversaries' incentives to renege from an agreement, i.e., the lack of credible commitments.

${ }^{6}$ Tir (2003) examines how the "tangibility" of exchanged territories influences the occurrence of future conflict. Fearon (1995) underlines the impact of resources that affect shifts in power, whereas Fearon (1996) theoretically demonstrates that resources which affect shifts in power usually do not cause war under defense-dominance. Van Evera (1999) posits what is probably the most extensive analysis of such resources that "enables the protection or acquisition of other resources" (p.105), although he avoids making a claim about its empirical validity. He suggests that the degree to which the resources are cumulative depends on technological evolution, change in military doctrine, offense-defense balance, and loss due to transfer such as residents' resistance. 
domestic economic and technological development besides political institutions spreads over security issues. Scholars have so far explored various characteristics of actors to explain the dynamics of war and peace. The most notable factor is material capability of imposing damage on others, ${ }^{7}$ domestic political and economic institutions, ${ }^{8}$ and inter-subjective ideas, beliefs, and preferences. ${ }^{9}$

Acknowledging these contributions, this study specifically focuses on actors' capabilities in exploiting resources, which are largely defined by economic wealth and technologies to be invested. This setting may envision a novel mechanism through which domestic economic and technological development besides political institutions spreads over security issues, which is relevant to the current situation in Asia subsuming rising China, India, and so-called "tigers."

Finally, this paper advocates reconsidering the role of conflict in international relations, demonstrating that the utility of war is conditional on the type of resources at stake and the characteristics of gainers. Although Clausewitz's classical notion that "war is an instrument of policy" has been widely accepted by scholars, they have paid little attention to the question of whether war truly helps countries to solve international disputes (Von Clausewitz, 1976, p.605).

Looking back at historical records, war in some instances leads to stable peace, whereas it is followed by recurrent military confrontations in others. This simple observation contrasts with most of current literature asserting that war uniformly mitigates its causes (ex. Blainey, 1988). ${ }^{10}$ A normative assertion seemingly exists behind the treatment of war as an ultimate solution to international disputes: war must play a positive role, if any, considering such huge human and material sacrifice. In fact, however, some wars clearly fail to create peace despite intolerable destruction. If this is the case, why do countries fight bloody wars? Why do they fail to achieve peace even with their citizens'

\footnotetext{
${ }^{7}$ As Legro and Moravcsik (1999) extensively examine, material capability consists of the long-standing core assumption of realists' paradigm and this predominant focus on material capability is widely employed beyond proclaimed realists. More particularly, material capabilities involve soldiers, arms, and geography, whereas military technologies, military doctrine, and tactics or economic wealth are also considered important (Biddle, 2004; Posen, 1984; Sechser and Saunders, 2010).

${ }^{8}$ For example, see Bueno de Mesquita et al. (2003); Fearon (1994); Frieden (1994); Goemans (2000); Russett (1995); Zakaria (1999). Institutions are the main focus of so-called liberalists' paradigm as well as the democratic peace literature.

${ }^{9}$ For example, see Finnemore (2004); Legro (2005); Wendt (1999).

${ }^{10}$ Without deeply exploring the role of war, early theoretical literature, treats war as a "costly lottery" in which disputes, or more broadly interactions, among states are terminated. One, if not the only, early exception is Wittman (1979). After some time, some scholars have turned their interests from the onset of war to termination and offer theories where war is treated as a continuation of bargaining. In these "costly process models," war is assumed to play distinctive roles: Powell (2004), Slantchev (2003), Smith and Stam (2004), and Wagner (2000) demonstrate that war solves informational asymmetry by conveying unmanipulated information such as the adversary's military strength through combats; destruction in war may render the balance of power where belligerents can credibly commit to maintaining peace (Leventoğlu and Slantchev, 2007). As for the benefit of war, therefore, few studies explore which war is most informative or effective in creating situation where peace is attainable. Important exceptions include Slantchev (2004) who indicates that war is more informative (1) when initiators suffer from a greater rate of casualties than their adversaries and (2) when initiators have less reserved power as is measured by the number of total population subtracted by the number of military personnel. Werner and Yuen (2005) also suggest that wars with consistent battle results are more informative.
} 
gloomy sacrifices? This study was an attempt to face these painful questions in hope of avoiding further violence in our world.

\subsection{Constructing Post-Conflict Peace}

Since the end of World War II and particularly after the end of the Cold War, people are seemingly less enthusiastic about considering international conflict, stating that the number of international conflicts is declining. Instead, unconventional violence, including civil war and terrorism, has attracted much attention.

Yet, it is still worthwhile to ask how we can create peace after international conflict because of its significant impact on human lives and wealth and all the more because of its difficulty. Even after 1946, the world underwent at least 35 full-scale wars. After the end of the Cold War, we observed at least nine full-scale wars and even more small-scale confrontations.

They created many tragic stories. The Vietnam War caused vast number of military and civilian casualties and persisting contamination of the land. In the Azeri-Armenian War over NagornoKarabakh that ended in 1994, millions of soldiers lost their lives, thousands of civilians were massacred, tortured, raped and plundered, and even more were deported. Even after the settlement, people continue to suffer from widely used landmines and new landmines continue to be installed today.

A problem is that international conflict has caused considerable suffering and that it often resumes. Among 56 pairs of countries that actively engaged in full-scale war between 1946 and 2004, more than $40 \%$ reverted to another full-scale war and many of them broke down within one year. Despite such gloomy facts, we have yet to fully understand what causes peace and violence after conflict. This research investigated post-conflict peace, hoping to help countries achieve and maintain ceasefires.

For policymakers and observers who are interested in conflict settlement, this study provides sensible grounds for determining successful third party intervention, demonstrating what prevents adversaries from achieving and maintaining a ceasefire and suggesting the role of a third party in removing the barriers. People have vocally argued about the extent to which and under what conditions third-party intervention, including military intervention, mediation, economic sanctions and foreign aid, can contribute to peace. To answer these important questions, researchers have explored the key to successful intervention, assuming that a third party must mitigate the general 
causes of war, such as informational asymmetry and a commitment problem, to help adversaries achieve and maintain a ceasefire (ex. Kydd, 2003, 2006; Smith and Stam, 2003). This study, in contrast, claims that we must first take a step back and elucidate why parties in conflict fail to achieve and maintain a ceasefire in one occasion and not in others to derive an appropriate role for a third party, without assuming it away.

Perceived in this light, the key to successful third-party intervention is not who the third party is or how the third party intervenes but what they do and when. Most of the existing literature has claimed that the "credibility" of an intervener is the key to successful third party intervention, assuming that it must solve informational asymmetry and/or a lack of commitment between adversaries. Therefore, the third party must be able to convey credible information regarding conflicting parties or to make a credible commitment for creating peace. From this perspective, researchers have argued that the characteristics of the mediator and the means of mediation are crucial. They have explored questions such as whether an international organization like the United Nations is more effective than neighboring countries; whether "neutral" countries are more desirable as peacekeepers than "biased" countries, which have political and economic interests in the dispute; and whether the United States should rely on diplomacy, rather than military force, in mediation (ex. Kydd, 2003, 2006; Shannon, Morey and Boehmke, 2010; Svensson, 2007; Wallensteen and Svensson, 2014).

This study argues, however, that the effects of an intervention depend on when a third party intervenes. Specifically, a third party, whether it is purely peace motivated, biased, greedy, diplomacy reliant, or military reliant, will not undermine peace as long as it intervenes before a ceasefire agreement is reached and behaves in a way that is consistent with the initial agreement. Adversaries make optimal choices about terminating or continuing a conflict, taking into account the intervention by the third party. Whoever the intervener is and whatever the level of commitment is, adversaries can make a sustainable agreement as long as they know such factors before they strike a bargain. To maintain a ceasefire, it hardly matters that the third-party makes no commitment, although the lack of a commitment may prevent adversaries from terminating conflict.

Given that settlement is achieved, counter-intuitively, a purely peace-motivated third-party must not attempt to tie the gainer's hands for post-conflict extraction of resources, but rather, it should help the gainer utilize resources when it turns out that her power growth is less than expected. This is because peace requires that the losing party does not develop any incentive to challenge the gainer. Fighting resumes when the gaining party turns out to have trouble exploiting acquired resources and the loser finds an opportunity to take some resources back. Conversely, fighting is less likely to 
resume when its power increases more than anticipated because the loser does not want to confront a strong opponent. Therefore, a serious threat to peace arises when the gaining party is declining, but not rising. In other words, post-conflict intervention is feasible only if the gainer has trouble exploiting resources obtained during the preceding conflict.

Post-conflict peace is difficult to attain. It is difficult because conflict that is fought to resolve disagreement among nations creates another cause of conflict. As long as conflict results in any form of resource transfer, seeds of discord are spread. Once countries fall into conflict, what can be done? Is it possible to prevent the seeds from sprouting? This study implies that it is challenging but not impossible if observers know the right timing to intervene and the right thing to do. To this end, however, we must first comprehend the mechanism through which conflict is resumed. Otherwise, insiders and outsiders of good will may actually do harm, as this study suggests. I hope that this study serves as a small but important step to advancing post-conflict peace. 
$\prod_{\text {Appendix }}$

\section{Proof of the Model}

Proof of Lemma 1 The gainer's choice in the last node:

$$
s_{2}^{G}= \begin{cases}\text { accept } & \text { if } x \geq \alpha f(\theta) \\ \text { reject } & \text { otherwise }\end{cases}
$$

Then, the loser's best offer $x^{*}$ is $\alpha f(\theta)$. Given this:

$$
s_{2}^{L}= \begin{cases}x^{*}=\alpha f(\theta) & \text { if } f(\theta) \leq \theta+\frac{1}{\alpha} \\ \text { resume } & \text { otherwise }\end{cases}
$$

The loser's choice in the first strategic game:

$$
s_{1}^{L}= \begin{cases}\text { settle } & \text { if } f(\theta) \leq 1+\frac{1}{\alpha} \\ \text { fight } & \text { otherwise }\end{cases}
$$

For the gainer, $s_{1}^{G}=$ settle is a dominant strategy.

Proof of Lemma 2 The gainer's choice in the last node:

$$
s_{2}^{G}= \begin{cases}\text { accept } & \text { if } x \geq \alpha f(\theta) \\ \text { reject } & \text { otherwise }\end{cases}
$$


Then, the loser's best offer $x^{*}$ is $\alpha f(\theta)$. Given this,

$$
s_{2}^{L}=f i g h t, \text { if }-\alpha(\theta+\epsilon)>1-\alpha f(\theta) \Rightarrow \epsilon \leq f(\theta)-\theta-\frac{1}{\alpha} \equiv \Lambda
$$

Therefore, the likelihood that conflict resumes is derived as follows.

$$
\begin{cases}p=0 & \text { if } f(\theta)<\theta+\frac{1}{\alpha}-\frac{1}{2 e} \\ p(\epsilon \leq \Lambda)=e\left(f(\theta)-\theta-\frac{1}{\alpha}\right)+\frac{1}{2} & \text { if } \theta+\frac{1}{\alpha}-\frac{1}{2 e} \leq f(\theta)<\theta+\frac{1}{\alpha}+\frac{1}{2 e} \\ p=1 & \text { if } f(\theta) \geq \theta+\frac{1}{\alpha}+\frac{1}{2 e}\end{cases}
$$

In the initial strategic game of ceasefire, the loser settles if $E^{L} \geq-\alpha$.

1. If $f(\theta)<\theta+\frac{1}{\alpha}-\frac{1}{2 e}$, i.e. $p=0$, then $E^{L}=1-\alpha f(\theta)$.

$$
s_{1}^{L}= \begin{cases}\text { settle } \quad & \text { if } f(\theta) \leq \min \left\{1+\frac{1}{\alpha}, \theta+\frac{1}{\alpha}-\frac{1}{2 e}\right\} \\ & \text { where } 1+\frac{1}{\alpha}<\theta+\frac{1}{\alpha}-\frac{1}{2 e} \text { if } \theta>1+\frac{1}{2 e} \\ \text { fight } & \text { otherwise }\end{cases}
$$

2. If $f(\theta) \geq \theta+\frac{1}{\alpha}+\frac{1}{2 e}$, i.e., $p=1$, then $E^{L}=-\alpha \theta . s_{1}^{L}=$ fight, $\forall f(\theta)$

3. If $\theta+\frac{1}{\alpha}-\frac{1}{2 e} \leq f(\theta)<\theta+\frac{1}{\alpha}+\frac{1}{2 e}$, i.e. $p=e\left(f(\theta)-\theta-\frac{1}{\alpha}\right)+\frac{1}{2}$,

then $E^{L}=p(-\alpha \theta)+(1-p)(1-\alpha f(\theta))$.

$$
s_{1}^{L}= \begin{cases}\text { settle } & \text { if } f(\theta) \leq \theta+\frac{1}{\alpha}+\frac{1-\sqrt{16 e(\theta-1)+1}}{4 e} \text { and } \theta \leq 1+\frac{1}{2 e} \\ \text { fight } & \text { otherwise. }\end{cases}
$$

because $E^{L} \geq-\alpha$ gives $f(\theta) \leq \theta+\frac{1}{\alpha}+\frac{1-\sqrt{16 e(\theta-1)+1}}{4 e}$ and $f(\theta) \geq \theta+\frac{1}{\alpha}+\frac{1+\sqrt{16 e(\theta-1)+1}}{4 e}$.

(a) $\theta+\frac{1}{\alpha}+\frac{1}{2 e}<\theta+\frac{1}{\alpha}+\frac{1+\sqrt{16 e(\theta-1)+1}}{4 e}$ because $\theta>1$ and $e>0$.

(b) $\theta+\frac{1}{\alpha}-\frac{1}{2 e} \leq \theta+\frac{1}{\alpha}+\frac{1-\sqrt{16 e(\theta-1)+1}}{4 e}<\theta+\frac{1}{\alpha}+\frac{1}{2 e}$ if $\theta \leq 1+\frac{1}{2 e}$.

(c) $\theta+\frac{1}{\alpha}+\frac{1-\sqrt{16 e(\theta-1)+1}}{4 e}<\theta+\frac{1}{\alpha}-\frac{1}{2 e}$ if $\theta>1+\frac{1}{2 e}$

For the gainer, $s_{1}^{G}=$ settle is the dominant strategy. 
Proof of Remark 6 The threshold between settlement and fight in the basic model is $1+\frac{1}{\alpha}$ and the threshold in the full model is $f^{*}(\theta)$.

Note the following.

$$
\lim _{\theta \rightarrow 1} f^{*}(\theta)=1+\frac{1}{\alpha}
$$

Now, consider $\theta$ such that $\theta=1+\delta$ where $\delta$ is an arbitrarily small positive number. Then,

$$
\begin{gathered}
f^{*}(\theta)-\left(1+\frac{1}{\alpha}\right)=\delta+\frac{1-\sqrt{16 e \delta+1}}{4 e} \equiv \Phi \\
\frac{\partial \Phi}{\partial \delta}=1-\frac{2}{\sqrt{16 e \delta+1}}
\end{gathered}
$$

There exists a value of $e$ which yields $\frac{\partial \Phi}{\partial \delta}>0$, considering that $\lim _{e \rightarrow \infty} \frac{\partial \Phi}{\partial \delta}=1$. - (A.2.)

This does not violate the constraining condition because we can let $\delta \rightarrow 0$, which guarantees $\theta \leq$ $1+\frac{1}{2 e}$.

With (A.1.) and (A.2.), there exists a set of values of parameters which yields $f^{*}(\theta)>1+\frac{1}{\alpha}$.

Proof of Proposition $1 \frac{\partial p}{\partial \alpha}=e \alpha^{-2}>0$. because $e>0$

Proof of Proposition $2 \frac{\partial p}{\partial \theta}=e\left(f^{\prime}(\theta)-1\right)>0$ because $f(\theta)>\theta$ and $e>0$. 


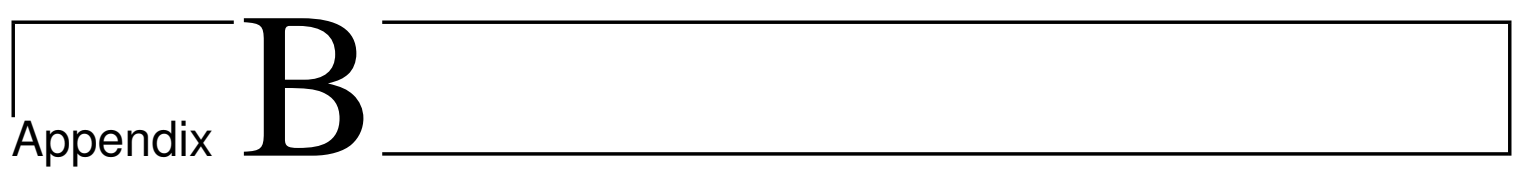

\section{Descriptive Statistics of Variables}

Table B.1: Summary Statistics

\begin{tabular}{lccccc}
\hline \multicolumn{1}{c}{ Variable } & Mean & Std. Dev. & Min. & Max. & N \\
\hline TERRITORIAL CHANGE & 0.155 & 0.362 & 0 & 1 & 891 \\
DENSITY OF EXCHANGED TERRITORY & 0.685 & 1.689 & 0 & 7.359 & 891 \\
AREA OF EXCHANGED TERRITORY & 1.361 & 3.244 & 0 & 12.070 & 891 \\
TERRITORIAL CHANGE INDEX & 1.664 & 4.005 & 0 & 14 & 890 \\
INDEX OF AGREEMENT STRENGTH & 4.357 & 2.387 & 0 & 9.5 & 876 \\
BATTLE CONSISTENCY & 0.42 & 0.428 & 0 & 1 & 876 \\
INTERRUPTED WAR & 0.284 & 0.451 & 0 & 1 & 876 \\
TIE & 0.446 & 0.497 & 0 & 1 & 876 \\
COST OF WAR & 9.302 & 2.35 & 5.602 & 14.039 & 876 \\
HISTORY OF CONFLICT & 0.752 & 0.828 & 0 & 3.412 & 876 \\
EXISTENCE AT STAKE & 0.265 & 0.442 & 0 & 1 & 876 \\
CONTIGUOUS & 0.655 & 0.476 & 0 & 1 & 876 \\
CHANGE IN RELATIVE CAPABILITIES & 0.123 & 0.282 & 0 & 5.43 & 770 \\
TERRITORY AT STAKE & 0.175 & 0.38 & 0 & 1 & 876 \\
\hline
\end{tabular}



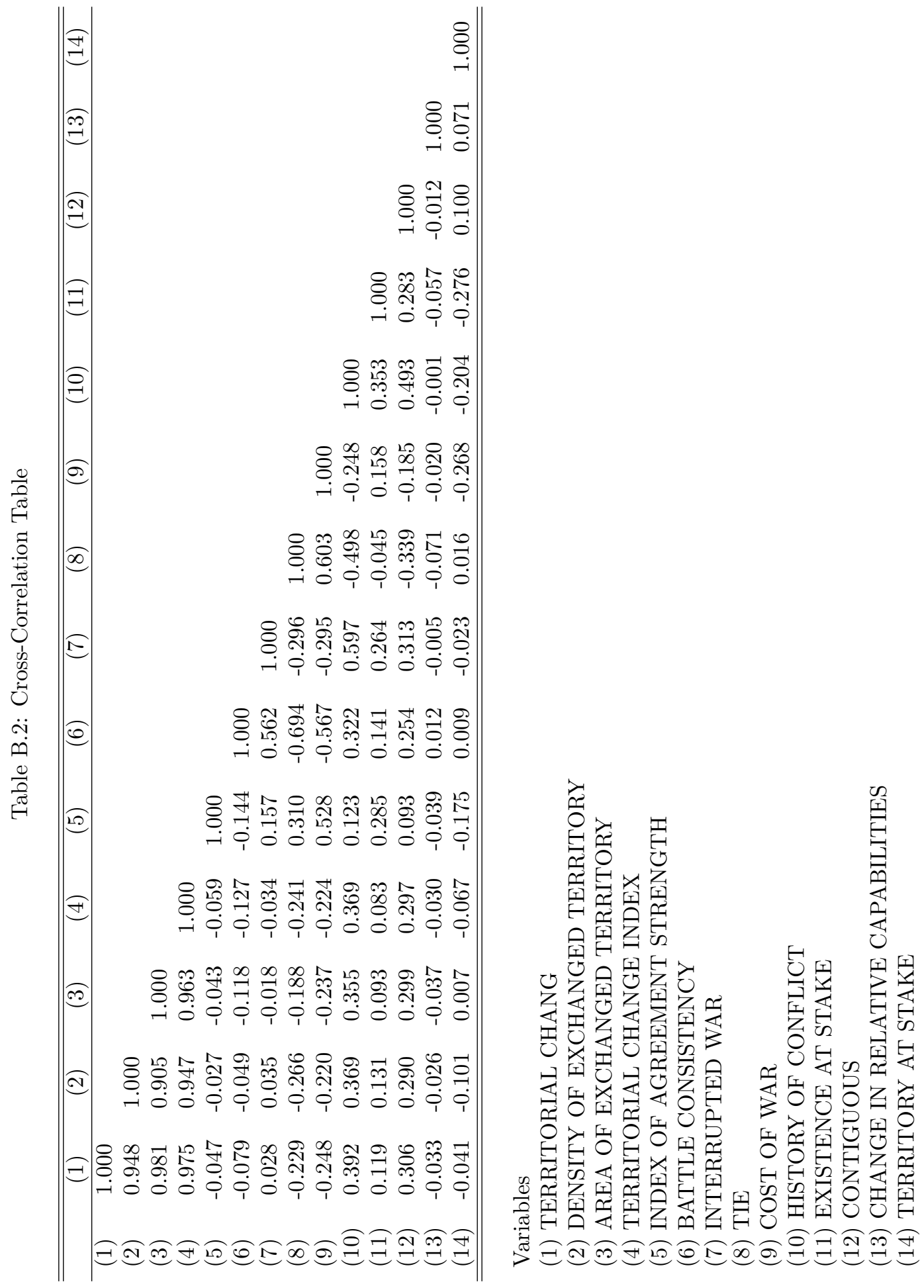

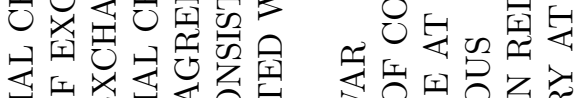

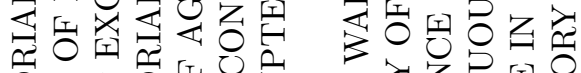

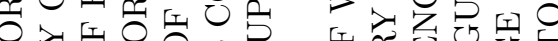

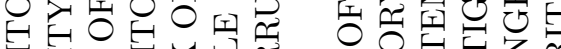

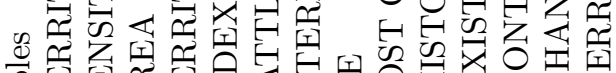

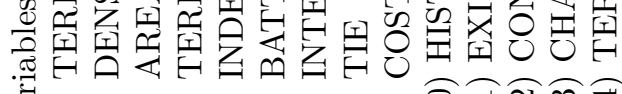

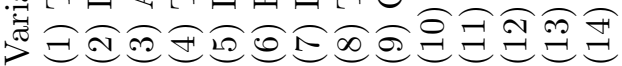


Appendix

\section{List of Cases}

The following list of cases reports the name of war, adversaries involved in the war, the date of a ceasefire, the date of failure if fighting resumed, the agreement strength provided by Forna, the consistency of battle outcomes provided by Werner and Yuen, and the name of exchanged territory if any. A gainer of territory is presented in bold.

Note that Fortna codes each agreement from 0 to 10 where the larger number means a stronger agreement. The data is retrieved from the time-constant data. Battle consistency is coded as " $\mathrm{H}$ " if it is higher than 0.5 and " $\mathrm{L}$ " if it is lower than 0.5, using the data provided by Werner and Yuen.

Ceasefires which took place after 1998 are also presented in the list. The name of war, adversaries, the date of a ceasefire, and the date of failure if any are identified, using the Expanded War Data provided by Gleditsch (2004).

The list starts from the next page. 


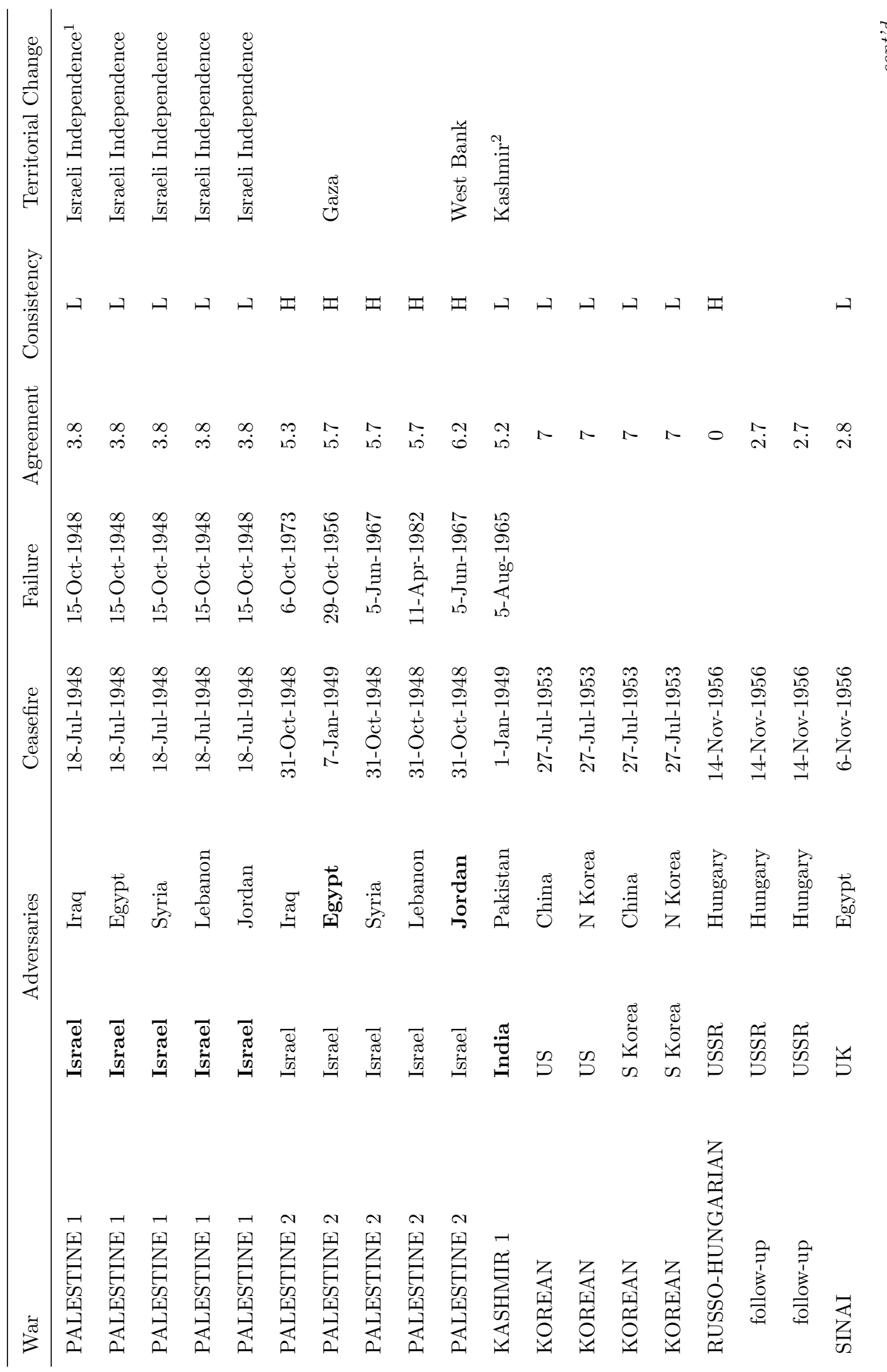




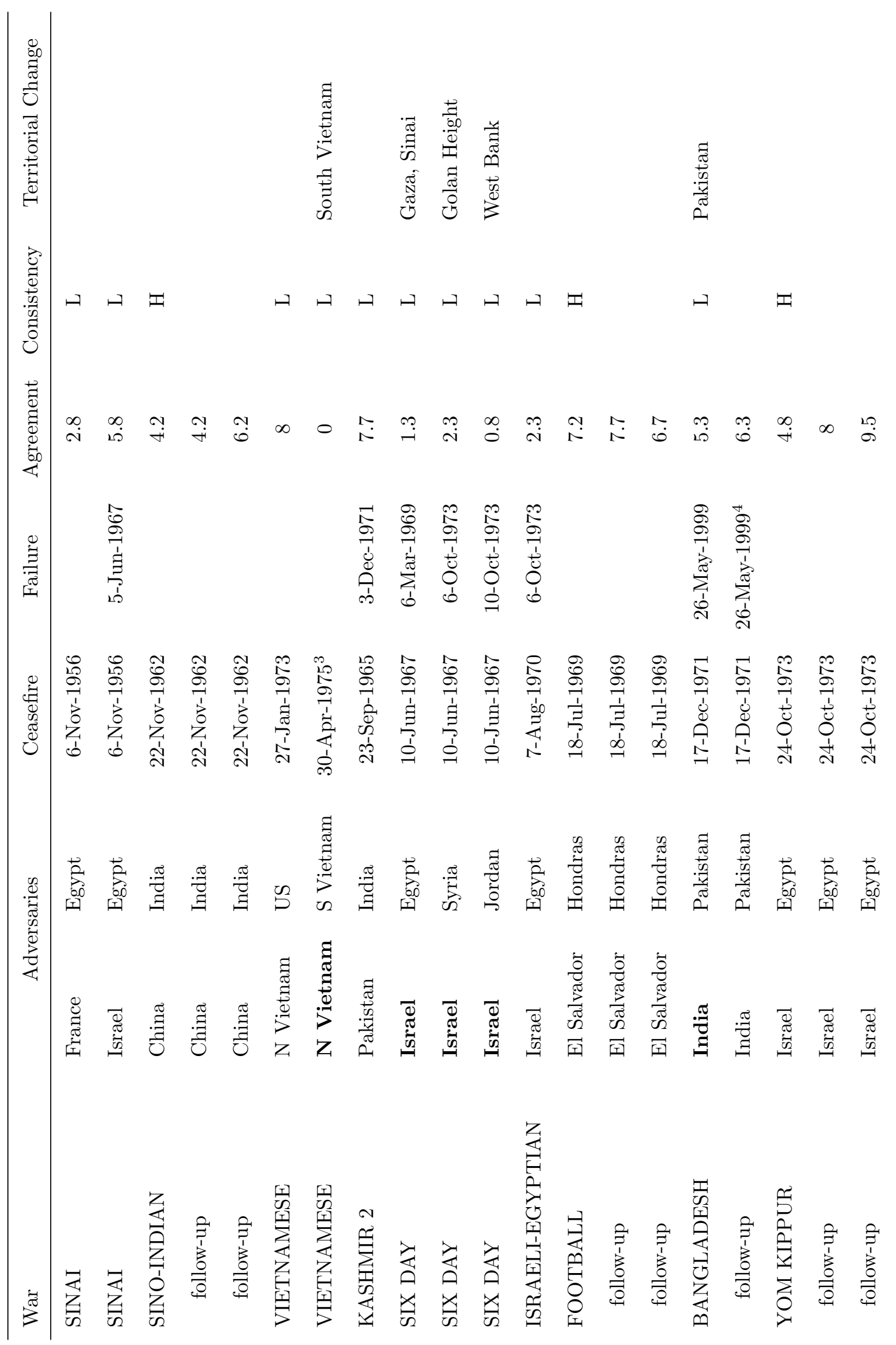




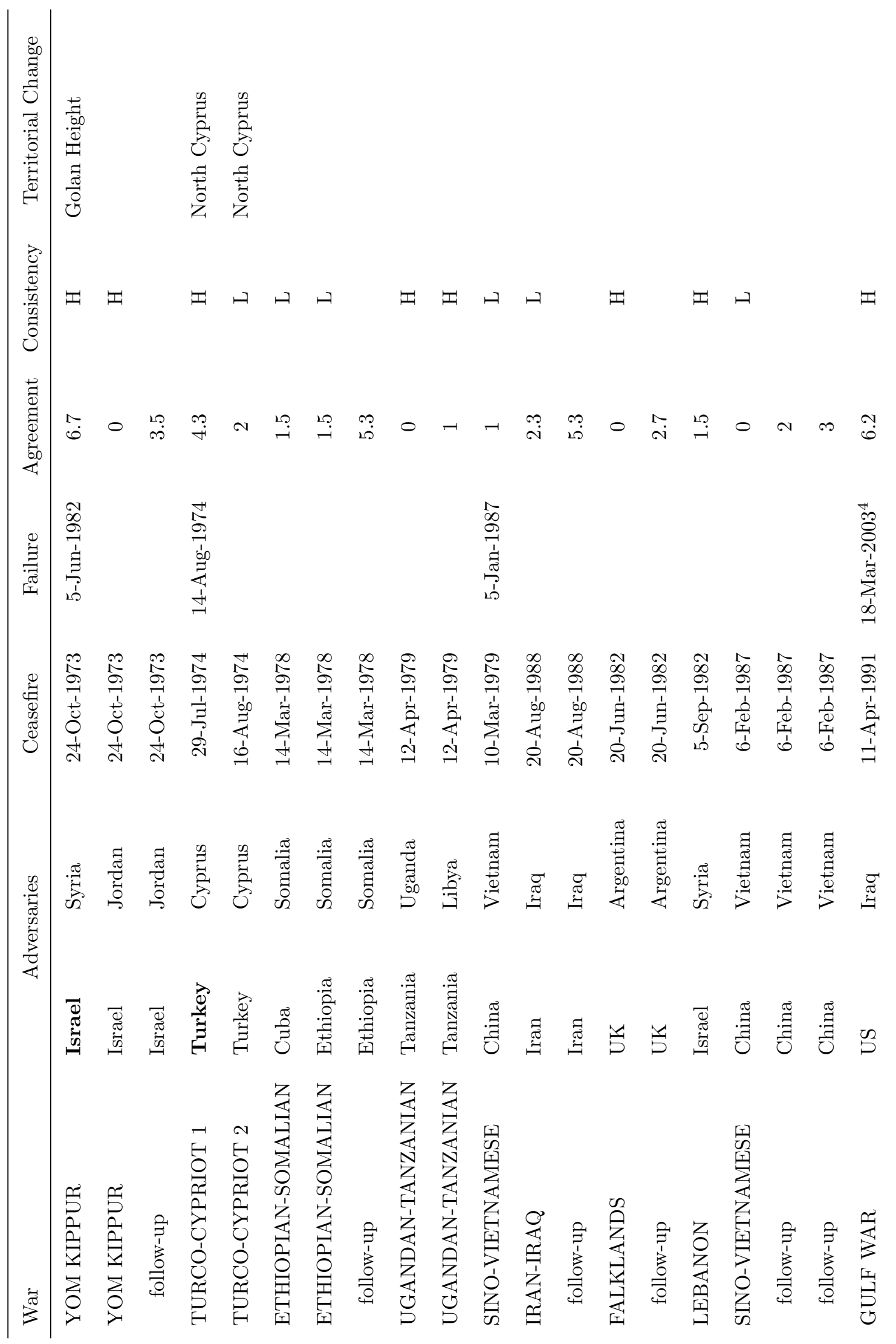




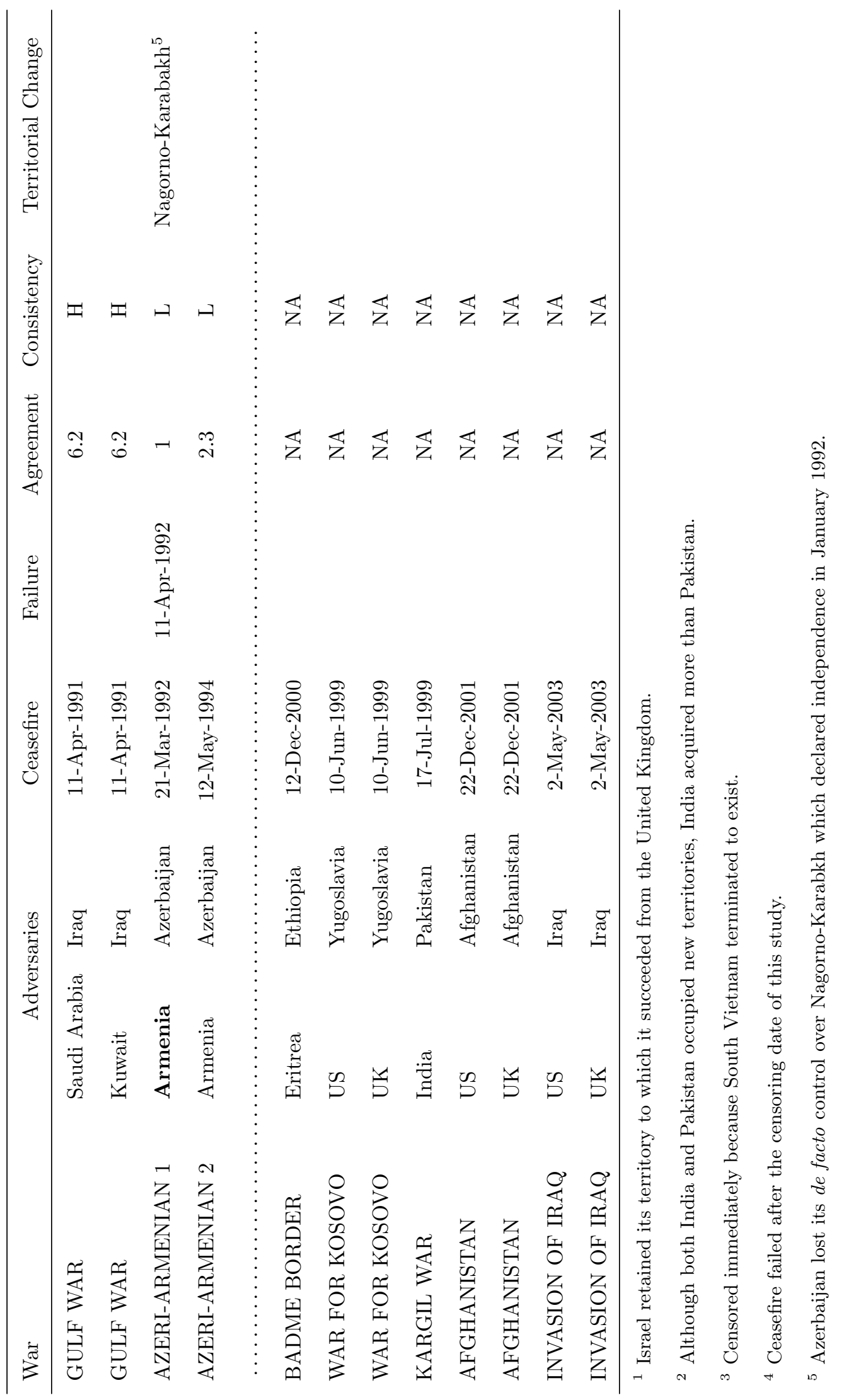

จุ๊ 
${ }_{\text {Apenendi }} \mathrm{D}$

\section{Post-Estimation Analysis}

This section provides several post-estimation analyses and results of analyses using different model specifications to examine the robustness of the results in Chapter 3.

\section{D.1 The Effect of Territorial Change (Table 3.1)}

1. I analyze the Model 5 in Table 3.1, using the Cox proportional hazards model with Efron method for tied observations. The results are reported in Column 1 in Table D.1.

2. The Sinai War between Israel and Egypt (id=18) is removed from the Model 5 in Table 3.1, based on the analysis of leverage in Figure D.1. Deviance residuals are obtained by resealing martingale residuals so that they have a symmetric distribution around zero. Deviance residuals must be randomly distributed around zero if the model is fitted adequately. Subjects with extreme values are possibly influential observations. Dots near zero are censored observations. The results are reported in Column 2 in Table D.1.

3. The Sinai War between Israel and Egypt (id=18) and the First Turco-Cypriot War (id=32) are removed from the Model 5 in the Table 3.1, based on the analysis of leverage in Figure D.1. The results are reported in Column 3 in Table D.1.

4. The Palestine War 2 between Isral and Syria (id=8), the Palestine War 2 between Israel and Jordan, the Sinai War between Israel and Egypt (id=18), and the Sino-Vietnamese War (id=39) are removed from the Model 1 in the Table D.1, based on the analysis of leverage in Figure D.2. The figure shows so-called dfbeta or the difference between the estimated parame- 
ter from the full data and the estimated parameter by fitting the model after removing the $i$ th subject. The $i$ th subject has a small influence on the estimate if its value of $d f b e t a$ is close to zero. The dfbetas were calculated for the Territorial Change Index, using the Cox model without clustering for technical reasons. Standard errors are reported. Figure D.3 shows dfbetas for Territorial Change Index, after removing the four subjects which have strong influences. Exclusion of the four subjects greatly improves the balance, while the substantive findings remain unchanged or even stronger. The results of this estimation are reported in Column 4 in Table D.1.

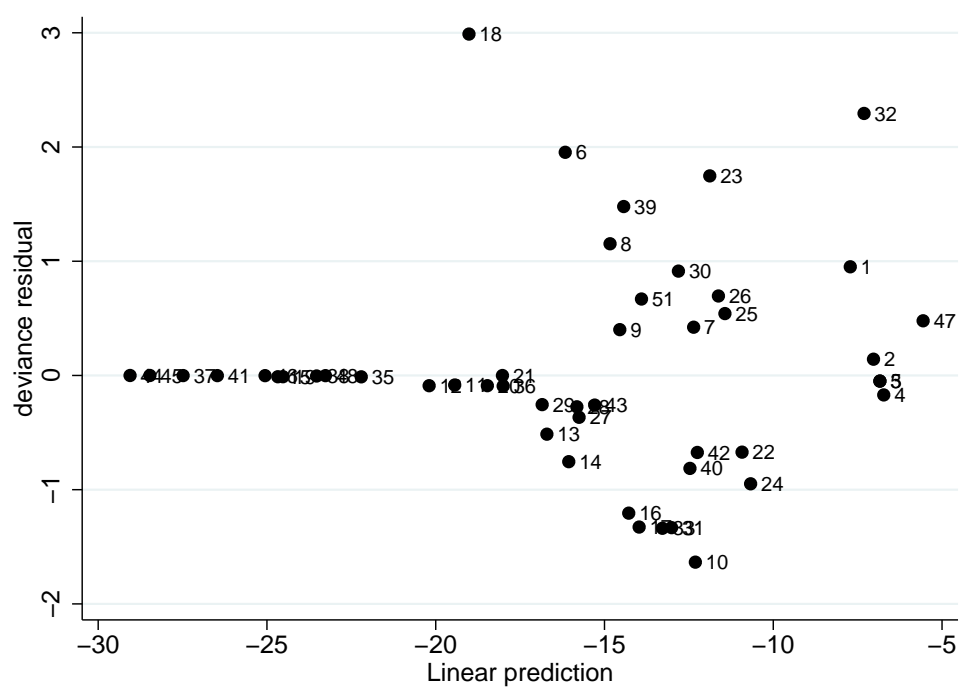

Figure D.1: Deviance Residuals of the original analysis (Model 5, Table 3.1) 


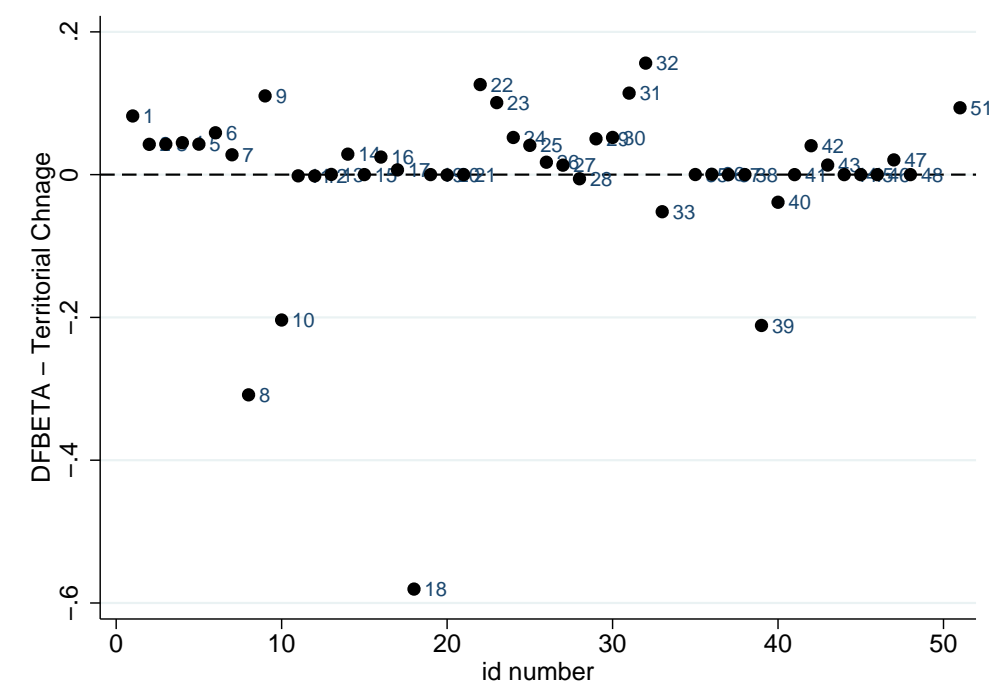

Figure D.2: Dfbeta of the quasi-original analysis (Model 1, Table D.1)

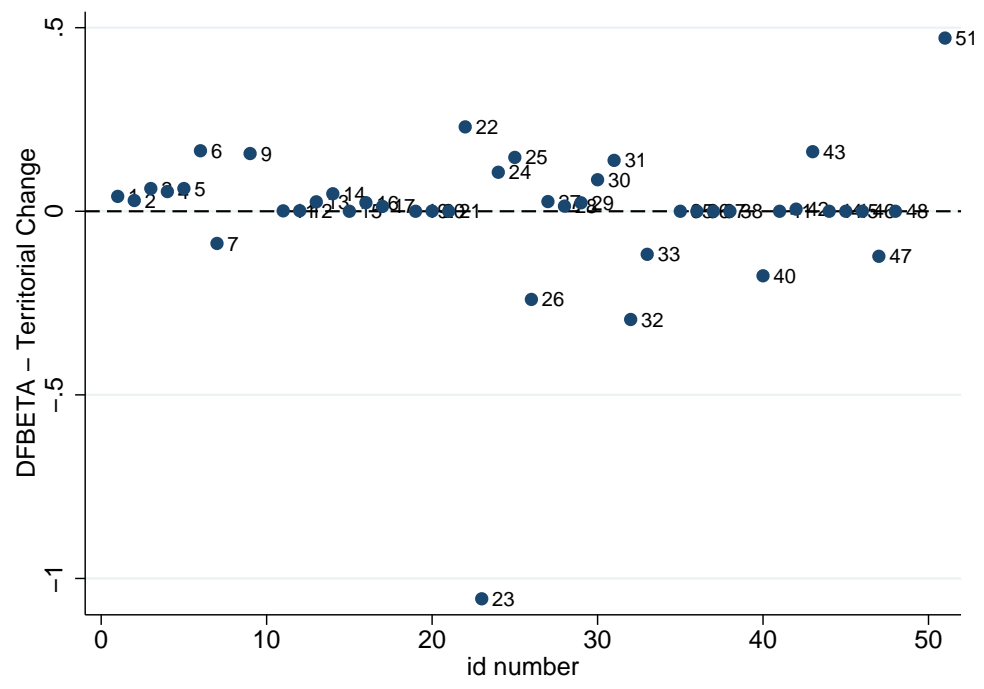

Figure D.3: Dfbeta of the post-estimation analysis (Model 4, Table D.1) 
Table D.1: Robustness Check, Table 3.1 in Chapter 3

\begin{tabular}{|c|c|c|c|c|}
\hline & $\begin{array}{l}(1) \\
\text { coef. }\end{array}$ & $\begin{array}{l}(2) \\
\text { coef. }\end{array}$ & $\begin{array}{l}(3) \\
\text { coef. }\end{array}$ & $\begin{array}{l}(4) \\
\text { coef. }\end{array}$ \\
\hline TERRITORIAL CHANGE & $\begin{array}{l}2.07^{*} \\
(0.81)\end{array}$ & $\begin{array}{l}3.16^{* *} \\
(1.21)\end{array}$ & $\begin{array}{l}2.93^{*} \\
(1.32)\end{array}$ & $\begin{array}{l}5.91^{* *} \\
(1.93)\end{array}$ \\
\hline $\begin{array}{l}\text { INDEX OF AGREEMENT } \\
\text { STRENGTH }\end{array}$ & $\begin{array}{l}-0.17 \\
(0.19)\end{array}$ & $\begin{array}{l}-0.52^{*} \\
(0.22)\end{array}$ & $\begin{array}{l}-0.64^{\dagger} \\
(0.33)\end{array}$ & $\begin{array}{l}-0.16 \\
(0.29)\end{array}$ \\
\hline BATTLE CONSISTENCY & $\begin{array}{c}-8.02^{* *} \\
(2.59)\end{array}$ & $\begin{array}{c}-8.11^{* * *} \\
(2.46)\end{array}$ & $\begin{array}{c}-9.77^{* * *} \\
(2.93)\end{array}$ & $\begin{array}{c}-11.5^{* *} \\
(3.97)\end{array}$ \\
\hline INTERRUPTED WAR & $\begin{array}{c}6.56^{* * *} \\
(1.53)\end{array}$ & $\begin{array}{c}8.25^{* * *} \\
(1.73)\end{array}$ & $\begin{array}{c}9.28^{* * *} \\
(2.40)\end{array}$ & $\begin{array}{l}12.2^{* *} \\
(3.74)\end{array}$ \\
\hline TIE & $\begin{array}{c}2.91 \\
(1.73)\end{array}$ & $\begin{array}{l}5.57^{* *} \\
(2.06)\end{array}$ & $\begin{array}{l}5.48^{* *} \\
(2.04)\end{array}$ & $\begin{array}{l}5.41^{\dagger} \\
(3.03)\end{array}$ \\
\hline COST OF WAR & $\begin{array}{c}-0.72^{* * *} \\
(0.17)\end{array}$ & $\begin{array}{c}-0.90^{* * *} \\
(0.22)\end{array}$ & $\begin{array}{c}-0.99^{* *} \\
(0.32)\end{array}$ & $\begin{array}{l}-1.17^{*} \\
(0.53)\end{array}$ \\
\hline HISTORY OF CONFLICT & $\begin{array}{c}0.67 \\
(0.41)\end{array}$ & $\begin{array}{c}0.63 \\
(0.56)\end{array}$ & $\begin{array}{l}0.50 \mathrm{r} \\
(0.45)\end{array}$ & $\begin{array}{c}0.36 \\
(0.58)\end{array}$ \\
\hline EXISTENCE AT STAKE & $\begin{array}{l}2.36^{*} \\
(1.06)\end{array}$ & $\begin{array}{c}3.24 \\
(2.07)\end{array}$ & $\begin{array}{c}4.83 \\
(2.76)\end{array}$ & $\begin{array}{l}4.24^{*} \\
(1.66)\end{array}$ \\
\hline CONTIGUOUS & $\begin{array}{c}0.71 \\
(1.08)\end{array}$ & $\begin{array}{c}1.16 \\
(1.73)\end{array}$ & $\begin{array}{c}0.89 \\
(1.74)\end{array}$ & $\begin{array}{l}0.0061 \\
(0.87)\end{array}$ \\
\hline $\begin{array}{l}\text { CHANGE IN RELATIVE } \\
\text { CAPABILITIES }\end{array}$ & $\begin{array}{c}1.37 \\
(0.90)\end{array}$ & $\begin{array}{l}1.36^{*} \\
(0.67)\end{array}$ & $\begin{array}{l}1.44^{*} \\
(0.71)\end{array}$ & $\begin{array}{l}6.27^{* *} \\
(2.30)\end{array}$ \\
\hline TERRITORY AT STAKE & $\begin{array}{c}-2.77^{*} \\
(1.13)\end{array}$ & $\begin{array}{c}-3.68^{\dagger} \\
(1.95)\end{array}$ & $\begin{array}{l}-3.01 \\
(2.39)\end{array}$ & $\begin{array}{c}-4.71^{\dagger} \\
(2.49)\end{array}$ \\
\hline Constant & & $\begin{array}{c}-12.2^{* *} \\
(4.11)\end{array}$ & $\begin{array}{c}-13.1^{* *} \\
(4.23)\end{array}$ & \\
\hline$p$ & & $\begin{array}{c}1.58 \\
(0.30)\end{array}$ & $\begin{array}{c}1.80 \\
(0.35)\end{array}$ & \\
\hline Observations & 770 & 757 & 756 & 709 \\
\hline Number of subjects & 48 & 47 & 46 & 44 \\
\hline $\mathrm{BIC}$ & 151.07 & 138.47 & 129.23 & 109.21 \\
\hline
\end{tabular}




\section{D.2 The Nature of Territorial Change (Table 3.2)}

1. I analyze Model 3 in Table 3.2, using the Cox proportional hazards model with Efron method for tied observations. The results are reported in Column 1 in Table D.2.

2. The Sinai War between Israel and Egypt (id=18) is removed from Model 3 in Table 3.2, based on the analysis of leverage in Figure D.4 and D.5. Dfbetas were calculated for Model 1 in Table D.2 without clustering for technical reasons. The results of this estimation are reported in Column 2 in Table D.2.

3. The Sinai War between Israel and Egypt (id=18) and the First Turco-Cypriot War (id=32) are removed from Model 3 in Table 3.2, based on the analysis of leverage in Figure D.4 and D.5. The results are reported in Column 3 in Table D.2.

4. TERRITORIAL CHANGE INDEX of Model 5 in Table 3.2 is replaced by TERRITORIAL CHANGE INDEX 2. INDEX 2 decreases the numerical jump in the distribution of the original variable. Recall that the smallest value of the original INDEX was \%, which may cause overestimation of the effect of the estimator, considering the large effect of territorial change itself. INDEX 2 addresses this issue by deleting the numerical gap. 7 in the original variable is 1 in the new variable. The results are reported in Column 4 in Table D.2. 


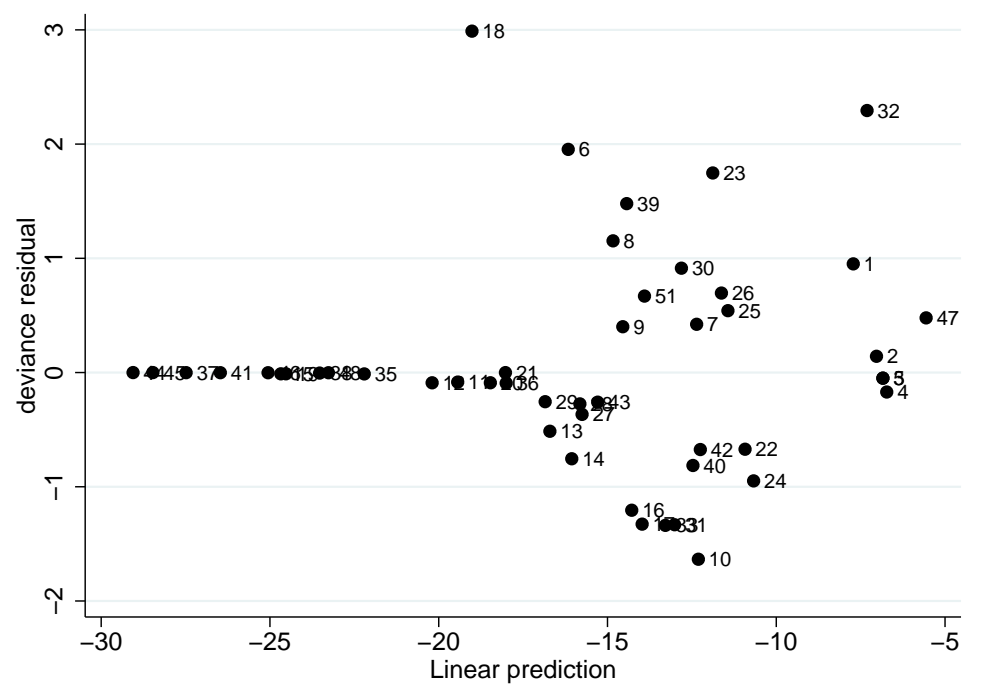

Figure D.4: Deviance Residuals of the original analysis (Model 3, Table 3.2)

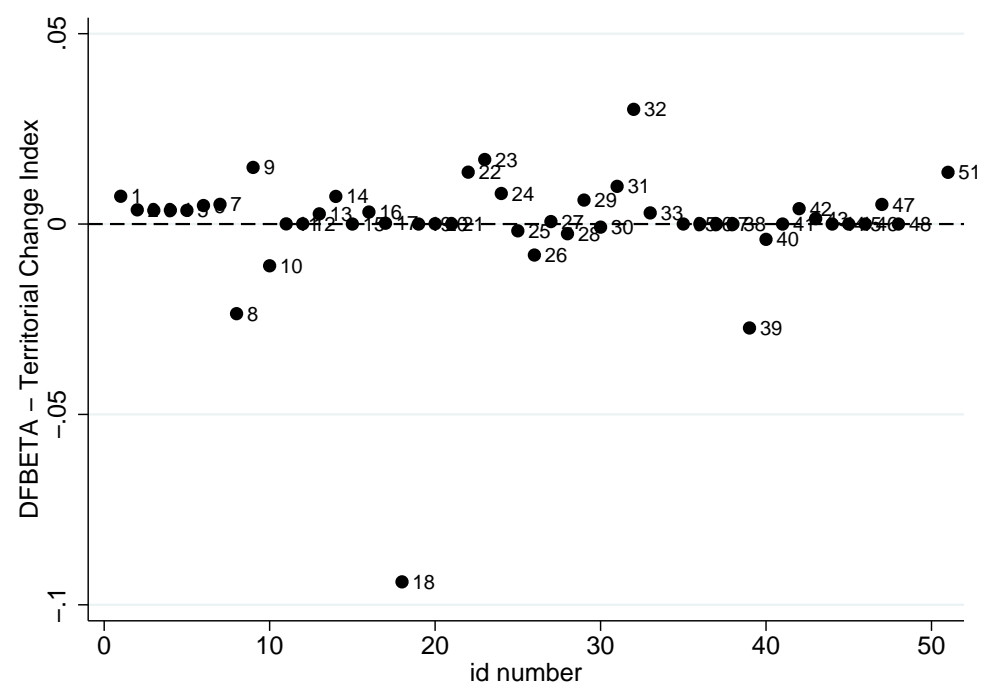

Figure D.5: Dfbeta of the quasi-original analysis (Model 1, Table D.2) 
Table D.2: Robustness Check, Table 3.2 in Chapter 3

\begin{tabular}{|c|c|c|c|c|}
\hline & $\begin{array}{l}(1) \\
\text { coef. }\end{array}$ & $\begin{array}{l}(2) \\
\text { coef. }\end{array}$ & $\begin{array}{l}(3) \\
\text { coef. }\end{array}$ & $\begin{array}{l}(4) \\
\text { coef. }\end{array}$ \\
\hline $\begin{array}{l}\text { TERRITORIAL CHANGE } \\
\text { INDEX }\end{array}$ & $\begin{array}{l}0.25^{*} \\
(0.11)\end{array}$ & $\begin{array}{l}0.47^{* *} \\
(0.17)\end{array}$ & $\begin{array}{l}0.42^{*} \\
(0.19)\end{array}$ & \\
\hline $\begin{array}{l}\text { TERRITORIAL CHANGE } \\
\text { INDEX2 }\end{array}$ & & & & $\begin{array}{l}0.76^{\dagger} \\
(0.40)\end{array}$ \\
\hline $\begin{array}{l}\text { INDEX OF AGREEMENT } \\
\text { STRENGTH }\end{array}$ & $\begin{array}{l}-0.23 \\
(0.21)\end{array}$ & $\begin{array}{c}-0.66^{* *} \\
(0.20)\end{array}$ & $\begin{array}{l}-0.75^{*} \\
(0.31)\end{array}$ & $\begin{array}{l}-0.41 \\
(0.33)\end{array}$ \\
\hline BATTLE CONSISTENCY & $\begin{array}{c}-7.35^{* *} \\
(2.52)\end{array}$ & $\begin{array}{c}-7.08^{* *} \\
(2.17)\end{array}$ & $\begin{array}{c}-8.06^{* * *} \\
(2.35)\end{array}$ & $\begin{array}{c}-5.01^{* *} \\
(1.88)\end{array}$ \\
\hline INTERRUPTED WAR & $\begin{array}{c}6.88^{* * *} \\
(1.48)\end{array}$ & $\begin{array}{c}9.60^{* * *} \\
(2.00)\end{array}$ & $\begin{array}{c}9.99^{* * *} \\
(2.03)\end{array}$ & $\begin{array}{l}7.52^{* *} \\
(2.83)\end{array}$ \\
\hline TIE & $\begin{array}{c}3.55 \\
(2.00)\end{array}$ & $\begin{array}{l}7.45^{* *} \\
(2.33)\end{array}$ & $\begin{array}{l}7.39^{* *} \\
(2.55)\end{array}$ & $\begin{array}{l}6.09^{*} \\
(2.73)\end{array}$ \\
\hline COST OF WAR & $\begin{array}{c}-0.69^{* * *} \\
(0.18)\end{array}$ & $\begin{array}{c}-0.89^{* * *} \\
(0.26)\end{array}$ & $\begin{array}{c}-0.90^{* * *} \\
(0.26)\end{array}$ & $\begin{array}{c}-0.90^{* * *} \\
(0.24)\end{array}$ \\
\hline HISTORY OF CONFLICT & $\begin{array}{l}0.78^{*} \\
(0.37)\end{array}$ & $\begin{array}{l}1.01^{*} \\
(0.44)\end{array}$ & $\begin{array}{l}1.00^{*} \\
(0.50)\end{array}$ & $\begin{array}{l}1.06^{*} \\
(0.52)\end{array}$ \\
\hline EXISTENCE AT STAKE & $\begin{array}{l}2.25^{*} \\
(0.97)\end{array}$ & $\begin{array}{l}2.71^{*} \\
(1.25)\end{array}$ & $\begin{array}{c}3.94 \\
(2.18)\end{array}$ & $\begin{array}{l}2.00^{*} \\
(0.84)\end{array}$ \\
\hline CONTIGUOUS & $\begin{array}{c}0.63 \\
(1.00)\end{array}$ & $\begin{array}{c}0.74 \\
(1.41)\end{array}$ & $\begin{array}{c}0.58 \\
(1.53)\end{array}$ & $\begin{array}{c}0.80 \\
(1.37)\end{array}$ \\
\hline $\begin{array}{l}\text { CHANGE IN RELATIVE } \\
\text { CAPABILITIES }\end{array}$ & $\begin{array}{l}1.20 \\
(0.84)\end{array}$ & $\begin{array}{l}1.20^{*} \\
(0.59)\end{array}$ & $\begin{array}{c}1.25 \\
(0.67)\end{array}$ & $\begin{array}{c}0.99 \\
(0.60)\end{array}$ \\
\hline TERRITORY AT STAKE & $\begin{array}{l}-2.48^{*} \\
(1.10)\end{array}$ & $\begin{array}{c}-3.56^{*} \\
(1.61)\end{array}$ & $\begin{array}{l}-2.96 \\
(2.15)\end{array}$ & $\begin{array}{l}-3.00^{*} \\
(1.48)\end{array}$ \\
\hline Constant & & $\begin{array}{c}-16.7^{* *} \\
(5.32)\end{array}$ & $\begin{array}{c}-17.6^{* *} \\
(5.84)\end{array}$ & $\begin{array}{l}-13.1^{*} \\
(5.81)\end{array}$ \\
\hline$p$ & & $\begin{array}{c}1.87 \\
(0.39)\end{array}$ & $\begin{array}{c}2.00 \\
(0.39)\end{array}$ & $\begin{array}{c}1.56 \\
(0.40)\end{array}$ \\
\hline Observations & 770 & 757 & 756 & 770 \\
\hline Number of subjects & 48 & 47 & 46 & 48 \\
\hline $\mathrm{BIC}$ & 149.75 & 132.33 & 125.39 & 148.28 \\
\hline
\end{tabular}




\section{Bibliography}

Acemoglu, Daron and James A Robinson. 2000. "Why Did the West Extend the Franchise? Democracy, Inequality, and Growth in Historical Perspective." The Quarterly Journal of Economics 115(4):1167-1199.

Acemoglu, Daron and James A. Robinson. 2006. Economic Origins of Dictatorship and Democracy. New York: Cambridge University Press.

Acemoglu, Daron, James A Robinson and Dan Woren. 2012. Why Nations Fail: The Origins of Power, Prosperity, and Poverty. New York: Crown Business.

Aristotle. 2004. The Nicomachean Ethics. Jonathan Barnes, J.A.K. Thomson, and Hugh Tredennick eds and trans. London: Penguin.

Bennett, D. Scott and Allan Stam. 2000. "EUGene: A Conceptual Manual." International Interactions 26:179-204.

URL: http://eugenesoftware.org

Bercovitch, Jacob and Richard Jackson. 1997. International Conflict: A Chronological Encyclopedia of Conflicts and Their Management, 1945-1995. Washington D.C.: Congressional Quarterly.

Biddle, Stephen. 2004. Military Power: Explaining Victory and Defeat in Modern Battle. Princeton, NJ: Princeton University Press.

Blainey, Geoffrey. 1988. Causes of War. New York: Simon and Schuster.

Bolt, Jutta and Jan Luiten van Zanden. 2013. "The First Update of the Maddison Project; ReEstimating Growth Before 1820." Maddison-Project Working Paper WP-4, University of Gronin- 
gen, January 5.

URL: http://www.ggdc.net/maddison/maddison-project/home.htm

Brecher, Michael and Jonathan Wilkenfeld. 1992. International Crisis Behavior Project, 1918-1988. Inter-university Consortium for Political and Social Research, 9286.

Bueno de Mesquita, Bruce, Alastair Smith, Randolph Siverson and James D. Morrow. 2003. The Logic of Political Survival. Cambridge, MA: The MIT Press.

Bueno de Mesquita, Bruce., James D. Morrow, Randolph M. Siverson and Alastair Smith. 2004.

"Testing Novel Implications from the Selectorate Theory of War." World Politics 56(3):363-388.

Camp, Glen D. 1980. "Greek-Turkish Conflict over Cyprus." Political Science Quarterly 95(1):43-70.

Central Intelligence Agency. 1988. South China Sea. Perry-Castañeda Library Map Collection, University of Texas [online, accessed 16 June 2014].

URL: http://www.lib.utexas.edu/maps/middle_east_and_asia/paracel_spratly_88.jpg

Central Intelligence Agency. 2012. Southeast Asia. Perry-Castañeda Library Map Collection, University of Texas [online, accessed 2 June 2014].

URL: http://www.lib.utexas.edu/maps/middle_east_and_asia/southeast_asia_pol_2012.pdf

Chang, Pao-min. 1986. The Sino-Vietnamese Territorial Dispute. New York: Praeger.

Collier, Paul and Anke Hoeffler. 2004. "Greed and Grievance in Civil War." Oxford Economic Papers 56(4):563-595.

Daniel M. Jones, Stuart A. Bremer and J. David Singer. 1996. "Militarized Interstate Disputes,18161992: Rationale, Coding Rules, and Empirical Patterns." Conflict Management and Peace Science 15(2):163-213.

Diehl, Paul F, ed. 1998. The Dynamics of Enduring Rivalries. Urbana, IL: University of Illinois Press.

Diehl, Paul F. and Gary Goertz. 2001. War and Peace in International Rivalry. Ann Arbor, MI: University of Michigan Press.

Downes, Alexander B. 2011. Targeting Civilians in War. New York: Cornell University Press. 
Fang, Songying. 2010. "The Strategic Use of International Institutions in Dispute Settlement." Quarterly Journal of Political Science 5(2):107-131.

Fearon, James. 2002. "Selection Effects and Deterrence." International Interactions 28(1):5-29.

Fearon, James D. 1994. "Domestic Political Audiences and the Escalation of International Disputes." American Political Science Review 88(3):577-592.

Fearon, James D. 1995. "Rationalist Explanations for War." International Organization 49(3):379414.

Fearon, James D. 1996. "Bargaining over Objects That Influence Future Bargaining Power." Manuscript .

Fearon, James D. 2005. "Primary Commodity Exports and Civil War." Journal of Conflict Resolution 49(4):483-507.

Finnemore, Martha. 2004. The Purpose of Intervention: Changing Beliefs About the Use of Force. New York: Cornell University Press.

Fortna, Virginia Page. 2004. Peace Time: Cease-fire Agreements and the Durability of Peace. Princeton, NJ: Princeton University Press.

Frieden, Jeffry A. 1994. "International Investment and Colonial Control: A New Interpretation." International Organization 48(04):559-593.

Fuhrmann, Matthew. and Todd S. Sechser. 2014. "Signaling Alliance Commitments: HandTying and Sunk Costs in Extended Nuclear Deterrence." American Journal of Political Science 58(4):919-935.

Gelpi, Christopher. 1997. "Democratic Diversions Governmental Structure and the Externalization of Domestic Conflict." Journal of Conflict Resolution 41(2):255-282.

Gilligan, Michael, Leslie Johns and B Peter Rosendorff. 2010. "Strengthening International Courts and the Early Settlement of Disputes." Journal of Conflict Resolution 54(1):5-38.

Gleditsch, Kristian S. 2004. "A Revised List of Wars Between and within Independent States, 18162002." International Interactions 30(3):231-262.

URL: http://privatewww.essex.ac.uk/ ksg/expwar.html 
Gleditsch, Kristian Skrede and Steve Pickering. 2014. "Wars are Becoming Less Frequent: A Response to Harrison and Wolf." The Economic History Review 67(1):214-230.

Goemans, Hein E. 2000. War and Punishment: The Causes of War Termination and the First World War. Princeton, NJ: Princeton University Press.

Goertz, Gary and Paul F. Diehl. 1992. Territorial Changes and International Conflict. London: Routledge.

Goertz, Gary and Paul F. Diehl. 1993. "Enduring Rivalries: Theoretical Constructs and Empirical Patterns." International Studies Quarterly 37(2):147-171.

Hassner, Ron E. 2003. "“To Halve and to Hold": Conflicts over Sacred Space and the Problem of Indivisibility." Security Studies 12(4):1-33.

Hood, Steven J. 1992. Dragons Entangled: Indochina and the China-Vietnam War. New York: ME Sharpe.

Hung, Nguyen Manh. 1979. "The Sino-Vietnamese Conflict: Power Play among Communist Neighbors." Asian Survey 19(11):1037-1052.

Hunt, Michael H. 1987. Ideology and US Foreign Policy. New Haven, CT: Yale University Press.

International Crisis Group. 2012. "Stirring Up the South China Sea (I).". [accessed 23 July, 2014].

URL: http://www.crisisgroup.org//media/Files/asia/north-east-asia/223-stirring-up-the-southchina-sea-i.pdf

International Monetary Fund. 2014. "World Economic Outlook (WEO).". [accessed 21 July, 2014]. URL: https://www.imf.org/external/pubs/ft/weo/2014/01/pdf/text.pdf

Jencks, Harlan W. 1979. "China's "Punitive" War on Vietnam: A Military Assessment." Asian Survey 19(8):801-815.

Kim, Woosang and James D Morrow. 1992. "When Do Power Shifts Lead to War?" American Journal of Political Science 36(4):896-922.

Kydd, Andrew. 2003. "Which Side Are You On? Bias, Credibility, and Mediation." American Journal of Political Science 47(4):597-611. 
Kydd, Andrew. 2006. "When Can Mediators Build Trust?" American Political Science Review 100(3):449-462.

Lake, David A. 1992. "Powerful Pacifists: Democratic States and War." American Political Science Review 86(1):24-37.

Le Billon, Philippe. 2001. "The Political Ecology of War: Natural Resources and Armed Conflicts." Political Geography 20(5):561-584.

Legro, Jeffrey W. 2005. Rethinking the World: Great Power Strategies and International Order. New York: Cornell University Press.

Legro, Jeffrey W. 2007. "What China will Want: the Future Intentions of a Rising Power." Perspectives on Politics 5(3):515-534.

Legro, Jeffrey W. and Andrew Moravcsik. 1999. "Is Anybody Still A Realist?" International Security $24(2): 5-55$.

Leventoğlu, Bahar and Branislav L. Slantchev. 2007. "The Armed Peace: A Punctuated Equilibrium Theory of War." American Journal of Political Science 51(4):755-771.

Li, Zoe. 2014. "China, Vietnam, Philippines Collide amid Escalating South China Sea Tensions." CNN . [accessed on 2 July, 2014].

URL: http://edition.cnn.com/2014/05/08/world/asia/south-china-sea-drilling/

Lo, Chi-kin. 1989. China's Policy towards Territorial Disputes: the Case of the South China Sea Islands. London: Routledge.

Lo, Nigel, Barry Hashimoto and Dan Reiter. 2008. "Ensuring Peace: Foreign-Imposed Regime Change and Postwar Peace Duration, 1914-2001." International Organization 62(4):717-736.

Lujala, Päivi. 2010. "The Spoils of Nature: Armed Civil Conflict and Rebel Access to Natural Resources." Journal of Peace Research 47(1):15-28.

Marshall, Monty G., Ted R. Gurr and Keith Jaggers. 2013. Polity IV Project: Political Regime Characteristics and Transitions, 1800-2013 [ver. p4v2013]. Vienna, VA: Center for Systemic Peace.

URL: http://www.systemicpeace.org/inscrdata.html 
Mathews, Jay. 1978. "Chinese Break Off Talks With Vietnam, Blaming 'Violence'." The Washington Post 27 September:A.18.

Morrison, Wayne M. 2014. "Chinas Economic Rise: History, Trends, Challenges, and Implications for the United States." Congresssional Research Service . [accessed on 25 November, 2014].

URL: http://fas.org/sgp/crs/row/RL33534.pdf

Ohtsuki, Kazuto. 2013. "A Theory of War and Forced Regime Change: Determinants and Consequences." Manuscript .

Organski, A. F. K. 1968. Wold Politics. Second ed. New York: Knopf.

Organski, A. F. K. and Jacek Kugler. 1980. The War Ledger. Chicago, IL: University of Chicago Press.

Pape, Robert Anthony. 1996. Bombing to Win: Air Power and Coercion in War. New York: Cornell University Press.

Posen, Barry. 1984. Sources of Military Doctrine: France, Britain and Germany Between the World Wars. New York: Cornell University Press.

Powell, R. 1999. In the Shadow of Power: States and Strategies in International Politics. Princeton, NJ: Princeton University Press.

Powell, R. 2006. "War as a Commitment Problem." International Organization 60(1):169-203.

Powell, Robert. 1996. "Uncertainty, Shifting Power, and Appeasement." American Political Science Review 90(4):pp. 749-764.

Powell, Robert. 2004. "Bargaining and Learning while Fighting." American Journal of Political Science 48(2):344-361.

Powell, Robert. 2012. "Persistent Fighting and Shifting Power." American Journal of Political Science 56(3):620-637.

Ramsay, Kristopher W. 2004. "Politics at the Waters Edge Crisis Bargaining and Electoral Competition." Journal of Conflict Resolution 48(4):459-486.

Ravallion, Martin and Shaohua Chen. 2007. "China's (Uneven) Progress against Poverty.” Journal of Development Economics 82(1):1-42. 
Reiter, Dan. 2009. How Wars End. Princeton, NJ: Princeton University Press.

Reiter, Dan and Allan C. Stam. 2002. Democracies at War. Princeton, NJ: Princeton University Press.

Ross, Michael L. 1999. "Review: The Political Economy of the Resource Curse." World Politics $51(2): 297-322$.

Ross, Michael L. 2004a. "How do Natural Resources Influence Civil War? Evidence from Thirteen Cases." International Organization 58(1):35-67.

Ross, Michael L. 2004b. "What Do We Know about Natural Resources and Civil War?" Journal of Peace Research 41(3):337-356.

Russett, Bruce M. 1995. Grasping the Democratic Peace: Principles for a Post-Cold War World. Princeton, NJ: Princeton University Press.

Salas, Miguel Tinker. 1992. "Sonora: The Making of A Border Society, 1880-1910." Journal of the Southwest 34(4):429-456.

Schoenberger, Laura. August 2006. Crossing the Line: the Changing Nature of Highlander CrossBorder Trade in Northern Vietnam. Master's thesis Geography Department, McGill University.

Schultz, Kenneth A. 1998. "Domestic Opposition and Signaling in International Crises." American Political Science Review 92(4):829-844.

Schultz, Kenneth A. 2001. Democracy and Coercive Diplomacy. Cambridge, UK: Cambridge University Press.

Schuman, Robert. 1950. "Declaration [on French proposal to place coal and steel under "higher authority"] by French Foreign Minister Robert Schuman. Paris, 9 May 1950.”. Reproduced from microfiche.

URL: http://aei.pitt.edu/14363/

Schwarz, Michael and Konstantin Sonin. 2008. "A Theory of Brinkmanship, Conflicts, and Commitments." Journal of Law, Economics, and Organization 24(1):163-183.

Sechser, Todd S. 2010. "Goliath's Curse: Coercive Threats and Asymmetric Power." International Organization 64(4):627-660. 
Sechser, Todd S and Elizabeth N Saunders. 2010. "The Army You Have: The Determinants of Military Mechanization, 1979-2001.” International Studies Quarterly 54(2):481-511.

Shannon, Megan, Daniel Morey and Frederick J Boehmke. 2010. "The Influence of International Organizations on Militarized Dispute Initiation and Duration1." International Studies Quarterly 54(4):1123-1141.

Shoji, Tomotaka. 2006. "Demarcation and Territorial Problems between Vietnam and China." NIDS Security Studies 8(3):53-67. [in Japanese].

Singer, J. David and Melvin Small. 1972. The Wages of War, 1816-1965: A Statistical Handbook. New York: John Wiley.

Slantchev, Branislav L. 2003. "The Principle of Convergence in Wartime Negotiations." American Political Science Review 97(4):621-632.

Slantchev, Branislav L. 2004. "How Initiators End Their Wars: The Duration of Warfare and the Terms of Peace." American Journal of Political Science 48(4):813-829.

Slantchev, Branislav L. 2005. "Military Coercion in Interstate Crises." American Political Science Review 99(4):533.

Small, Melvin and J. David Singer. 1982. Resort to Arms: International and Civil Wars, 1816-1980. Beverly Hills, CA: Sage Publication.

Smith, Alastair. 1998. "Extended Deterrence and Alliance Formation." International Interactions $24(4): 315-343$.

Smith, Alastair and Allan C Stam. 2004. "Bargaining and the Nature of War." Journal of Conflict Resolution 48(6):783-813.

Smith, Alastair and Allan Stam. 2003. "Mediation and Peacekeeping in a Random Walk Model of Civil and Interstate War." International Studies Review 5(4):115-135.

Stam, Allan C. 1996. Win, Lose, or Draw: Domestic Politics and the Crucible of War. Ann Arbor, MI: University of Michigan Press.

Svensson, Isak. 2007. "Bargaining, Bias and Peace Brokers: How Rebels Commit to Peace." Journal of Peace Research 44(2):177-194. 
Swatland. 1954. "Draft Loant Agreement, prepared by Mr. Swatland in Luxembourg, 20 March 1954." File 452.11 High Authority: Budget and Financial Questions, the Archive of European Integration (AEI), University of Pittsburgh .

The Associated Press. 2010. "Vietnam: Seeking Fishermen's Release." The New York Times 7 October, Late Edition:A.12.

The National Statistical Service of NKR. N.d. Statistical Yearbook of Nagorno-Karabakh Republic, 2006-2012. online document.

URL: http://www.stat-nkr.am/index.php?option=com_contentEview=articleEid=358\%3A-20062012Ecatid=43\%3A2006-2012-EItemid=5986lang=en

Thompson, Gerald E. and Thomas J. Cram. 1968. "Railroads and Mines in Arizona: The Cram Memoir of 1858." Arizona and the West 10(4):363-376.

Tir, Jaroslav. 2003. "Never-Ending Conflicts? Territorial Changes as Potential Solutions for Territorial Disputes." Conflict Management and Peace Science 20:59-83.

Tir, Jaroslav, Philip Schafer, Paul F Diehl and Gary Goertz. 1998. "Territorial Changes, 1816-1996: Procedures and Data." Conflict Management and Peace Science 16(1):89-97.

URL: http://www.correlatesofwar.org/COW2\%20Data/TerrChange/terrchange.html

Trainor, Bernard E. 1987. "Russians in Vietnam: U.S. Sees a Threat." The New York Times 1 March:A.18.

Turner, Sarah. 2010. "Borderlands and Border Narratives: A Longitudinal Study of Challenges and Opportunities for Local Traders Shaped by the Sino-Vietnamese Border." Journal of Global History 5(2):265-287.

Van Evera, Stephen. 1998. "Offense, Defense, and the Causes of War." International Security $22(4): 5-43$.

Van Evera, Stephen. 1999. Causes of War: Power and the Roots of Conflict. New York: Cornell University Press.

Von Clausewitz, Carl. 1976. On War. Michael Howard and Peter Paret eds. and trans. Princeton: Princeton University Press. 
Wagner, R. Harrison. 1994. "Peace, War, and The Balance of Power." American Political Science Review 88(3):593-607.

Wagner, R. Harrison. 2000. "Bargaining and War." American Journal of Political Science 44(3):469484.

Wallensteen, Peter and Isak Svensson. 2014. "Talking Peace: International Mediation in Armed Conflicts." Journal of Peace Research 51(2):315-327.

Weisiger, Alex. 2013. Logics of War: Explanations for Limited and Unlimited Conflicts. New York: Cornell University Press.

Wendt, Alexander. 1999. Social Theory of International Politics. Cambridge, UK: Cambridge University Press.

Werner, Suzanne. 1999. "The Precarious Nature of Peace: Resolving the Issues, Enforcing the Settlement, and Renegotiating the Terms." American Journal of Political Science 43(3):912-934.

Werner, Suzanne. and Amy Yuen. 2005. "Making and Keeping Peace." International Organization $59(2): 261-292$.

Wittman, Donald. 1979. "How a War Ends: A Rational Model Approach." Journal of Conflict Resolution 23(4):pp. 743-763.

Wolford, Scott, Dan Reiter and Clifford J Carrubba. 2011. "Information, Commitment, and War." Journal of Conflict Resolution 55(4):556-579.

Womack, Brantly. 1994. "Sino-Vietnamese Border Trade: The Edge of Normalization." Asian Survey $34(6): 495-512$.

Xinhua News Agency. 1979a. "Background of the Sino-Vietnamese Border Conflict." Beijing Review [Japanese edition] 17(12):21-23.

Xinhua News Agency. 1979b. "Xinhua News Agency derivers a statement on behalf of the government of the People's Republic of China." Beijing Review [Japanese edition] 17(10):12-13. (English transration adapated from Hood (1992, p.54).

Young, John W. and John Kent. 2004. International Relations since 1945. Oxford, UK: Oxford University Press. 
Zakaria, Fareed. 1999. From Wealth to Power: the Unusual Origins of America's World Role. Princeton, NJ: Princeton University Press. 